\title{
WestVirginiaUniversity
}

THE RESEARCH REPOSITORY @ WVU

Graduate Theses, Dissertations, and Problem Reports

2004

\section{Separation of small particles due to density differences in a CFB riser system}

Jeremy L. Regester

West Virginia University

Follow this and additional works at: https://researchrepository.wvu.edu/etd

\section{Recommended Citation}

Regester, Jeremy L., "Separation of small particles due to density differences in a CFB riser system" (2004). Graduate Theses, Dissertations, and Problem Reports. 1458.

https://researchrepository.wvu.edu/etd/1458

This Thesis is protected by copyright and/or related rights. It has been brought to you by the The Research Repository @ WVU with permission from the rights-holder(s). You are free to use this Thesis in any way that is permitted by the copyright and related rights legislation that applies to your use. For other uses you must obtain permission from the rights-holder(s) directly, unless additional rights are indicated by a Creative Commons license in the record and/ or on the work itself. This Thesis has been accepted for inclusion in WVU Graduate Theses, Dissertations, and Problem Reports collection by an authorized administrator of The Research Repository @ WVU. For more information, please contact researchrepository@mail.wvu.edu. 


\title{
Separation of Small Particles Due to Density Differences in a CFB Riser System
}

\author{
Jeremy L. Regester \\ Thesis Submitted to the \\ College of Engineering and Mineral Resources \\ at West Virginia University \\ in partial fulfillment of the requirements \\ for the degree of \\ Master of Science \\ in \\ Mechanical Engineering \\ Eric K. Johnson, Ph.D., Chair \\ Bruce S. Kang, Ph.D. \\ Frank L. Saus, Ph.D. \\ Department of Mechanical Engineering \\ Morgantown, West Virginia \\ 2004
}

Keywords: Circulating Fluidized Bed, Riser, Dry Separation by Density 


\section{ABSTRACT \\ Separation of Small Particles Due to Density \\ Differences in a CFB Riser System}

\section{Jeremy L. Regester}

Common wet density separation processes require large amounts of water, expensive wastewater cleanup, and do not effectively recover fine particles. A circulating fluidized bed riser system was developed as an exploratory system for dry separation by density that will eliminate many problems associated with wet separation. The system sends an air-solid mixture through a vertical riser. The flow pattern in the riser, established by varying gas velocity $\left(\mathrm{U}_{\mathrm{o}}\right)$ and mass flux $\left(\mathrm{J}_{\mathrm{p}}\right)$, allowed dense particles to collect at the bottom of the riser while less dense particles were collected through the riser exit at the top. The system was developed with many variables used to determine the most effective system geometry for separation. The system was capable of separating $83 \%$ of the dense particles and only $1.3 \%$ of the less dense particles from the mixture. The separation quality can be adjusted by altering $U_{0}, J_{p}$, or the system geometry. 


\section{Table of Contents}

Abstract

$\underline{\text { Page }}$

ii

Acknowledgements

V

List of Figures

$\mathrm{X}$

List of Tables

xiii

List of Symbols

xiv

Chapters

1. Introduction

1

2. Background 3

2.1 The Need for Particle Separation by Density 3

2.2 Current Density Separation Techniques

3

2.2.1 Wet Separation Methods

2.2.2 Dry Separation Methods

2.3 Basic Flow in the Riser of a CFB

2.3.1 Theoretical Flow Regime in the CFB Riser

2.3.2 Core-Annulus Flow in the Riser of a CFB

2.4 $\underline{\text { Separation Mechanisms in a CFB Riser }}$

16

2.4.1 Gravitational Force

2.4.2 Radial Forces in the Riser

2.4.3 Cluster Break-Up Phenomena

2.4.4 Segregation by Density Difference

3. Experimental System and Procedure

3.1 Circulating Fluidized Bed System

3.1.1 Design of the Riser

3.1.2 Design of the Riser Outlet

3.1.3 Design of the Cyclone

3.1.4 Design of the Distributor

3.1.5 Design of the Collection Bins

3.1.6 Design of Pneumatic Transport System

3.1.7 Design of the Hoppers

3.1.8 Design of the Frame

3.2 Instrumentation

3.2.1 Data Acquisition System

3.2.2 Flow Meters

3.2.3 Pressure Transducers

3.2.4 Pressure Sensors/Regulators

3.2.5 Load Cells 
3.3 Procedures $\quad 43$

3.3.1 Start-Up Procedure

3.3.2 Observations

3.3.3 Shut-Down Procedure

3.3.4 Calibration

3.4 Test Matrix

3.4.1 Initial Particle Sizing

3.4.2 Initial CFB Flow Tests

3.4.3 Initial Separation Tests

3.4.4 Effect of Collection Gap Width

3.4.5 Effect of Riser Height

3.4.6 Effect of Internal Ring

3.4.7 Effect of Outlet

3.4.8 Effects of Initial Heavy Particle Mass Fraction

3.4.9 Size Distribution After Tests

4. Results and Analysis $\quad 54$

4.1 Introduction to the Data $\quad 54$

4.2 Initial CFB Flow Tests $\quad 54$

4.3 Initial Separation Tests $\quad 58$

4.4 Effect of Collection Gap Width 67

4.5 Effect of Riser Height $\quad 68$

4.6 Effect of Internal Rings $\quad 71$

4.7 Effect of Outlet $\quad 75$

4.8 Effect of Initial Heavy Particle Mass Fraction 79

4.9 $\underline{\text { Size Distribution of Individual Tests }} \quad 81$

5. Conclusions and Recommendations $\quad 82$

5.1 Conclusions $\quad 82$

5.2 Recommendations $\quad 84$

$\begin{array}{ll}\text { References } & 85\end{array}$

$\begin{array}{ll}\text { Appendices } & 87\end{array}$

Appendix A: Initial CFB Flow Tests $\quad 88$

Appendix B: Initial Separation Tests $\quad 90$

Appendix C: Effect of Collection Gap Width 94

Appendix D: Effect of Riser Height 95

Appendix E: Effect of Internal Rings 96

Appendix F: Effect of Outlet 98 


\section{ACKNOWLEDGEMENTS}

I, Jeremy Lynn Regester, the author of this delectable specimen of a paper would like to take this opportunity to take a break from the finishing touches to thank the people who have assisted with this research, Dr. Eric Johnson, Dr. Frank Saus, and Dr. Bruce Kang for their encouragement, guidance, and patience throughout this research project, Dr. Johnson especially for the original idea that made up this project. Dr. Kang especially for teaching me the value of punctuality. Dr. Saus for not making fun of me too much and for supplying me with the best compressor ever known to man. I want to thank CAST and DOE for supporting this project. I want to thank Mark Hamrick, Lou Hamrick and all the guys down at NorthCo for their assistance in building this beast. I also want to thank Ming and Robert for their graduate student expertise and David Haines for spending time with me climbing all over the High Bay area to hook stuff up, we held up the world with but a hose clamp. And I'd like to thank the inventor of duct tape because there pretty much isn't anything that can't be done with it, I hope he married the daughter of the hose clamp guy, their kids would be BRILLIANT.

Thanks to the teachers that have influenced me over the years. Thanks to all the teachers $\mathrm{K}$ through 4, you were all too cool. Thanks to all the teachers that made me diagram sentences over and over and over, it taught me that if you are forced to do something for long enough you will eventually see its value, which is making your thesis longer and thus more impressive by complaining about it 10 years later in the acknowledgements section. You guys rock. Thanks to my history teachers for making everything that is so truly interesting and important seem so ridiculously boring. What month day and year was Queen Jezebel III told to stop slicing onions by a mob of crying 
men, thus marking the first and last celebration of "Stop Slicing Them Bloody Onions Day" in England? These same teachers can't remember their anniversary and they're going to give me a C- for not giving two shakes of a tail feather when the exact date of this stuff is. Thank you Mr. Combs for actually teaching me something in high school that I may use other than how to make a paper football out of my diagramming sentences assignment. Thanks Dr. Marcello Napolitano for being one of the best teachers ever, for putting up with all of our stupid questions, and having a great sense of humor...for the most part. Oh, and Ricottilli IS TO a real word. Thanks to the few other good teachers I've had over the years for getting me through all of this. Thank you to the remaining teachers for teaching me that you don't have to be good at your job to get paid for doing it for a really long time. At least you taught me something I guess.

Thanks are deserved for my roommates over the years. They were the best of times, they were the worst of times, and I wouldn't trade them for the world, unless I was assured that global warming and the immanent death of the human race was just a big myth. Thanks Chad for showing me up at guitar and making me just give up and concentrate on engineering instead. Thanks Rocky for giving and receiving the world's best advice that was never taken advantage of. Thanks David and Danny for supporting my Nutty Bar addiction and not kicking me out. A special thanks to Danny "the eye" for being about as unselfish as they come and for taking all of our really funny jokes so well. Thanks for not charging me 40 cents for ranch every time. Thanks Robie for being a good golf class partner and for being there for me when nobody else wanted to discuss why the moon looks really big when it's far away in Colorado, how we never really went there, and how a urinal works. Thanks for believing in me when our golf teachers didn't. 
Thanks to my preacher Karl $M_{\equiv}^{c}$ Larty for being such an encouragement to me over the years here and providing a good nudge every once in awhile. Thanks for teaching me so much and opening up your house and your home to me and so many others. Thanks for making it possible for me to go on Mexico trips which were some of the most life changing experiences of my life, and thanks Sandy for telling me I WAS going the first year, for I was then afraid not to go and it was good.

Thanks go out to the family that does it all. I thank my uncle Tim for letting me break tons of stuff and bust millions of hydraulic hoses without yelling at me. Thanks for having faith in me even when I probably deserved none. Thanks for having the patience to put up with a teenager that probably stayed over too late every night over the summer. Thanks for finally admitting that it was my deer. Thanks go to all the aunts and uncles cause there ain't a bad one of ya. Thanks go out to my Grandparents for setting that oh so important foundation in life. You did great. Grandma Sapp for being so loving of your rotten grandkids, Grandpa Sapp for making me that really cool mouse doorstop when I was 5, it said it all, Grandpa Regester for teaching me to work my tail off and for always inventing new machines around the mill so we could work easier and more efficient, and Grandma Regester for making cookies and laughing at my lame jokes, also for not always collecting on the cookie fee, its helped out here in my college fund. Thanks to my sis' Angela for being so cool and letting me copy your Kindergarten projects. I was at a $2^{\text {nd }}$ grade cut and paste level by the time I even started Kindergarten.

Thank you Mom for being the toughest mom in the world. Its quite amazing and I don't know how you do it. Thanks for being excited the first time I built a weird structure out of blocks. Thanks for buying me Lego's. Thanks for taking me places and showing 
me things. Thanks for making my laundry shoot idea a reality. Thanks for making me chop on that tree with a dull ax. Thanks for making me get braces even though I said I hated you for it. Thanks for making me go to church. Thanks for talking to me and not holding back. Thanks for showing such amazing strength when none was even expected. Thanks for the world's BEST mashed potatoes. Thank you for all that you've given and all you will give, it hasn't gone unnoticed. Thanks Paul for supporting Mom's antique addiction when none of the rest of us would, its saved me and Angela hours of needless meandering.

Thanks dad for working so hard to support us and for helping me collect the worlds best leaf collection ever. Thanks for going easy on me for shooting arrows into the couch, I never did figure out how you knew to come to the sliding door that day after work. Thanks for letting me run the knuckle boom and the carriage, I was without a doubt the coolest kid ever, and you were without a doubt the best dad ever.

Thanks to my fiancé for her involvement with my life and for putting up with every bit of it along the way. You've been my home base throughout this whole school thing and it's been the best...really. Thanks for caring for me and holding me when I needed it. Thanks for waiting 'til everyone else was in bed for my calls. Thanks for growing with me, even if it was slowed by my procrastination. Thanks for singing in the car around me. Thanks for tolerating Spongebob Squarepants every so often. Thanks for being you and letting me be me, except for the rare occasion that me being me means that I dance. Thanks for letting me know when I'm making a fool of myself. Thanks for holding nothing back from me. Thanks for your little tap dance at the Wharf with your hat. Thanks for letting me push/ride the shopping cart too fast...sometimes. Thank you 
for not giving up on me and realizing my potential. Thanks for being so sweet (like candy) as to crying tears of joy and happiness when I really try to make you whether you really had to cry or not. Thanks for liking Alison Kraus for me. Thank you for being the best thing that ever happened to me, except for maybe that time I got to go to Pigeon Forge. It was my freshman year and my grandparents were having their...I love you.

Finally, thank you the reader for reading this thesis. Thanks for not complaining about me writing this acknowledgements section as if I was dying or something, it made it much more meaningful and fun. Thanks for not being ticked that I didn't leave a dollar in it for you. Thanks for not complaining about not being in it or for being in it. If there is one thing in life that I've learned its that you cannot allow your happiness to be gauged on acknowledgements sections of masters theses. There is more to life, I think. Thank you and good night.

Oh, and thank you God, for not forgetting me even when I seem to forget you way too often. You never fail me. 


\section{LIST OF FIGURES}

Figure \# $\quad$ Title $\quad \underline{\text { Page \# }}$

2.3.1a Theoretical Flow Regime Diagram 15

2.3.2a Velocity Profile Schematic in a CFB Riser 15

Operating in the Core-Annulus Flow Regime

2.4a Schematic of a Circulating Fluidized Bed (CFB) Riser System 21

$\begin{array}{lll}2.4 \mathrm{~b} & \text { Potential Separation Mechanisms } & 22\end{array}$

2.4.1a Terminal Velocity with respect to Particle Size 23

3 System Diagram 25

3.1.1a Riser Assembly 33

3.1.1b Riser Sections 33

$\begin{array}{lll}3.1 .1 \mathrm{c} & \text { Flange } & 34\end{array}$

3.1.2a Outlets 34

3.1.3a Typical Cyclone Geometry Ratios 35

3.1.3b Primary Cyclone 36

3.1.3c Secondary Cyclone 36

$\begin{array}{lll}\text { 3.1.6a Pneumatic Transport System } & 37\end{array}$

$\begin{array}{lll}\text { 3.1.7a } & \text { Hopper } & 37\end{array}$

3.1.8a System Assembly on Frame 38

$\begin{array}{lll}3.4 & \text { Initial Size Distribution } & 53\end{array}$

4.2a Experimental Flow Regime Diagram for Riser 56

4.2b Percent of Riser Occupied by Different Flow Regimes 56

4.2c Height of Dilute Flow Regime versus Mass Flux 57 
4.3a Effects of Number of Passes on Heavy Particle Collection 61 Efficiency at $3.53 \mathrm{~m} / \mathrm{s}$

4.3b Effects of Number of Passes on Light Particle Collection

61

Efficiency at $3.53 \mathrm{~m} / \mathrm{s}$

4.3c Effects of Number of Passes on Heavy Particle 62

Mass Fraction at $3.53 \mathrm{~m} / \mathrm{s}$

4.3d Effects of Superficial Velocity and Number of Passes on

Heavy Particle Collection Efficiency at $1.90 \mathrm{~kg} / \mathrm{m}^{2} \mathrm{~s}$

4.3e $\quad$ Effects of Superficial Velocity and Number of Passes on

63

Light Particle Collection Efficiency at $1.90 \mathrm{~kg} / \mathrm{m}^{2} \mathrm{~s}$

4.3f Effects of Superficial Velocity and Number of Passes on

63

Heavy Particle Mass Fraction at $1.90 \mathrm{~kg} / \mathrm{m}^{2} \mathrm{~s}$

4.3g Heavy Particle Collection Efficiency versus Mass Flux

64

4.3h Light Particle Collection Efficiency versus Mass Flux 64

4.3i Heavy Particle Mass Fraction vs. Mass Flux 65

4.3j DP/DH Along Riser Height $\left(\mathrm{mm} \mathrm{H}_{2} \mathrm{O} / \mathrm{mm}\right) @ 2.69 \mathrm{~kg} / \mathrm{m}^{2} \mathrm{~s} \quad 65$

4.3k DP/DH Along Riser Height $\left(\mathrm{mm} \mathrm{H}_{2} \mathrm{O} / \mathrm{mm}\right) @ 3.35 \mathrm{~m} / \mathrm{s}$

4.4a $\quad$ Effects of Gap Variation $\quad 67$

4.5a Effect of Riser Height on Heavy Particle Collection 69

Efficiency

4.5b Effect of Riser Height on Heavy Particle Mass 69

Fraction

4.5c Effect of Riser Height Variation $\quad 70$

4.6a Effect of Internals on Collection Efficiency 73

4.6b Effect of Internal Ring on Heavy Particle Mass Fraction Collected 73

4.6c Effect of Internal Rings on DP/DH Along Riser Height $\quad 74$

4.7a Gap Comparison for 90 Degree Outlet 77 
$\begin{array}{lll}4.7 \mathrm{~b} & \text { Outlet Comparison } & 77\end{array}$

4.7c $\quad 90$ Degree Outlet Bend 78

4.7d Effect of Outlet Design on DP/DH Along Riser Height 78

4.8a Effects of Initial Heavy Particle Mass Fraction 80

4.8b Effects of Initial Heavy Particle Mass Fraction $\quad 80$

4.9 Size Distribution for Test Conditions $3.17 \mathrm{~m} / \mathrm{s}$ and $1.42 \mathrm{~kg} / \mathrm{m}^{2} \mathrm{~s} \quad 81$ 


\section{LIST OF TABLES}

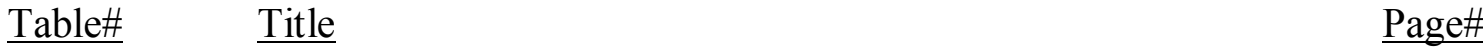

3.1.3 Cyclone Performance Chart 29

3.4 Size Distribution of Steel and Sand Test Particles 47 


\section{SYMBOL}

\begin{tabular}{|c|c|}
\hline$\underline{\text { Symbol }}$ & $\underline{\text { Meaning }}$ \\
\hline $\mathrm{Ar}$ & Archimedes Number \\
\hline $\mathrm{B}_{\mathrm{c}}$ & Width of Cyclone Inlet \\
\hline $\mathrm{D}_{\mathrm{o}}$ & Internal Ring Diameter \\
\hline $\mathrm{D}_{\mathrm{c}}$ & Diameter of Main Cylinder of Cyclone \\
\hline $\mathrm{D}_{\mathrm{e}}$ & Diameter of Cyclone Air Outlet \\
\hline $\mathrm{D}_{\mathrm{pc}}$ & Particle Cut Diameter \\
\hline $\mathrm{D}_{\mathrm{R}}$ & Riser Diameter \\
\hline $\mathrm{d}_{\text {Heavy }}$ & Heavy Particle Diameter \\
\hline $\mathrm{d}_{\text {Light }}$ & Light Particle Diameter \\
\hline$d_{\mathrm{p}}$ & Particle Diameter \\
\hline $\mathrm{F}_{\mathrm{G}}$ & Gravitational Force \\
\hline G & Solid Mass Flux in the Riser \\
\hline $\mathrm{G}_{\mathrm{c}}$ & Upward Solid Flux in the Core of the Riser \\
\hline g & Gravitational Acceleration \\
\hline $\mathrm{H}_{\mathrm{c}}$ & Height of Cyclone Inlet \\
\hline $\mathrm{H}_{\mathrm{R}}$ & Riser Height Above Distributor \\
\hline $\mathrm{h}_{\mathrm{vi}}$ & Cyclone Velocity Head \\
\hline $\mathrm{J}_{\mathrm{c}}$ & Diameter of Cyclone Solid Outlet \\
\hline $\mathrm{J}_{\mathrm{p}}$ & Solid Mass Flux into the Riser \\
\hline $\mathrm{L}$ & Length \\
\hline $\mathrm{L}_{\mathrm{c}}$ & Length of Main Cylinder of Cyclone \\
\hline $\mathrm{m}$ & Mass \\
\hline $\mathrm{N}$ & Number of Turns in Cyclone \\
\hline $\mathrm{P}$ & Pressure \\
\hline$P_{c}$ & Number of Cyclone Inlet Heads \\
\hline $\mathrm{R}$ & Radius of the Riser \\
\hline $\mathrm{Re}_{\mathrm{t}}$ & Reynolds Number at the Terminal Velocity \\
\hline $\operatorname{Re}_{\mathrm{tr}}$ & Reynolds Number at the Transport Velocity \\
\hline$r_{c}$ & Radius of the core \\
\hline $\mathrm{S}_{\mathrm{c}}$ & Height of Inlet Above Cyclone Air Outlet \\
\hline
\end{tabular}




$\begin{array}{ll}\mathrm{U}_{\mathrm{o}} & \text { Superficial Air Velocity in Riser } \\ \mathrm{U}_{\mathrm{fd}} & \text { Upper Gas Velocity Bound for Core/Annulus Flow } \\ \mathrm{U}_{\mathrm{gc}} & \text { Gas Velocity in the Core } \\ \mathrm{U}_{\mathrm{mfHeavy}} & \text { Minimum Fluidization Velocity of Heavy Particles } \\ \mathrm{U}_{\mathrm{mflight}} & \text { Minimum Fluidization Velocity of Light Particles } \\ \mathrm{U}_{\mathrm{pt}} & \text { Particle Terminal Velocity } \\ \mathrm{U}_{\mathrm{sc}} & \text { Solid Velocity in the Core of the Riser } \\ \mathrm{U}_{\mathrm{TO}} & \text { Critical Velocity For Particle Mixing } \\ \mathrm{U}_{\mathrm{t}} & \text { Terminal Velocity of the Particle } \\ \mathrm{U}_{\mathrm{tf}} & \text { Lower Gas Velocity Bound for Core/Annulus Flow } \\ \mathrm{V}_{\mathrm{i}} & \text { Cyclone Inlet Velocity } \\ \mathrm{V}_{\mathrm{p}, \mathrm{c}} & \text { Particle Velocity in the Riser } \\ \mathrm{V}_{\mathrm{p}} & \text { Volume of Particle } \\ \bar{x} & \text { Heavy Particle Mass Fraction in the Bed } \\ \mathrm{Z}_{\mathrm{c}} & \text { Length of Main Cone of Cyclone }\end{array}$

\section{Greek}

$\Delta$

$\varepsilon_{\infty}$

$\varepsilon_{c}$

$\mu$

$\eta$

$\eta_{\mathrm{sa}}$

$\eta_{\mathrm{st}}$

$\omega_{\mathrm{H}, \mathrm{R}}$

$\rho$

$\rho_{\mathrm{g}}$

$\rho_{\text {heavy }}$

$\rho_{\text {light }}$

$\rho_{\mathrm{p}}$

$\rho_{\mathrm{s}}$
Change or Differential

Voidage in the Riser

Voidage in the Core of the Riser

Viscosity

Collection Efficiency

Light Particle Collection Efficiency

Heavy Particle Collection Efficiency

Heavy Particle Mass Fraction

Density

Gas Density

Heavy Particle Density

Light Particle Density

Particle Density

Solid Density 


\section{CHAPTER 1}

\section{INTRODUCTION}

Research in the field of dry separation of particles according to density differences is important in the minerals processing industry. A dry process will reduce separation costs by eliminating the need to dry particles separated using the common wet separation processes. A dry separation process will reduce wastewater cleanup needed for the exit slurry from a wet separation process. The wet separation process also requires large amounts of water, which may not be readily available. As ideal mining sites become less plentiful, minerals are being mined in areas with insufficient water resources for conventional wet processing. Transporting minerals, before the separation process, to a more suitable area for wet processing would be expensive and inefficient. A dry separation process would eliminate the need for a large amount of water resources in order to efficiently have a mine.

A circulating fluidized bed (CFB) riser system was investigated in order to explore the potential for dry separation of a dense material from a lighter material. The system uses the commonly accepted flow pattern in a riser denoted as fast fluidization. This flow pattern consists of two regions, the core and the annulus. The core of the riser is dominated by a dilute upward flow of air/solid mixture coupled with a denser downward annulus flow of solids along the riser wall. The proposed system used this flow pattern to allow the solid mixture to circulate within the length of the riser. The anticipated denser particles in the annulus would drop through the airflow and enter a collection bin. The low-density particles are transported along the length of the riser, pass through a series of cyclones, and collect in a product hopper. 
A sequence of the tests was performed to determine the conditions under which the riser may perform a dry separation process. The performance was noted for various ranges of mass flow rate and airflow rate into the system. The suitable separation conditions determined the range of operating conditions for the test matrix.

The efficiency of separation process will be observed. The rate at which mass can be processed by the system as well as the required air supply were noted. These characteristics of the system were used to compare the system to some current separation methods in an attempt to determine the feasibility of the full-scale system in the coal preprocessing industry. 


\section{CHAPTER 2}

\section{BACKGROUND}

\subsection{The Need for Particle Separation by Density}

One of the largest environmental problems in coal mining is associated with the pyrite found in the coal. The burning of pyrite during the combustion process is a significant environmental issue. Pyrite that is successfully removed from the coal supply before combustion can still have a strong negative impact on the environment by polluting the groundwater.

During the combustion process, pyritic sulfur $\left(\mathrm{FeS}_{2}\right)$ found in coal produces sulfur dioxide $\left(\mathrm{SO}_{2}\right)$. A portion of the $\mathrm{SO}_{2}$ forms $\mathrm{SO}_{3}$, which attacks portions of a coal boiler. $\mathrm{SO}_{2}$ and $\mathrm{SO}_{3}$ exit the boiler and combine with water in the atmosphere. This results in sulfuric acid $\left(\mathrm{H}_{2} \mathrm{SO}_{4}\right)$, which is commonly known as acid rain. It is important to effectively reduce the pyrite content of the coal supply before the combustion process in order to reduce the amount of acid rain produced.

When pyrite is mined and exposed to oxygen, it oxidizes and forms sulfuric acid. Currently, lime is placed upstream of the water flow that is contaminated by mining waste to neutralize the resulting acidity.

\section{$\underline{\text { 2.2 Current Density Separation Techniques }}$}

As of $1995,45-50$ percent of mined coal in the U.S. was processed at a coal preparation plant. Coal preparation effectively reduces $75-80 \%$ of ash, and $15-80 \%$ of trace elements with an $85-90 \%$ Btu recovery rate, but many of these processes are time consuming. One of the major sources of sulfur in coal is pyrite $\left(\mathrm{FeS}_{2}\right)$, and pyrite 
reduction rates are around only $35-70 \%$ for the current coal cleaning systems. (Fonseca, A.G. 1995)

\subsubsection{Wet Separation Methods}

Pyrite is commonly removed before the combustion process using the froth flotation method. This method is effective but produces large quantities of wastewater slurries, which are disposed of in holding ponds. The pyrite that is collected during this process and disposed of in the ponds will oxidize and form sulfuric acid. This results in acidic contamination of the groundwater. A dry separation technique would essentially eliminate this waste water and eliminate many environmental issues.

Zimmels (1985) covered the theory of density separation of particulate systems. Gravitational and centrifugal methods have been used successfully to separate particles according to density ranging from molecular to the size of a tennis ball. Gravitational density separation using a sink-float process has been used in coal preparation where heavier ash-bearing particles are removed from clean, lighter coal particles. Zimmels (1985) also notes that density separation can only be achieved in special cases where the particles are relatively large.

Luttrell et al. (1998) demonstrates the rejection of pyrite using the flotation method and combining the flotation method with a Multi-Gravity Separator (MGS), which is similar to a shaking table, but also utilizes centrifugal forces. They describe a $60 \%$ rejection of pyrite using flotation and $83.6 \%$ rejection using both flotation and MGS. 


\subsubsection{Dry Separation Methods}

In order to eliminate the environmentally unfriendly wet methods of coal cleaning, a dry separation system must be developed. Donnelly (1999) lists advantages of dry cleaning of coal to include:

- Eliminating tailing slurries caused by wet separation

- Eliminating expensive dewatering processes

- Dry cleaning plants could be smaller, cheaper and more energy efficient.

- Eliminating tailing ponds that are ecologically problematic.

- Ultra-fine coal particles may be collected easier.

Disadvantages of dry cleaning coal with current technology includes:

- Lower separating efficiencies

- Processes are susceptible to moisture in the feed coal that may require pre-drying

- High amounts of dust from crushed coal

- Low operation capacity

Donnelly mentions pneumatic oscillating tables, air jigs, and air-dense medium fluidized beds as various dry cleaners that have been used. The use of air tables and jigs has declined due to low capacities, efficiencies, and dust generation.

Chen and Yang (2003) mention the necessary development of efficient dry coal separation. They mention that 3 to 5 tons of water that are required for conventional jigging of one ton of coal. Much of China's coal reserves cannot use this method due to inadequate amounts of water reserves near mining regions. Also, the high moisture content of coal that has been separated using wet methods makes transporting expensive and is effected by freezing in cold weather. They mention that oscillating tables, air jigs, and air-dense medium fluidized beds have been used commercially. Pneumatic separators were implemented in China in 1967 but are no longer used due to strict size constraints, low separation efficiency, high airflow rates, and serious dust pollution to the 
atmosphere. The China University of Mining and Technology (CUMT) established the air-dense medium fluidized bed for $50-6 \mathrm{~mm}$ size fraction coal. The plant has a capacity of $50 \mathrm{t} / \mathrm{hr}$ and was accepted by the Chinese government in 1994. A 700,000 t/yr plant using this technology has gone into commercial testing.

Chen and Yang (2003) explain that the air-dense medium fluidized bed does not effectively separate particles smaller than 50-6 mm. They state that particles smaller than this are increasing in mined minerals due to increased mechanical mining. Also, pyrite is embedded mainly in fine coal. They investigated a vibrating air-dense medium fluidized bed, which is designed to better separate fine particles. The mechanically vibrated laboratory apparatus showed that fine coal with a size of 6-0.5 $\mathrm{mm}$ with an ash content of $16.57 \%$ was cleaned to an ash content of $8.35 \%$. This is approximately a $50 \%$ reduction in the ash content of coal by dry beneficiation.

Hucko and Schimmoller (1995) explain that Cs'o'ke et al. presented a theoretical analysis of a countercurrent airflow separator. Experimental results were obtained with a 10-100 mm sample of coal. Terminal velocity differences in the particles were used to generate three output streams varying in product quality. The device has been used to clean a $20-40 \mathrm{~mm}$ coal stream with a less efficient separation compared to cleaning devices that are water based. The operating costs are claimed to be much lower compared to the dense-medium devices that it replaced and construction and operation are claimed to be simple.

Donnelly (1999) also mentions a method of separating fine coal using an aerodynamic separator. The aerodynamic separation feeds sized material into a horizontal wind tunnel and relies on the shorter distance traveled by the dense particles in the 
mixture to separate according to density. This process has weaknesses concerning the necessary size classifying before hand, dust control, and the effective separation of larger coal rather than coal fines that are the emphasis of this project. 


\subsection{Basic Flow in the Riser of a CFB}

\subsubsection{Theoretical Flow Regime in the CFB Riser}

The three distinct flow regimes of a CFB riser with solid/air flow are dilute, dense, and core/annulus or fast fluidization flow. Dilute flow occurs when the solid content in the riser is very dilute and essentially moves straight up and out of the riser without apparent re-circulation within the riser. Dense flow occurs when the solid concentration in the riser due to re-circulation becomes high enough to disrupt the upward flow of the air through the riser and causes a bubbling action of the air through some or all of the riser. This is known as a bubbling bed. Core/annulus flow occurs in the transition between dilute and dense flow and is characterized by heavy circulation of the particles within the riser in which the particles flow rapidly upward in the core of the riser and flow downward along the wall or annulus of the riser. The particles may alternate back and forth from the core to the annulus flow numerous times before traveling through the outlet of the riser.

The flow regime diagram is used to show the flow regime in the riser for various combinations of the mass flow rate of the solids and the airflow rate into the system. The regimes can be theoretically estimated given the size of the particles, density of the particles, air density and viscosity, the Archimedes Number, and the Reynolds Number. The equations that were used to estimate the flow regimes were found in Fan and Zhu (1998). To start the calculations, the Reynolds number for the transport velocity, which is the minimum velocity at which the particle will be transported through the riser, was found:

$$
\operatorname{Re}_{t r}=2.28 A r^{0.419}
$$


where $A r=\frac{\rho\left(\rho_{p}-\rho\right) g d_{p}^{3}}{\mu^{2}}$

The terminal velocity of the particle can be determined using the following equation from Fan and Zhu (1998):

$$
U_{p t}^{1.4}=0.072 \frac{d_{p}^{1.6}\left(\rho_{p}-\rho_{g}\right) g}{\rho_{g}^{0.4} \mu^{0.6}} \quad 2<\mathrm{Re}_{\mathrm{t}}<500
$$

The particle Reynolds Number based on the particle terminal velocity was found using the particle terminal velocity from above:

$$
\operatorname{Re}_{t}=\frac{\rho U_{p t} d_{p}}{\mu}
$$

The lower bound for the gas velocity for the fast fluidization regime $\left(\mathrm{U}_{\mathrm{tf}}\right)$ is found using:

$$
U_{t f}=39.8 \sqrt{g d_{p}}\left(\frac{J_{p}}{\rho U_{t f}}\right)^{0.311} \operatorname{Re}_{t}^{-0.078}
$$

and $J_{p}$ is the solid mass flux into the riser. The solid mass flux is the mass flow rate into the system divided by the cross sectional area of the riser and has dimensions of $1 \mathrm{~b} / \mathrm{in}^{2} \mathrm{~s}$. The upper bound of the gas velocity for the fast fluidization regime can be found by:

$$
U_{f d}=21.6 \sqrt{g d_{p}}\left(\frac{J_{p}}{\rho U_{f d}}\right)^{0.542} A r^{0.105}
$$

The solid mass flux was assumed for a range of values and the upper and lower bounds of the velocity for the fast fluidization regime were determined throughout that range.

Figure 2.3.1a shows the theoretical flow regime diagram of the riser given an average particle diameter of 250 microns. The density of the test sand was used to predict the flow regime diagram for the system since the mass percentage of sand in the test mixture is over $95 \%$. 


\subsubsection{Core-Annulus Flow in the Riser of a CFB}

The flow regime that was the basis for the concept of particle separation in a CFB Riser was the core/annulus flow. The downward flow along the riser wall and circulation of particles up and down the riser between the core and the annulus flow allows a combination of the three separation mechanisms previously mentioned to occur.

Yang (1995) observed the velocity of the solid in the annulus near the riser wall and the interface of core-annulus in the riser of a CFB. The solid velocity was shown to be downward in the annulus of the flow near the riser wall and upward in the center or core of the riser. Figure 2.3.2a shows the typical velocity profile along the diameter of a riser operating in the core/annulus flow regime. The annulus was shown to have a maximum downward velocity ranging from 0.2 to over $0.4 \mathrm{~m} / \mathrm{s}$ for superficial gas velocities of 4.9 and $3.6 \mathrm{~m} / \mathrm{s}$ respectively and solid mass flux of 26 and $32 \mathrm{~kg} / \mathrm{m}^{2} \mathrm{~s}$ respectively. The distance from the wall at which the upward core flow was determined, along the height of the riser, was shown as a ratio of the thickness of the annulus over the radius of the riser. The interface profile along the height of the riser was shown to be an S-shaped profile and the ratio ranged from 0.15 to 0.2 near the bottom of the riser to a range of 0.1 to 0.125 at approximately 5 meters above the distributor. The radius of the riser was $100 \mathrm{~mm}$. The tests that were used to show this interface profile were with a superficial velocity ranging from 3.6 to $4.9 \mathrm{~m} / \mathrm{s}$ and a solid mass flux through the riser ranging from 26 to $58 \mathrm{~kg} / \mathrm{m}^{2} \mathrm{~s}$. The experiment showed the interface of the core-annulus flow that moved further from the wall as the superficial velocity decreased or as the solid mass flux increased. 
Bolton Et al. (1988) conducted tests with a riser approximately 15 feet high with a 90 degree swept outlet at the top. The riser was operated with a bubbling or slugging dense flow at the bottom and a core-annulus flow in the upper portion. The tests measured the mass flow rate downward along the wall at various heights on the riser. The tests showed an exponential decrease of solid flow rate downward in the annulus as the height increased throughout the core-annulus region.

Rhodes, et al (1988) conducted tests to determine the vertical solid flux at various radial locations in the riser. The riser was fitted with a low restriction 90 degree outlet. They concluded that there was upward mass flow in the core and downward mass flow near the riser wall or annulus. They also noted that the magnitude of both the core and annulus mass flow decreased along the height of the riser. They note that the overall mass flow rate through the cross section of the riser is the same along the riser height and is equal to the mass flow rate out of the top of the riser.

Herb et al. (1992) observed the solid mass flux in two risers of differing diameters and heights. Three particle sizes were tested to observe the effects of particle size on mass flux. Superficial gas velocity and solid mass flux were also varied during testing to determine effects on mass flux. The tests confirmed core-annulus flow characteristics with a dilute, upward flowing core and a dense, downward flowing annulus. The downward solid flux along the riser wall was shown to be larger at lower elevations in the vertical riser. An increase in the total solids mass flow by a factor of two did not significantly change the downward solid flux in the annulus. A decrease in the superficial gas velocity showed an increase in the upward solid flow as well as an increase in downward solid flow. They determined that by decreasing a high superficial gas velocity 
one can increase the circulation rate, the down-flow along the riser wall, and mean residence times for particles. The riser diameter was not shown to alter the annular mass flux significantly.

Rhodes et al. (1992) observed the motion of alumina particles in a CFB riser using a high-speed video camera. They observed that the particles predominantly moved downward near and against the riser wall. Some particles were observed to descend in arch-shaped swarms with velocities in the range of 0.3 to $0.4 \mathrm{~m} / \mathrm{s}$. At suspension densities greater than $5.6 \mathrm{~kg} / \mathrm{m} 3$, steady bulk down-flow in the range of $1 \mathrm{~m} / \mathrm{s}$ was observed. They observed three flow forms along the riser wall; they are dilute uniform flow, dense uniform flow, and swarm flow. Steady bulk down-flow was associated with the point where dilute flow and swarm flow were equally likely.

Hirama et al. (1992) defined an S-shaped curve, which shows the interface of a dense/dilute region. They showed that the density distribution appears at relatively low superficial gas velocities and solid mass flux. The height of the dense/dilute region interface was shown to be a function of the solid mass flux at any given superficial gas velocity. The interface was not found for gas velocities that were greater than the transport gas velocities. A conceptual flow regime diagram was created for a CFB riser. The diagram broke the flow states into five regimes: particulate fluidization, bubbling fluidization, turbulent fluidization, dense-phase transport, and dilute-phase transport. Both the bubbling and turbulent fluidization regimes are part of the dense/dilute region interface when the solid mass flux is less than the solid entrainment rate from their bed surfaces. 
Bai et al. (1992) performed tests to determine the axial distribution of the averaged cross sectional voidage in a fast fluidized bed. The tests showed that the voidage distribution is affected by operating conditions and riser geometry. A riser with a restrictive exit design will perform with a C-shaped voidage profile instead of the $\mathrm{S}$ shaped voidage profile exhibited with a low restriction exit. The voidage profile is inversely proportional to the density distribution curve used by Hirama et al (1992). The C shaped profile shows high voidage in the middle of the riser length and low voidage in the top and bottom of the riser.

Pugsley et al (1993) developed a model to predict the flow structure in a CFB riser. A prediction for the total pressure drop in the riser per unit length was developed and was given as:

$$
\left(\frac{d P}{d L}\right)_{\text {Total }}=\left(\frac{d P}{d L}\right)_{\text {SoidHoldUp }}+\left(\frac{d P}{d L}\right)_{\text {Acceleration }}
$$

The pressure drop due to the gas and solid friction were excluded since they were found to be negligible compared to the solid hold up and acceleration effects. Substituting the equations for each component gives:

$$
\left(\frac{d P}{d L}\right)_{\text {Total }}=\rho_{p} g\left(1-\varepsilon_{\infty}\right)+\frac{\rho_{p}\left(1-\varepsilon_{c}\right)\left(\Delta V_{p, c}\right)^{2}}{2 \Delta L}
$$

This shows that the pressure drop along the riser height per unit length is a function of the particle density, voidage in the riser, and velocity of the particle.

Berruti and Kalogerakis (1989) developed a model to estimate the core-annulus flow characteristics. The upward solid flux in the core of the riser is given as:

$$
G_{c}=U_{S C}\left(1-\varepsilon_{C}\right) \rho_{S}\left(\frac{r_{c}}{R}\right)^{2}
$$


where $U_{S C}$ is the solid velocity in the core of the riser, $\varepsilon_{c}$ is the core voidage, and $r_{c}$ is the core radius.

$$
\varepsilon_{c}=1-\frac{G_{c}}{U_{S C} \rho_{S}\left(\frac{r_{c}}{R}\right)^{2}}
$$

The solid velocity in the core can be approximated using:

$$
U_{S C}=U_{g c}-U_{t}
$$

where $U_{g c}$ is the gas velocity in the core and $U_{t}$ is the terminal velocity of the particle. $U_{g c}$ can be approximated using:

$$
U_{g c}=\frac{U_{o}}{\varepsilon_{c}}\left(\frac{r_{c}}{R}\right)^{2}
$$

where $U_{o}$ is the superficial velocity of the air. The upward flux of solids in the core is calculated using:

$$
G_{c}=G+\left(1-\left(\frac{r_{c}}{R}\right)^{2}\right) \rho_{s}\left(1-\varepsilon_{c}\right) U_{t}
$$



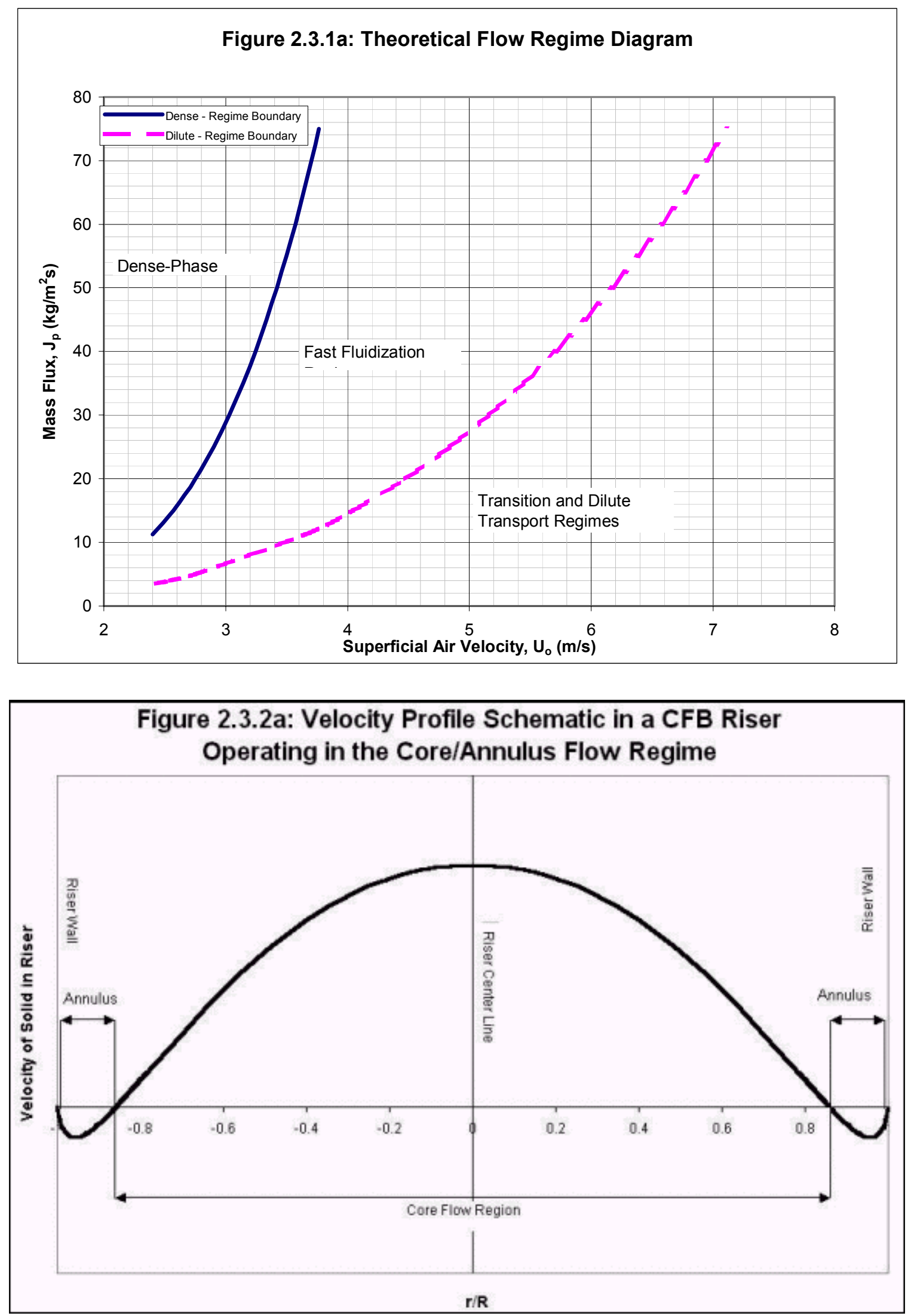


\subsection{Separation Mechanisms in a CFB Riser}

A circulating fluidized bed CFB riser is an upward gas flow that entrains particles throughout the riser. Gas is introduced into the riser by a distributor plate at the bottom of the riser. Solid particles are then introduced to the flow above the distributor. The gassolid mixture flows up the riser and exits through a gas/solid separator such as a cyclone. The solids are collected into a downcomer and can then be re-circulated through the riser. Figure 2.4a shows a typical CFB riser. While in the riser, the particles can travel in various ways according to the gas flow rate and mass flow rate of particles into the riser.

There are three distinct flow regimes that can be present in a riser with solid/gas flow (Fan, 1998). The three regimes are dense flow, dilute flow, and core/annulus or fast fluidization flow. The basic mechanisms that will potentially allow separation of particles according to density in a CFB Riser are the gravitational force, radial force due to a velocity gradient in the riser, particle-particle interactions, turbulence, and the cluster break-up phenomena. These mechanisms are shown in Figure 2.4b. Many of these mechanisms are not well understood. Therefore, an empirical method to determine a critical velocity at which segregation according to particle density will occur in the riser will be observed.

\subsubsection{Gravitational Force}

The gravitational force is given as:

$$
F_{G}=m g=V o l_{p} \rho_{p} g
$$

In the case where two particle types with similar particle size distribution are to be separated according to density, the gravitational force is directly related to the density of 
the particles. The forces for two separate particle densities with the same size can be written as a ratio that is equal to the ratio of the particle densities.

$$
\frac{F_{G_{\text {heary }}}}{F_{G_{\text {light }}}}=\frac{\rho_{\text {heavy }}}{\rho_{\text {light }}}
$$

Steel and sand particles have a density ratio of 5 which results in a gravitational force for steel that is 5 times that of sand provided that the particles are of similar sizes.

The difference in the gravitational force corresponds to a difference in the terminal velocity for the two particle types. The terminal velocity of the two particle types being separated can easily be estimated to give an estimate for the range of riser superficial velocity that would be appropriate for separation. The terminal velocity of a particle is a function of the particle size and density as well as the air properties. The change in the terminal velocity due to the differences in particle density will be used in this experiment to investigate separation according to density. Due to the effect of the particle size on the terminal velocity, the size of the particles will have to be relatively similar in order for the terminal velocity to be used for density separation purposes. The effect of the size distribution will be observed.

The terminal velocity of the particle can be estimated for the sand and steel particles using the equation given in section 2.3.1. The terminal velocity is estimated for a range of particle diameters for both the sand and steel particles. The results are shown in Figure 2.4.1a. The figure shows that the high density of the steel requires a steel particle 200 microns in diameter to have a higher terminal velocity than a sand particle 500 microns in diameter. Therefore, the air velocity through the riser can theoretically be adjusted to separate steel particles from sand particles using the terminal velocity with a size range of 300 microns. 


\subsubsection{Radial Forces in the Riser}

The airflow rate through a riser is not uniform due to friction along the riser wall. The velocity profile through the cross section of the riser will be higher towards the core of the riser and lower along the wall due to wall friction.

Yamamoto et al. (1991) conducted tests to determine the effects of a velocity gradient on the radial lift on a spherical particle at high Reynolds numbers from 4000 to 35000. They measured surface pressure distribution, used a pendant method, and observed the trajectories of spheres falling in upward shear flows. Their studies showed that the lift force was in the direction of the lower velocity flow and that the velocity gradient had little effect on the drag. This study shows that with the velocity profile in a riser, the particles will be pushed towards the wall. As the particles are pushed towards the lower velocity region, the particles will have a higher tendency to fall back down the riser due to the lower local velocity. This will produce the core/annulus flow, which will be discussed further.

Zhang (1991 p.46,82) shows two possible modes of solid transfer from the core to the annulus and vice versa during core-annulus flow in a riser. The first mode occurs during developing flow in the riser. Developing flow is defined as flow in which the change in pressure per unit height of the riser is not constant. This mode shows solids transferring from the core to the annulus at various heights along the riser. Solid transfer from the annulus to the core primarily occurred at the base of the riser. This mode shows that solids will travel up the riser in the core for an unknown distance before migrating to the annulus. Once the particle has reached the annulus, it will most likely travel all the way down the riser to the distributor. The second mode occurs when flow is developed or 
where the change in pressure along the height of the riser per unit length is constant. This second mode is characterized by solid flow in both directions at various heights along the riser. This mode shows that particles can enter the annulus or leave the annulus at any height.

\subsubsection{Cluster Break-Up Phenomena}

Clusters of particles that flow down the annulus of the riser flow will disintegrate and tend to circulate back up through the core. As the cluster breaks up, the heavy particles can continue to move downward along the riser wall. The light particles tend to be caught in the up-flow of the core. By putting a gap between the riser wall and the distributor, the heavy particles can travel along the wall and past the distributor and into a collection bin. To take full advantage of the break-up of clusters, the break-up must occur above the distributor in order for the particles to efficiently separate from one another. If the clusters reach the distributor before breaking up, the cluster will either travel through the collection gap or be broken up by the distributor and separation will not occur efficiently.

\subsubsection{Segregation by Density Difference}

Geldart (1986) explains segregation of powders of different densities in a fluidized bed riser. The empirical model estimates the critical velocity where mixing begins to take place instead of segregation within the riser according to density. The model uses the density and diameter of each particle type, the height and diameter of the riser, and the minimum fluidization velocity of the two particles types. 


$$
U_{T O}=U_{m f \text { Light }}\left[\left(\frac{U_{\text {mfHeavy }}}{U_{\text {mflight }}}\right)^{1.2}+0.9\left(\frac{\rho_{\text {heavy }}}{\rho_{\text {light }}}-1\right)^{1.1}\left(\frac{d_{\text {heavy }}}{d_{\text {light }}}\right)^{0.7}-2.2 \sqrt{\bar{x}\left(1-e^{-H / D}\right)^{1.4}}\right]
$$

where $\mathrm{U}_{\mathrm{mfHeavy}}$ and $\mathrm{U}_{\mathrm{mflight}}$ are the minimum fluidization velocity for the heavy and light particles respectively. $\bar{x}$ is the heavy particle mass fraction in the bed and $\mathrm{U}_{\mathrm{TO}}$ is the velocity at which mixing of particles of different densities begins. Segregation of particles of varying densities will occur at velocities lower than the critical mixing velocity.

Zhang (1991 p.36) performed tests in a circulating fluidized bed using a particlesampling probe at various radial positions in the riser. They experienced blocking in the probe tip near the wall of the riser due to large coal particles, while sampling towards the center of the riser did not result in probe blockage. Their tests showed that particles collected near the wall were $7.8 \%$ larger than those colleted in the core at an elevation of $5.65 \mathrm{~m}$ above the distributor. They concluded that the larger particles tend to stay in the lower zone of the riser and near the wall. The forces resulting in this radial segregation according to size distribution may translate to segregation according to density differences in our tests.

Dry (1987) described the possible particle segregations in both the vertical and radial directions in a CFB. They explained that segregation was suppressed by superficial velocities that were greater than the terminal velocity of all of the particles that are in the bed. Cluster formation also suppressed the segregation phenomenon. A CFB riser operating in the dilute phase where particle interactions are limited and clusters do not dominate the flow should exhibit segregation if large size or density distributions are present. 


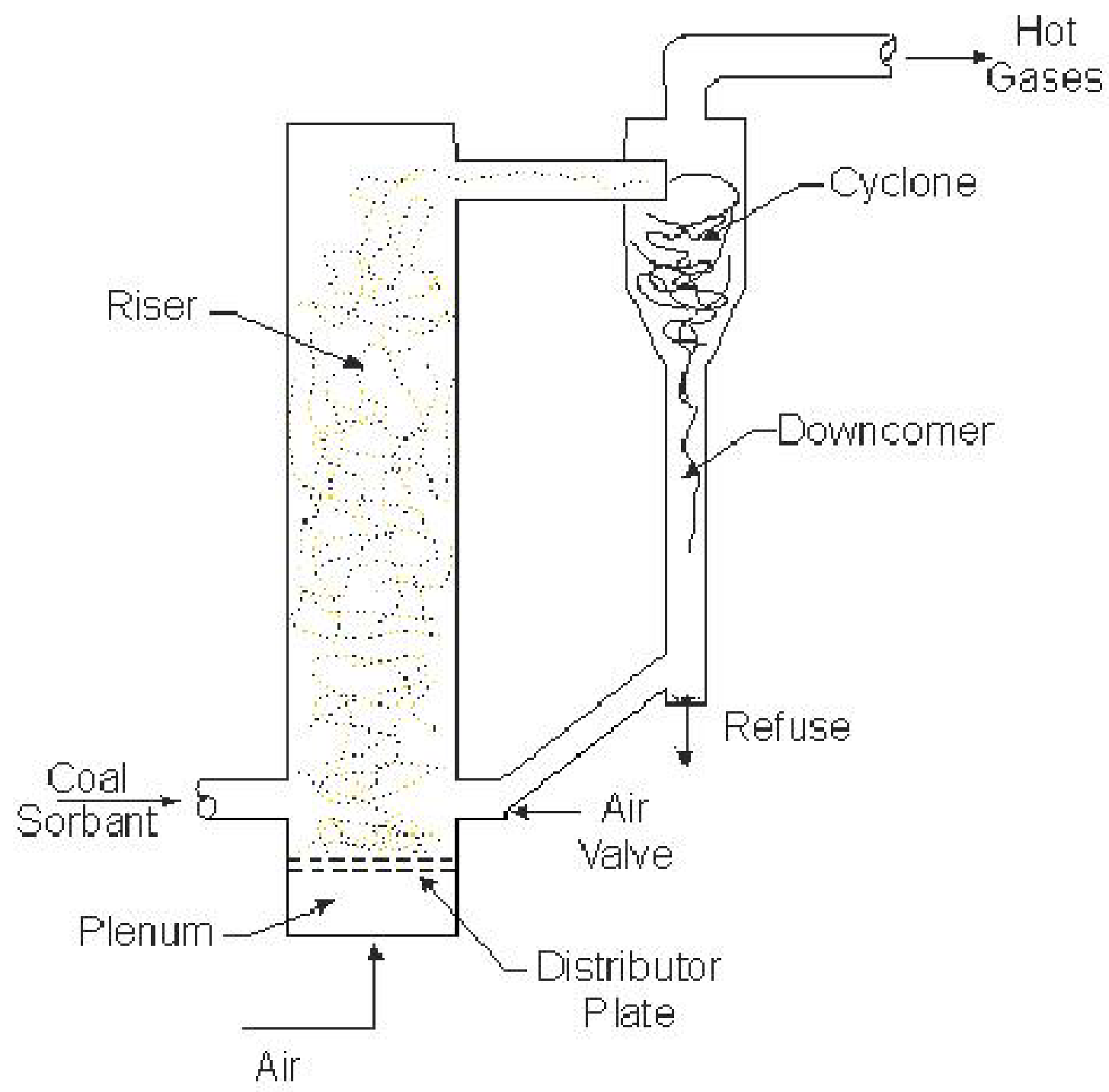

Figure 2.4a: Schematic of a Circulating Fluidized Bed (CFB) Riser System 
1) Radial Force

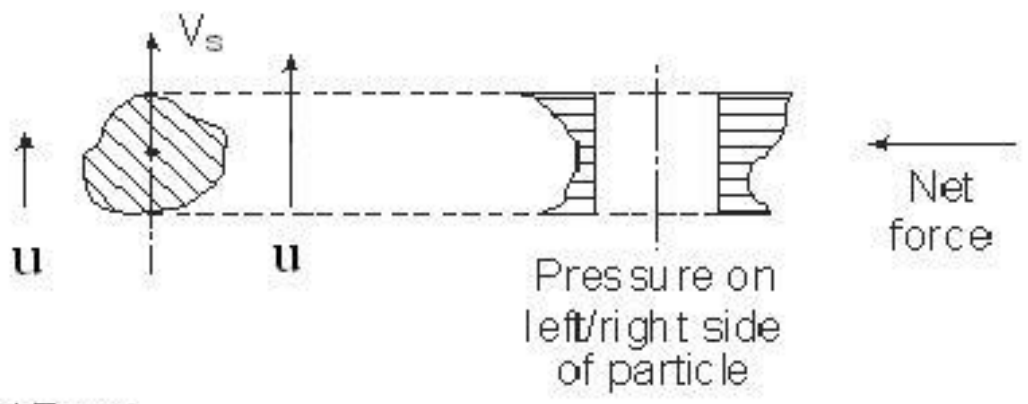

2) Gravitational Force

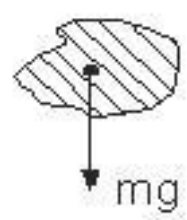

3) Cluster Break-Up Phenomenon
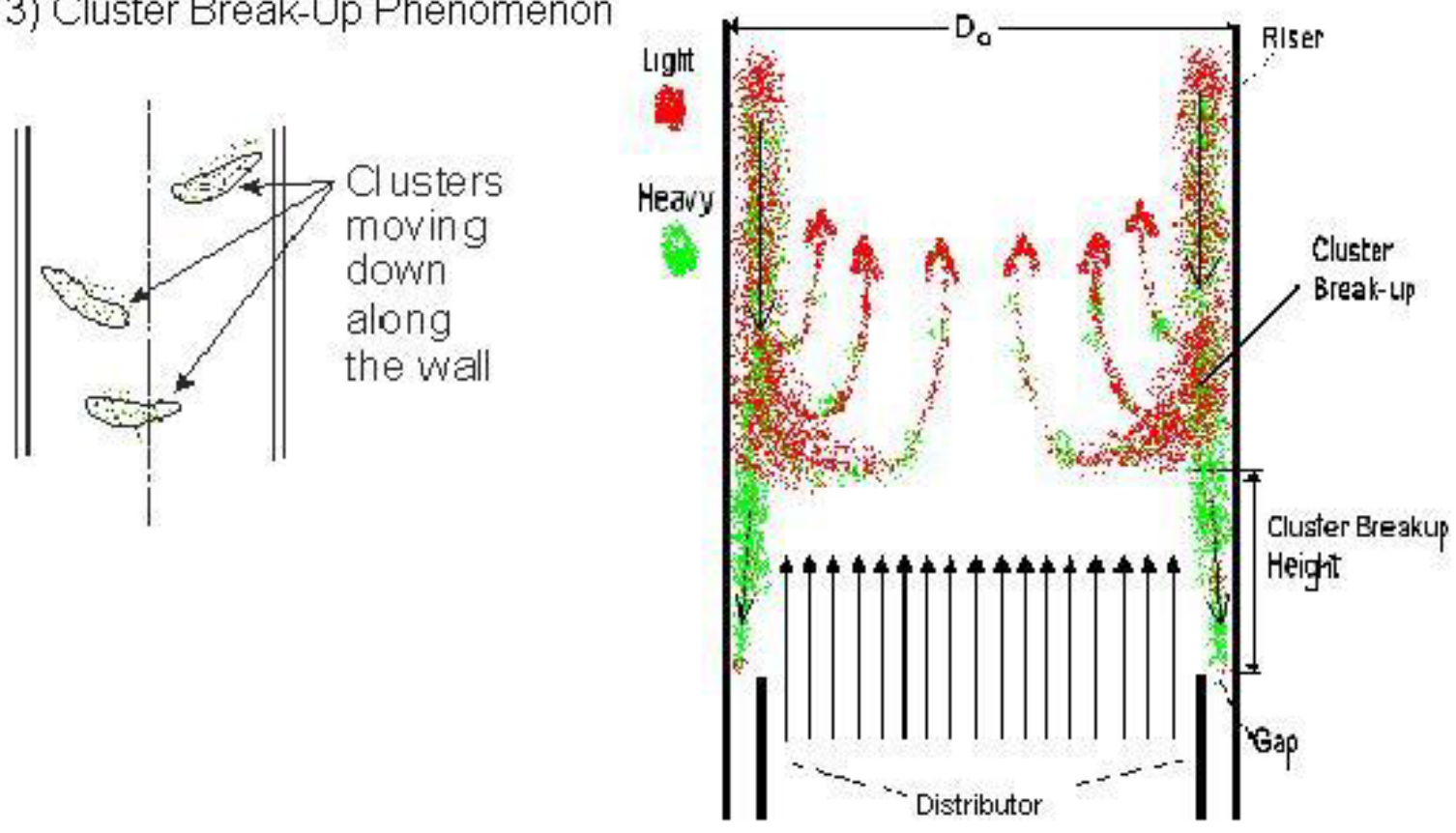

Figure 2.4b: Potential Separation Mechanisms 


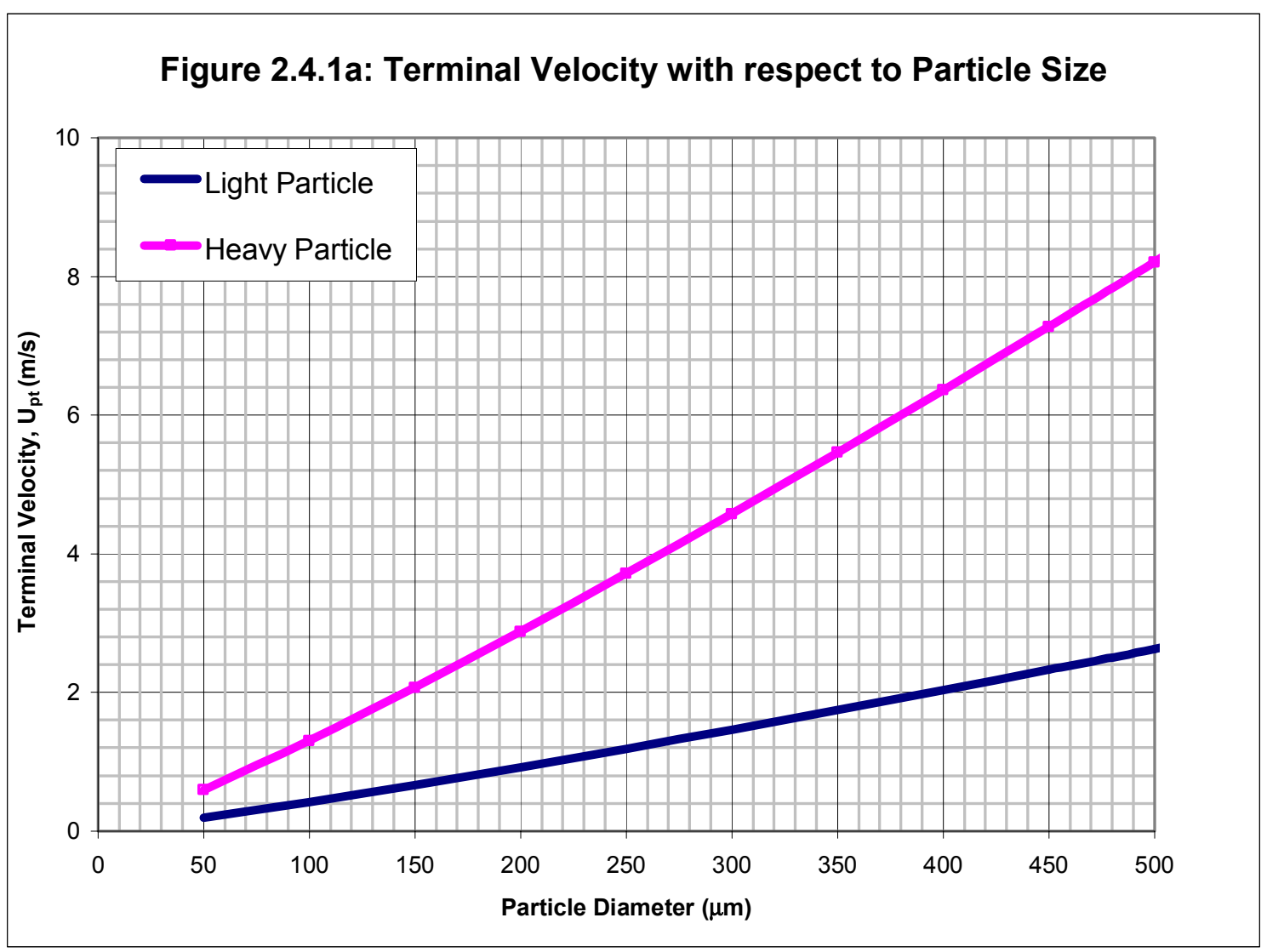




\section{CHAPTER 3}

\section{EXPERIMENTAL SYSTEM AND PROCEDURE}

\subsection{Circulating Fluidized Bed System}

A Circulating Fluidized Bed (CFB) system was designed to investigate the flow conditions in the CFB riser and observe the effectiveness of dry separation due to various flow regimes. The CFB riser was set-up in the NRCCE High Bay Testing Area at West Virginia University. A two-stage cyclone system was employed to separate the particles exiting from the top of the riser from the airflow. A bubbling water filtration system was

connected to the gas outlet of the $2^{\text {nd }}$ cyclone to trap fines that were not collected by the cyclones. The riser height, collection gap width, internal rings, and outlet geometry were modified and observed for their effects on possible separation efficiency for the riser. The complete system can be seen in Figure $\mathbf{3}$. 


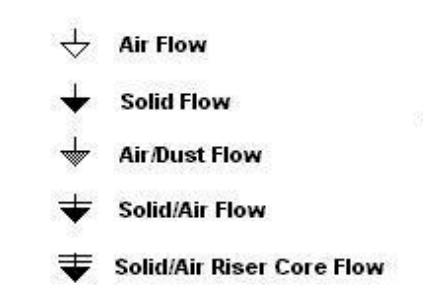

1 \& 2. Feed/Product Hopper

a. High Pressure Solid Feed Gate Valve

b. Low Pressure Solid Feed Valve

c. Hopper Valve

d. Tank Pressurizing Valve

e. Cyclone Solid Exhaust Valve

f. Distributor Solid Feed Valve

3. Riser

4. Distributor

5. Distributor Valve

6. Excess Particle Bin

7. Dense Particle Bin

8. Heavy Particle Gap

9. Primary Cyclone

10.Secondary Cyclone

11.Air Filter

12.Main Air Pressure Valve

13.Main Tank Air Pressure Valve

14.Flow Meter

15.Solid Delivery Apparatus

16.Load Cell

17.System Unloading Valve

18.Main Tank Pressurizing Gate Valve

19.Pressure Regulator/Gauge

20.Cyclone Solid Exhaust Splitter

21.Waste Bin

Ilote: All valves are globe valves unless otherwise noted

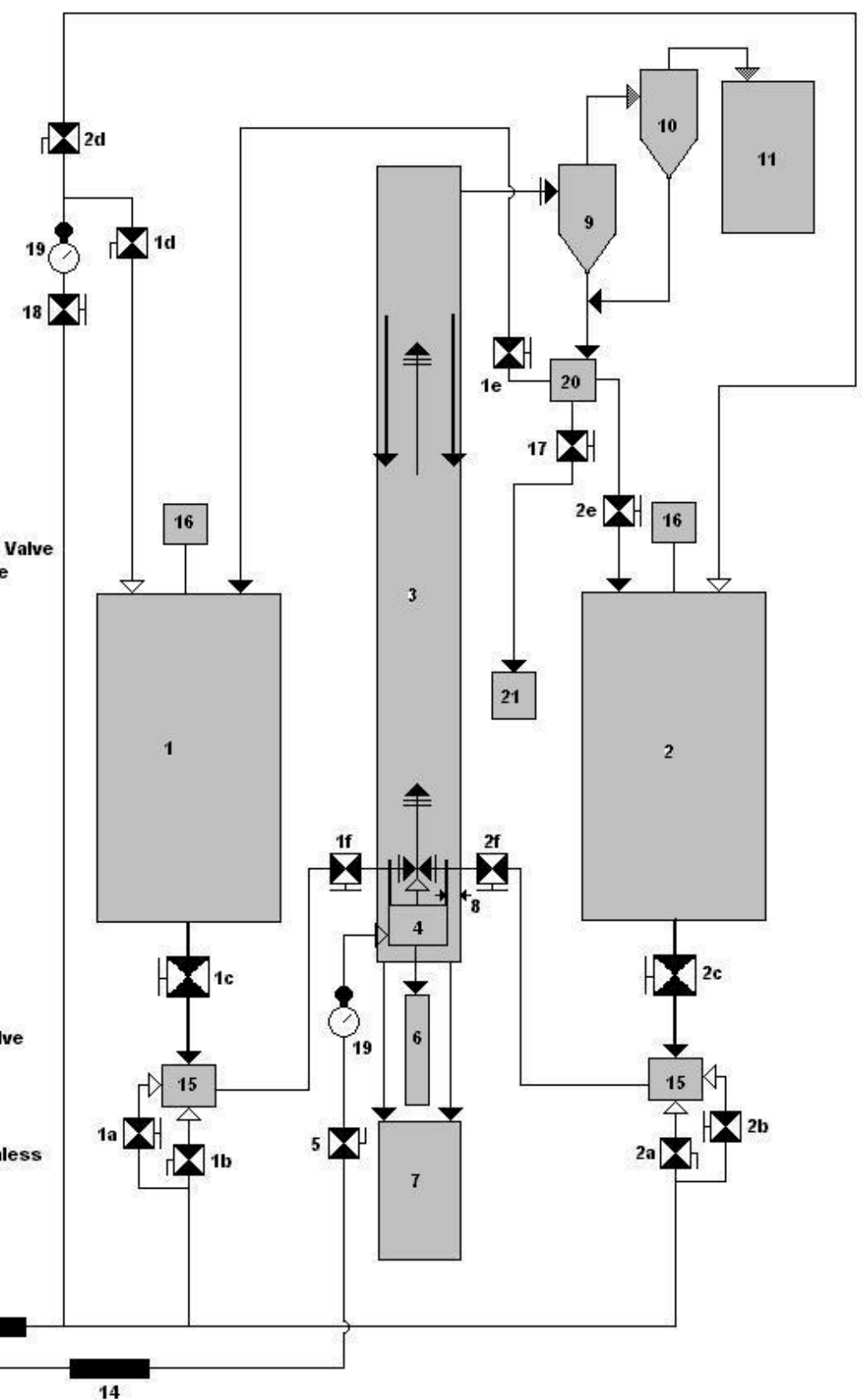

Figure 3: System Diagram 


\subsubsection{Design of the Riser}

The riser is made of clear acrylic tube with an inside diameter of 5 inches (127 $\mathrm{mm})$ and a wall thickness of 0.25 inches $(20.8 \mathrm{~mm})$. The diameter of the riser was chosen as 5 inches $(127 \mathrm{~mm})$ considering an average particle size of 250 microns in order to allow good particle/air flow. The transparent riser wall allows observation in the flow pattern in order to make adjustments to the flow parameters in order to achieve the desired flow regime. The riser is comprised of various sections of lengths of 1,2 , or 3 feet $(305,610$, or $914 \mathrm{~mm})$. The sections were joined using flanges in order to make the height of the riser a variable for the experiment. The flanges were connected to the ends of the riser by three setscrews and glue. The flanges were constructed out of $1 / 2$ inch (41.6 $\mathrm{mm}$ ) thick acrylic sheets and consist of 6 boltholes to assure a consistent pressure around the flange circumference. Paper gaskets were used between the flanges in order to prevent leakage. The height of the riser was chosen as 8 feet $(2.44 \mathrm{~m})$ for the preliminary tests in order to have a height to diameter ratio of approximately 20 , which is common among CFB risers. The original riser length of 8 feet $(2.44 \mathrm{~m})$ was broken into 6 sections so that the length of the riser could be altered during the experimental testing in order to obtain ideal flow characteristics. Pressure taps were installed in 1 foot $(205 \mathrm{~mm})$ increments along the entire length of the riser. Four pressure taps were used during each test providing 3 differential pressure transducers with equal differential lengths for each test according to the height of the riser. The riser assembly can be seen in Figure 3.1.1a. The three sizes of riser sections used are shown in Figure 3.1.1b. The cross section of a flange and riser section is shown in Figure 3.1.1c. 


\subsubsection{Design of the Riser Outlet}

The original outlet for the riser was designed to be a side outlet with a 6 inch (152 $\mathrm{mm})$ stagnation area above the outlet. The outlet was a 1.5 inch $(38.1 \mathrm{~mm})$ diameter hole in the side of a 1 foot $(205 \mathrm{~mm})$ long riser section. One end of the riser was capped off with 0.5 inch $(13.7 \mathrm{~mm})$ acrylic sheet and the other end was flanged and bolted to the top of the riser assembly. The outlet hole was positioned horizontally at 90 degrees from the direction of primary riser airflow. The flow was sent through the outlet and directly sent into the primary cyclone using a combination of PVC joints, clear, flexible tubing, and hose clamps. The side outlet assembly can be seen in FIGURE 3.1.2a.

An alternate outlet was designed after observation of the air/solid flow pattern in the riser during the early separation tests. It was observed that the stagnation portion of the riser above the side outlet was allowing the solids to rebound off of the end cap at the top of the riser. This downward rebounding of the solids caused circulation throughout the riser including down flow along the riser wall that was much higher than what was deemed necessary for separation conditions. This high down flow of solids resulted in high collection rates of light solids in the heavy particle collection bin. It was determined that the effects of a swept 90 degree outlet of the same diameter as the riser should be observed. This design would theoretically eliminate the rebound effect of the side outlet and possibly allow for much higher mass flux into the system without an unnecessarily high amount of solid down-flow. Figure 3.1.2a shows the 90 degree swept outlet assembly. 


\subsubsection{Design of the Cyclone}

A two-stage cyclone was employed due to its simplicity, cost effectiveness, and relatively good efficiency. The dimensions for the cyclones were designed using the guidelines found on page 92 of Air Pollution Engineering Manual (Danielson, 1967). These dimensions are shown in Figure 3.1.3a.

The flow rate through the cyclone was estimated to be between 9.8 to $14.7 \mathrm{ft} / \mathrm{s}$ ( 2.99 to $4.48 \mathrm{~m} / \mathrm{s}$ ). The inlet velocity, $\mathrm{V}_{\mathrm{i}}$ into the cyclone was found by dividing the inlet area into the airflow rate. The number of cyclone inlet heads is given as:

$$
P_{c}=\frac{8 H_{c} B_{c}}{D_{e}}
$$

for a cyclone with these proportion. $\mathrm{H}_{\mathrm{c}}$ and $\mathrm{B}_{\mathrm{c}}$ were taken to be the diameter of the inlet for the secondary cyclone. The velocity head (in. $\mathrm{H}_{2} \mathrm{O}$ ) is given by:

$$
h_{v i}=\frac{1}{2} \rho V_{i}^{2}
$$

The total pressure drop across the cyclone is found using:

$$
\Delta P=P_{c} h_{v i}
$$

The cut size of the cyclone is the diameter of the particles in which the cyclone should have a collection efficiency of $50 \%$. The cut size in feet is calculated for the cyclones using the equation:

$$
D_{p c}=\sqrt{\frac{9 \mu D_{c}}{2 N V_{i}\left(\rho_{p}-\rho_{g}\right) \pi}}
$$

where $\mathrm{N}$ is the number of turns within the cyclone that the solids make and is estimated by dividing the total length of the cyclone by the inlet height, and $V_{i}$ is the inlet velocity in feet per second. The densities are used as $\mathrm{lb} / \mathrm{ft}^{3}$ and the viscosity is in $\mathrm{lb}_{\text {mass }} / \mathrm{ft} *$ s. Table 
3.1.3 shows the characteristics of each of the cyclones at the minimum and maximum estimated inlet flow rate conditions.

\begin{tabular}{|c|c|c|c|c|}
\hline & Primary & Primary & Secondary & Secondary \\
\hline Flow rate (CFM) & 85 & 120 & 85 & 120 \\
\hline Area (ft^2) & 0.056 & 0.056 & 0.012 & 0.012 \\
\hline Inlet Velocity (ft/s) & 25.5 & 36 & 115 & 163 \\
\hline \# of Cyclone Inlet Heads & 16 & 16 & 7.2 & 7.2 \\
\hline Velocity Head (in H20) & 25 & 50 & 510 & 1016 \\
\hline Pressure Drop in (H2O) & 398 & 793 & 3669 & 7312 \\
\hline Number of Turns & 6 & 6 & 15 & 15 \\
\hline Cut Diameter (microns) & 8.38 & 7.06 & 3.94 & 3.32 \\
\hline
\end{tabular}

\section{Table 3.1.3: Cyclone Performance Chart}

The first cyclone is slightly larger than the second and is designed to collect the largest particles, leaving the smaller secondary cyclone to collect the fines. The secondary cyclone uses a circular inlet in order to keep assembly costs to a minimum, while the primary cyclone uses the traditional rectangular inlet in order to maximize collection efficiency. The primary and secondary cyclones can be seen in Figure 3.1.3b and Figure 3.1.3c respectively.

\subsubsection{Design of the Distributor}

The distributor is a vital contributor to the flow characteristics of the gas-solid mixture in a CFB riser. The distributor in this experiment had an adjustable outer radius in order to create a variable gap between the riser wall and the distributor. This gap was used to collect the dense particles flowing downward along the riser wall. The distributor was designed in the shape of a funnel at 60 degrees with a drain hole at the bottom so that any particles left in the riser at the end of the experimental procedure drained out the hole in the bottom of the riser rather than fall onto the distributor and into the holes of the distributor. This allowed all of the particles that enter the system during the test 
procedure to be accounted for at the end of the experiment. The conical section of the distributor was drilled with numerous holes to supply the primary airflow into the riser. A gap adjustment ring decreases the $1 / 4$ inch $(6.4 \mathrm{~mm})$ of the distributor to a gap of $1 / 8$ inch (3.2 mm). Another ring allows complete closure of the gap in order to observe flow characteristics of the particles in the riser given various mass and air flow rates. The canister has an inlet on each side above the distributor cone that continues through the riser wall and allows the solid/air mixture to enter the riser flow.

\subsubsection{Design of the Collection Bin}

The heavy particle collection bin and excess particle bins were designed to be connected to the bottom of the distributor assembly. The heavy particle collection bin collects the particles that fall along the wall of the riser past the distributor through the collection gap. It was built out of the same acrylic tube as the riser wall and was capped at the bottom with an acrylic sheet. The top is flanged and connects to the flange at the bottom of the riser section of the distributor assembly. The excess particle collection bin is designed to collect particles that remain in the riser at the time of shutdown. The particles that do not leave through the outlet or fall through the collection gap fall through the distributor drain and into the excess particle collection bin. It was threaded to the distributor drain.

\subsubsection{Design of the Pneumatic Transport System}

The pneumatic transport system is used to transport the solid particles from the hoppers to the riser using compressed air. The system was designed using a 2-stage air 
delivery system. The system uses high and low air pressure to transport the air from the bottom of the hopper to the riser. The solids drop into the top of the pneumatic transport system from the hoppers and were then injected into the low-pressure air stream by the high-pressure air. The tanks were also pressurized to balance the backpressure on the outlets of the hoppers due to upstream airflow in the riser and the pneumatic transport system. The pressure is adjusted depending on the mass flux desired and the riser operating conditions.

The high pressure air line and solid feed line were made from copper tubing. The low pressure feed was constructed of steel with an acrylic section at the point of low pressure/high pressure mixture so that the solid flow could be observed. The acrylic tube is then connected to the distributor using a series of PVC and clear, flexible tubing. Figure 3.1.6a shows the pneumatic transport system.

\subsubsection{Design of the Hoppers}

The 2 identical hoppers were designed to hold approximately 2000 pounds (907 $\mathrm{kg}$ ) of the solid mixture. Each of the hoppers can be used as either a feed hopper for the riser or a product bin to collect the particles that travel through the riser and the series of cyclones. One hopper was loaded manually through a hole in the top and would then serve as the feed hopper. The second hopper would then function as the product hopper and was connected to the bottom outlet of the cyclones. Once the solids have been sent through the system once, the feed hopper was then function as the product hopper and is hooked up to the cyclone outlets while the second hopper is then used as the feed hopper and sends the solids into the riser. The hoppers were 3 feet $(914 \mathrm{~mm})$ diameter cylinders 
4 feet $(1.22 \mathrm{~m})$ tall with a $1.5 \mathrm{ft}(457 \mathrm{~mm}), 45$ degree conical section at the bottom with a 2 inch $(50.8 \mathrm{~mm})$ diameter exit port. The walls of the tank were made from 1/16 inch (5.2 $\mathrm{mm}$ ) thick steel with stringers added for strength. A tank pressurization line is connected to a second hole in the top of the feed hopper in order to pressurize the tank and aid in the solid feeding process. The tanks were hung using 3 chains connected from the top of the main cylinder of the hopper to a joining ring above the hopper, which is connected to the load cell. The hopper dimensions can be seen in Figure 3.1.7a.

\subsubsection{Design of the Frame}

The system was all connected to a frame made of 4 inch $(102 \mathrm{~mm})$ tubular steel. The frame was fitted with 4 industrial wheels so that it could be repositioned around the lab area easily. The riser was connected to the outside of the frame with padded supports using hose clamps to hold it onto the supports. The riser was placed on the outside of the frame so that the hoppers could be slid underneath an exhaust hood in the experimental area. The cyclones were connected to a piece of 4 inch $(102 \mathrm{~mm})$ channel steel that was bolted onto the frame for easy detachment of the cyclones from the frame. The hoppers were connected to load cells that were connected to the frame using special pivoting bolts to allow limited movement of the hoppers. Two air manifolds were also bolted onto the frame. The frame is shown in Figure 3.1.8a with the hoppers, riser, and cyclones shown in their respective mounted positions. 


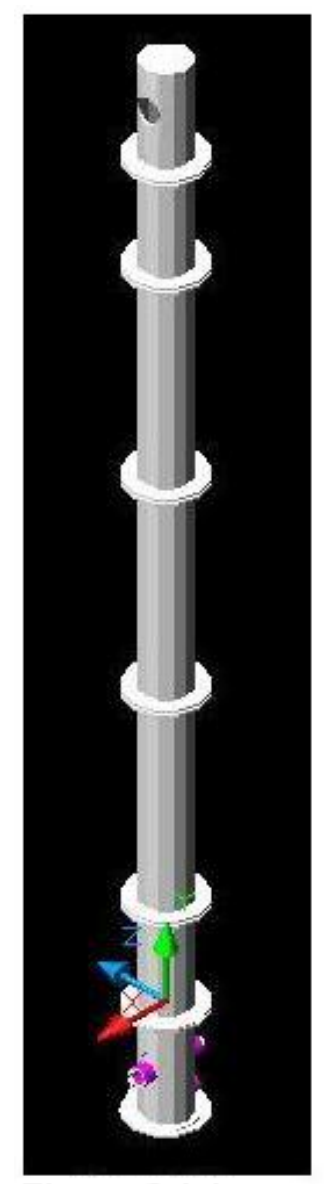

Figure 3.1.1a:

Riser Assembly

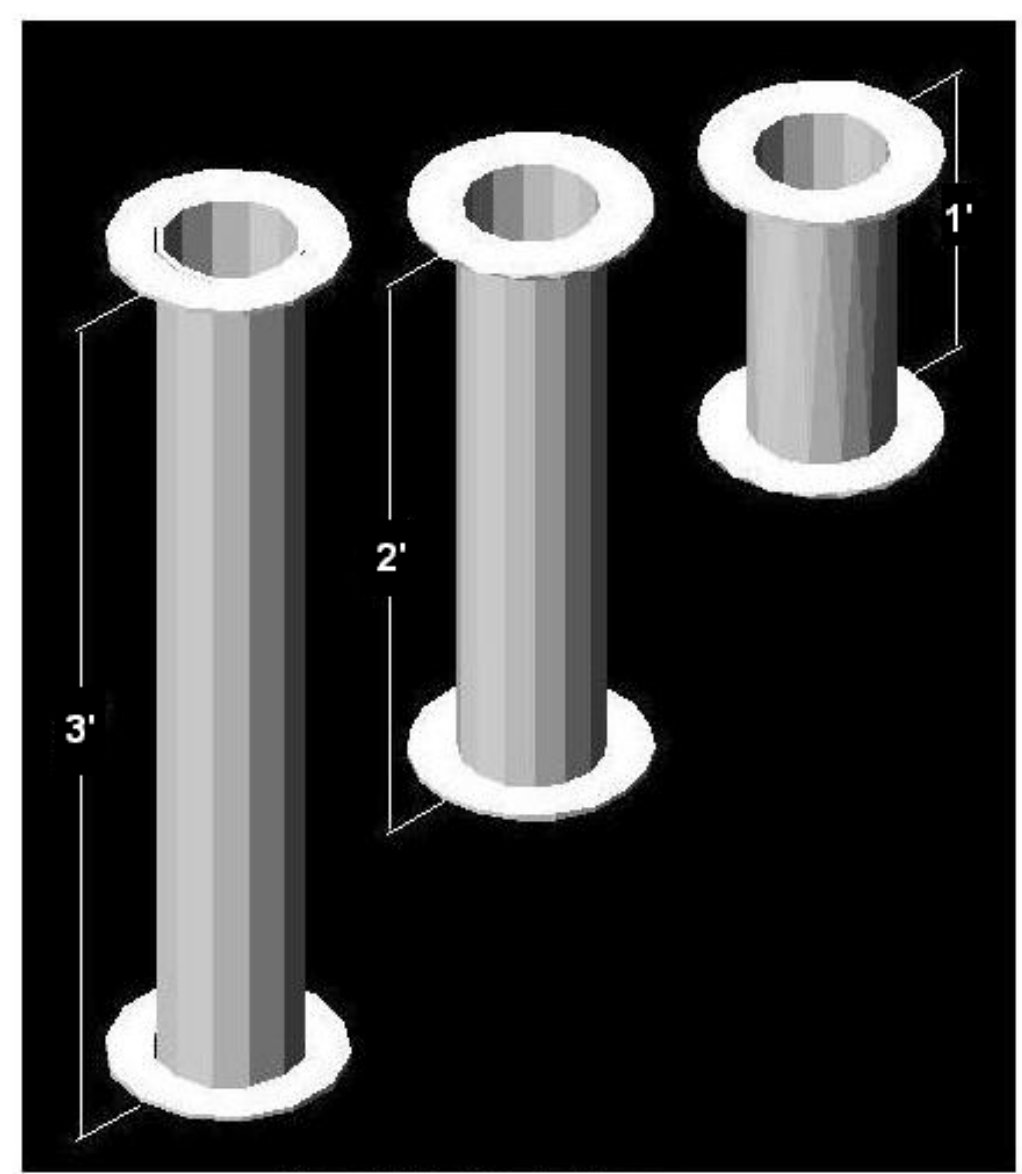

3.1.1b: Riser Sections 


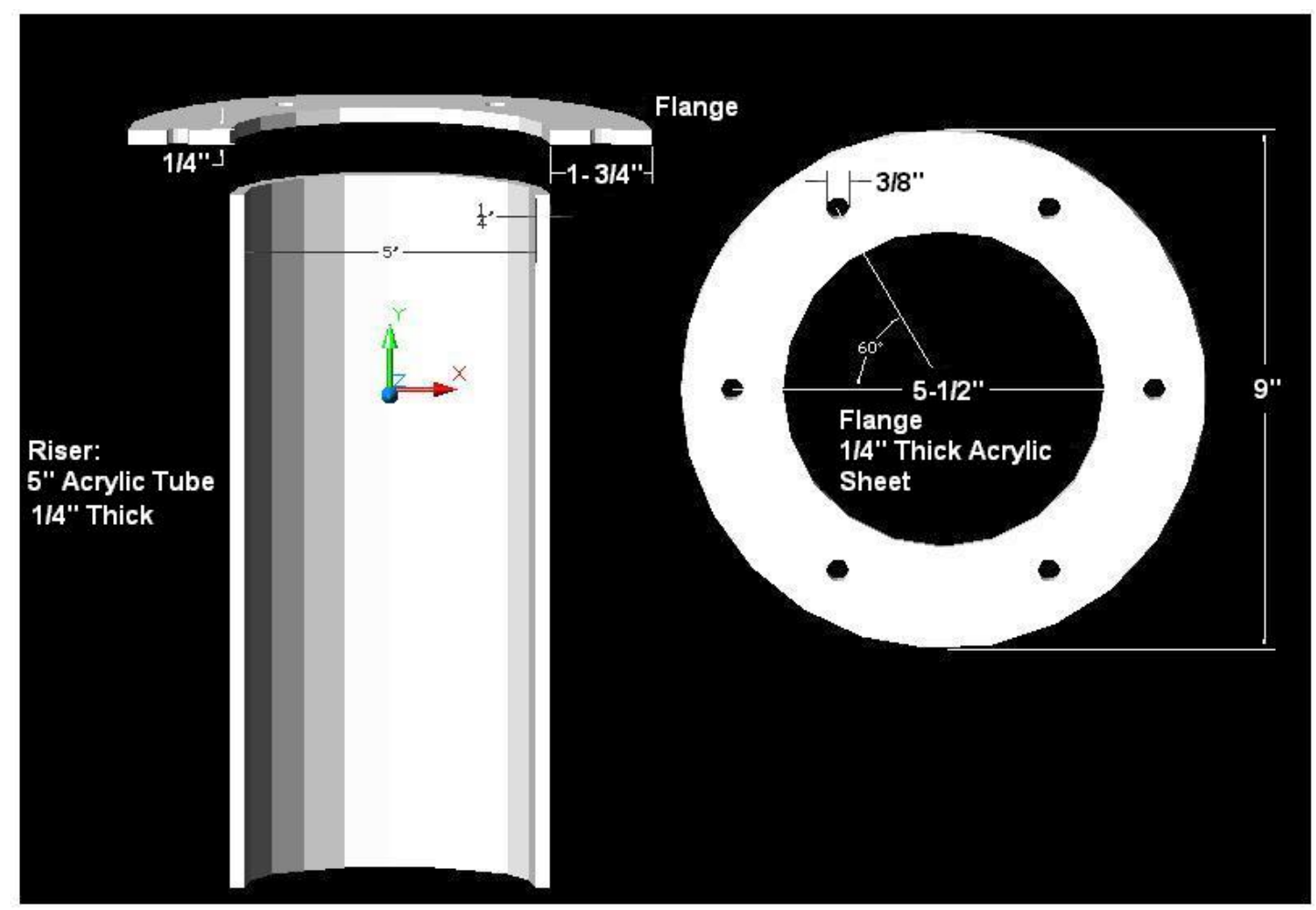

Figure 3.1.1c: Flange

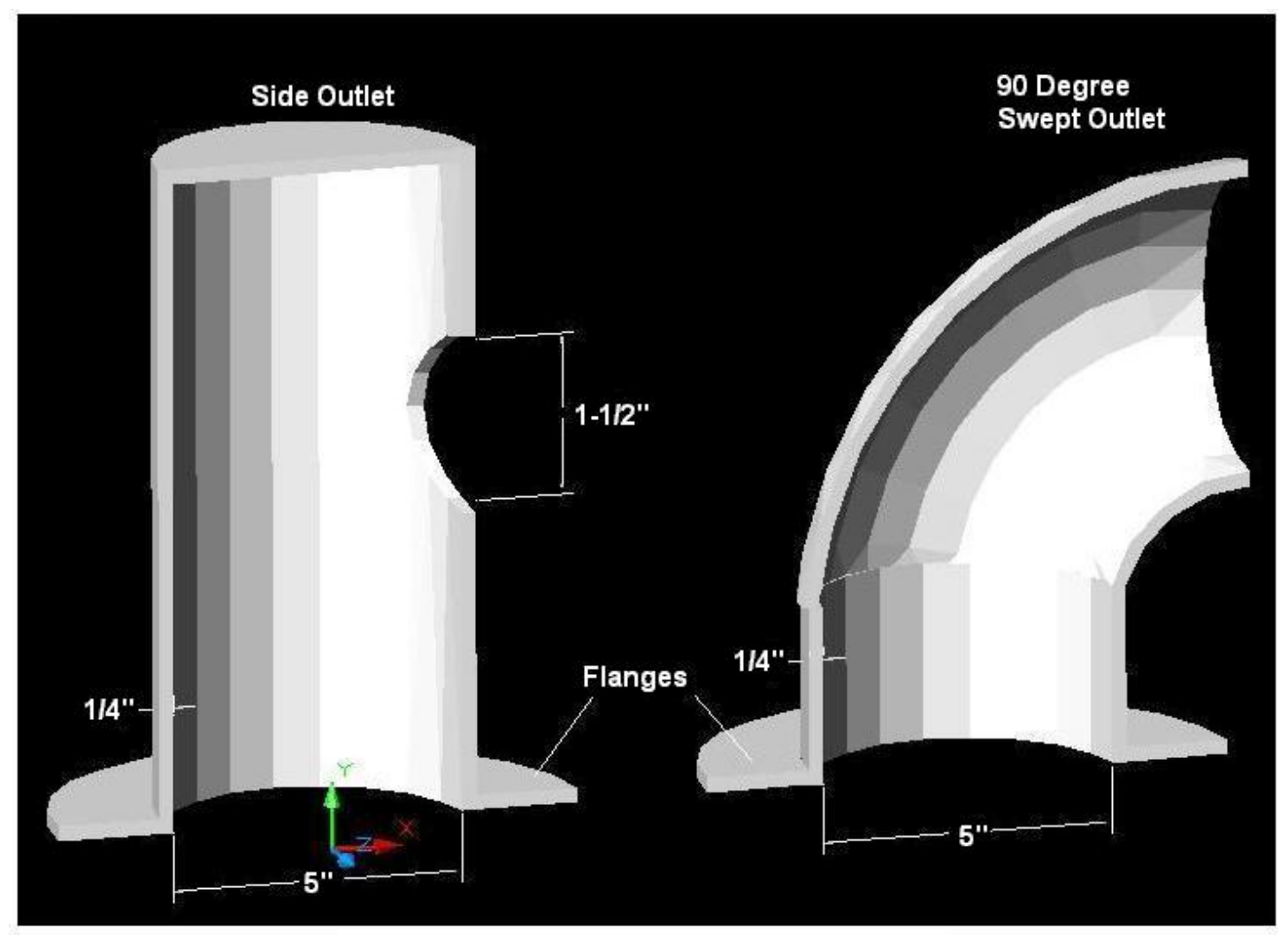

Figure 3.1.2a: Outlets 


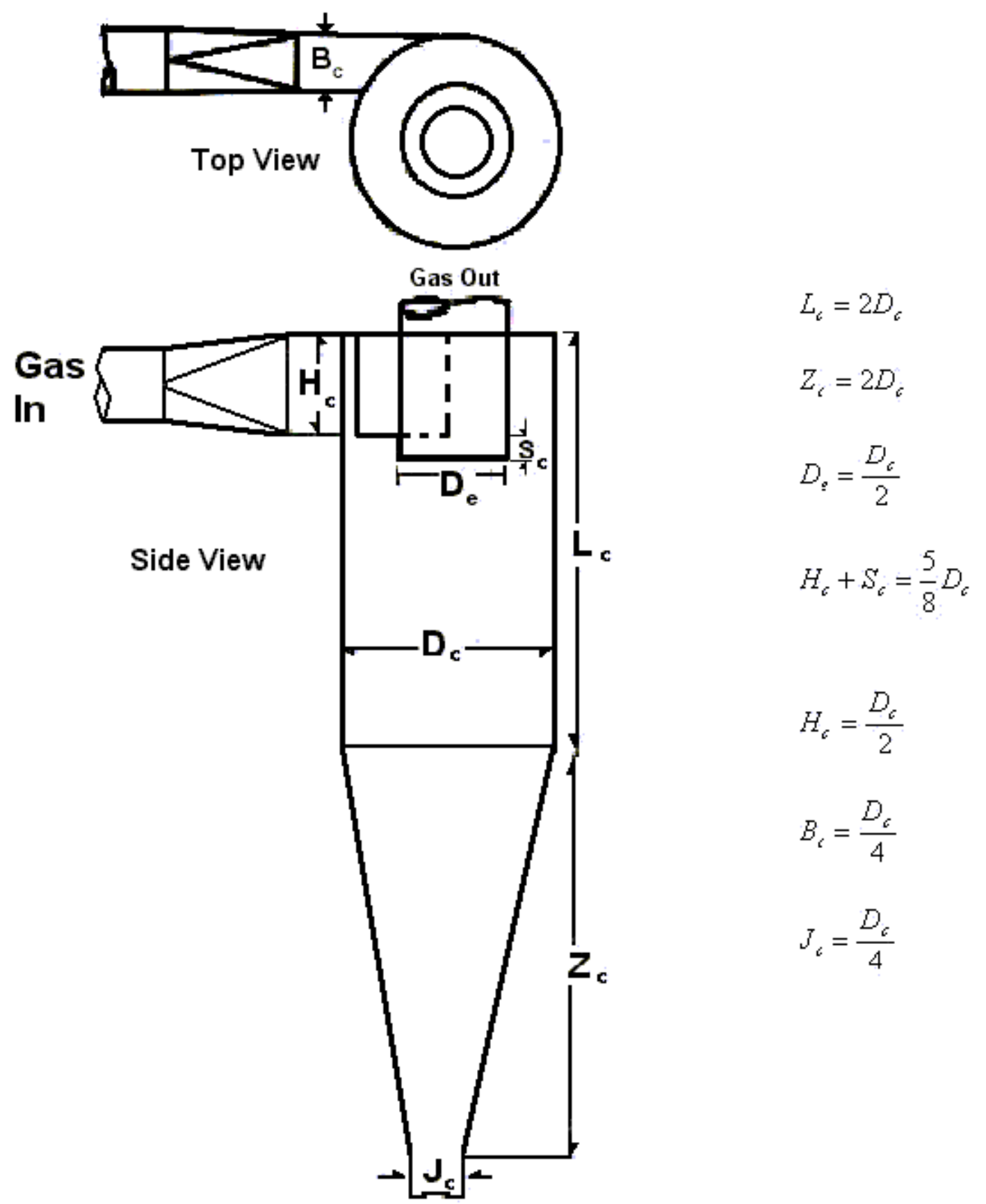

Figure 3.1.3a: Typical Cyclone Geometry Ratios 


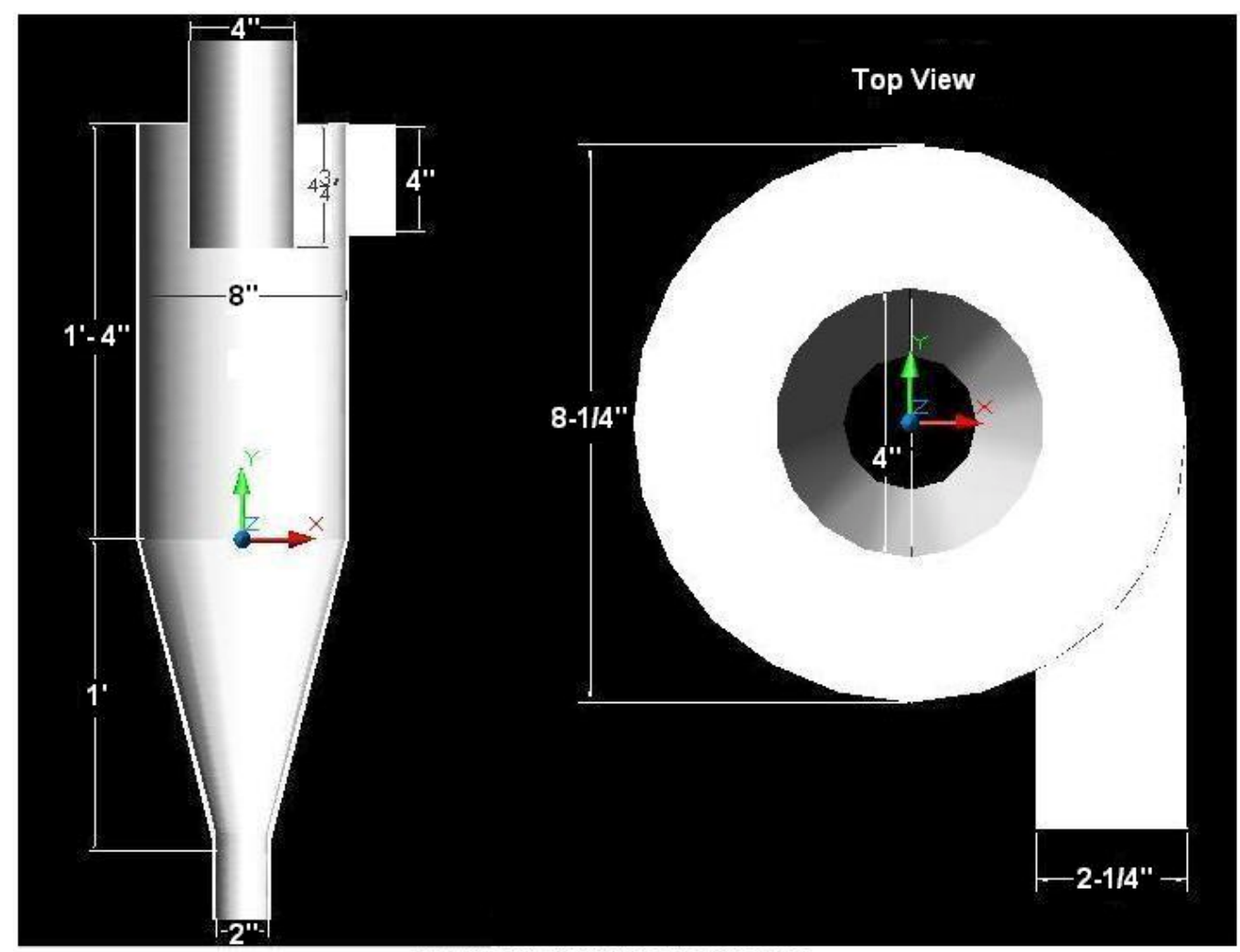

Figure 3.1.3b: Primary Cyclone

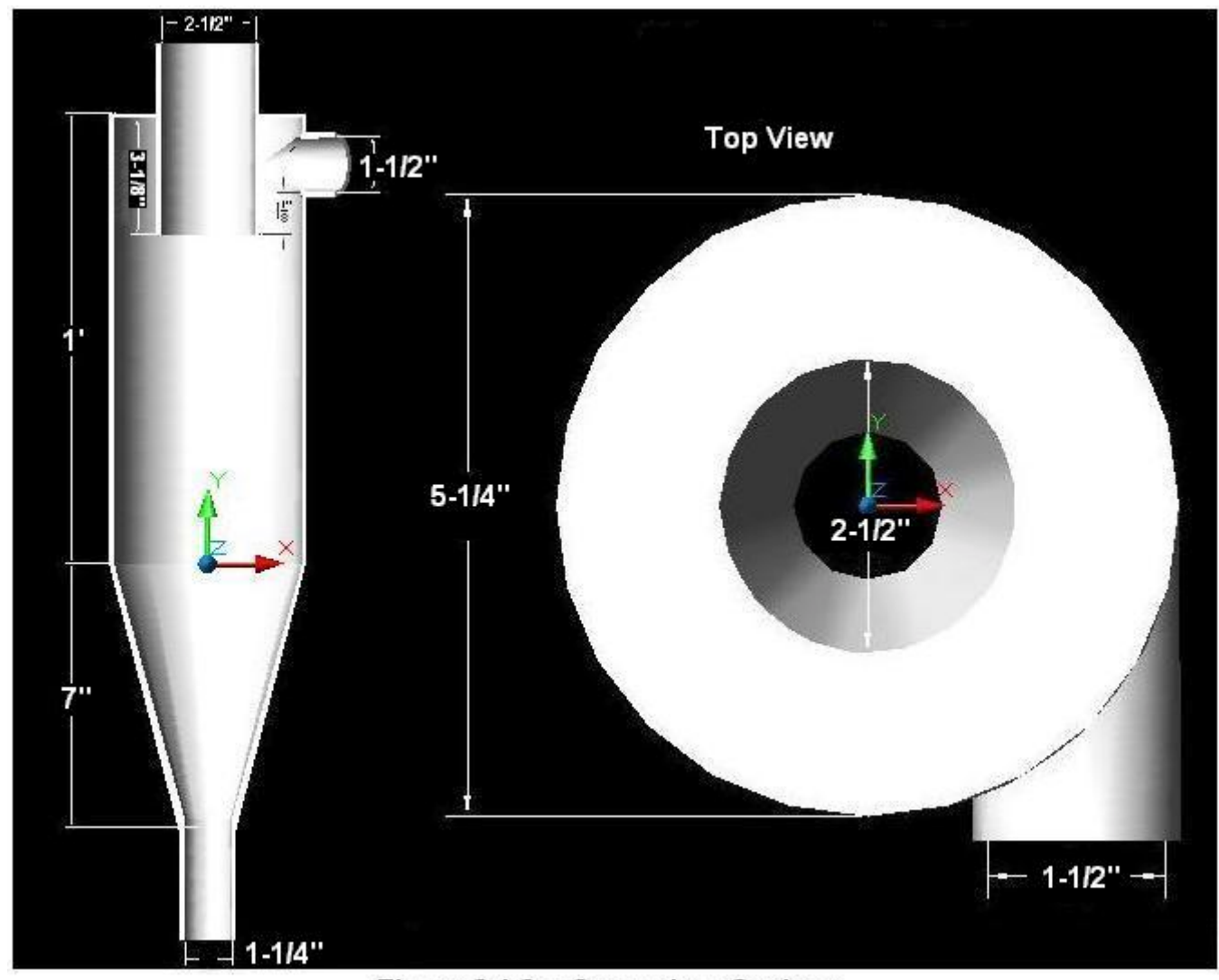

Figure 3.1.3c: Secondary Cyclone 


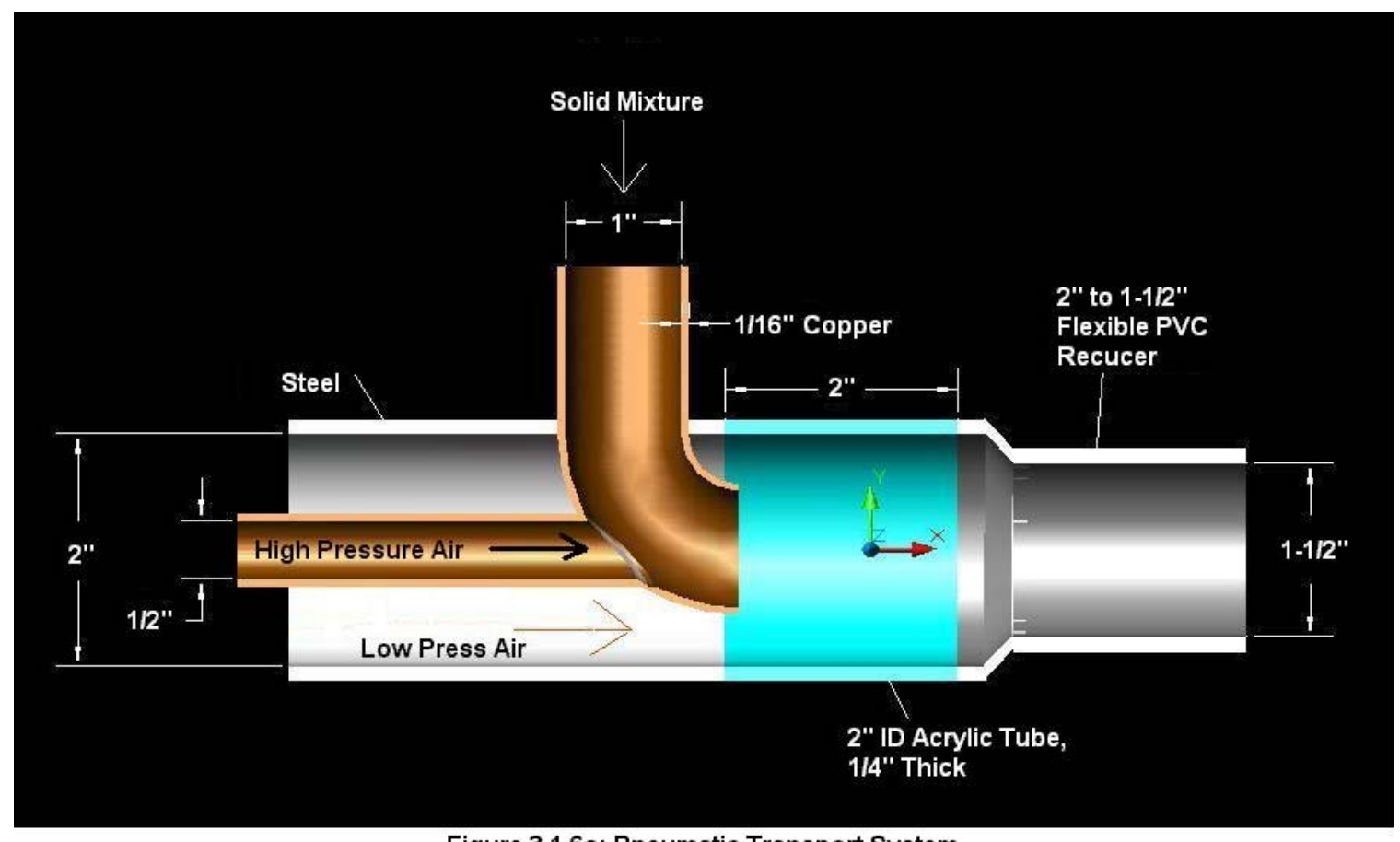

Figure 3.1.6a: Pneumatic Transport System

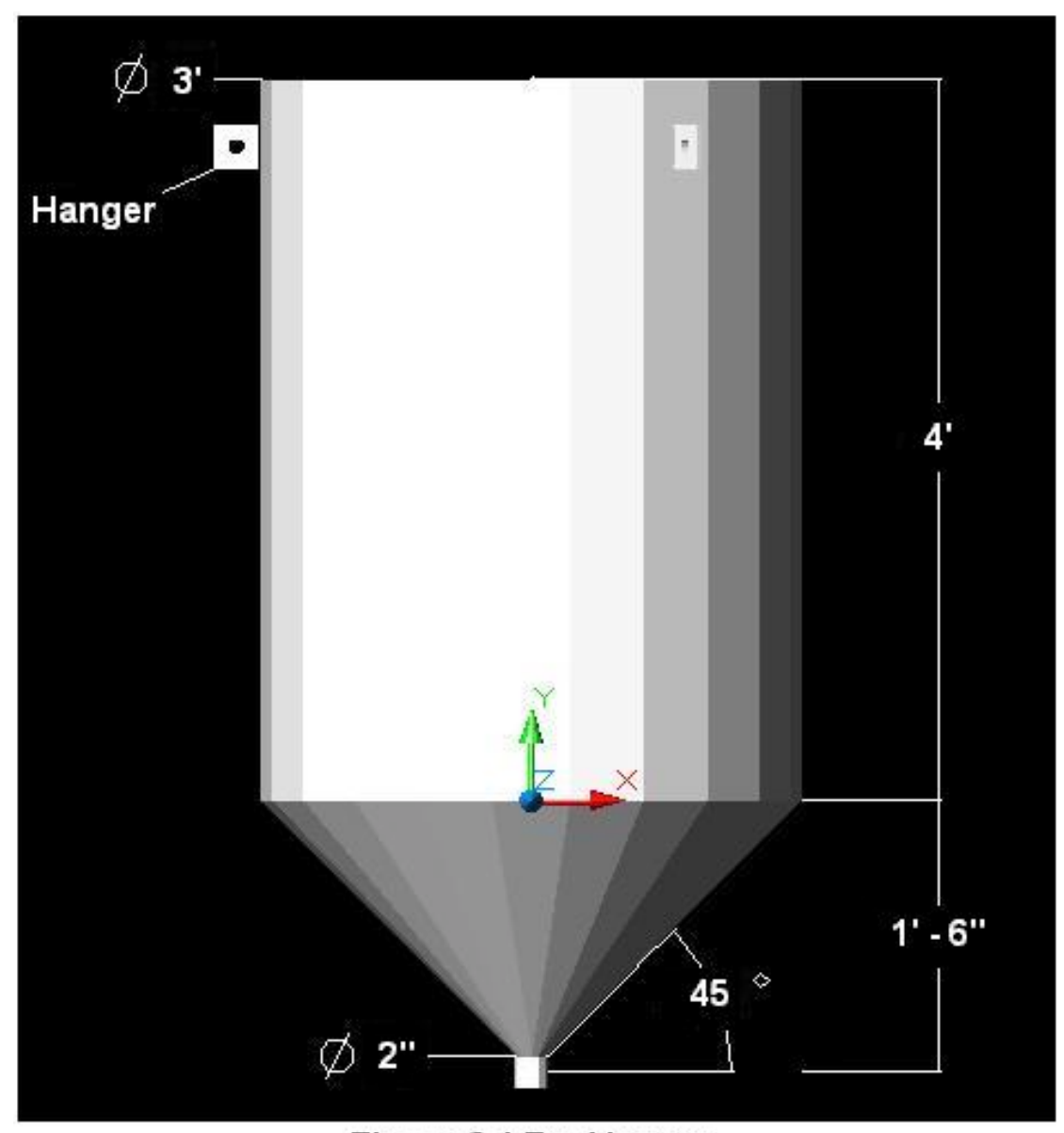

Figure 3.1.7a: Hopper 


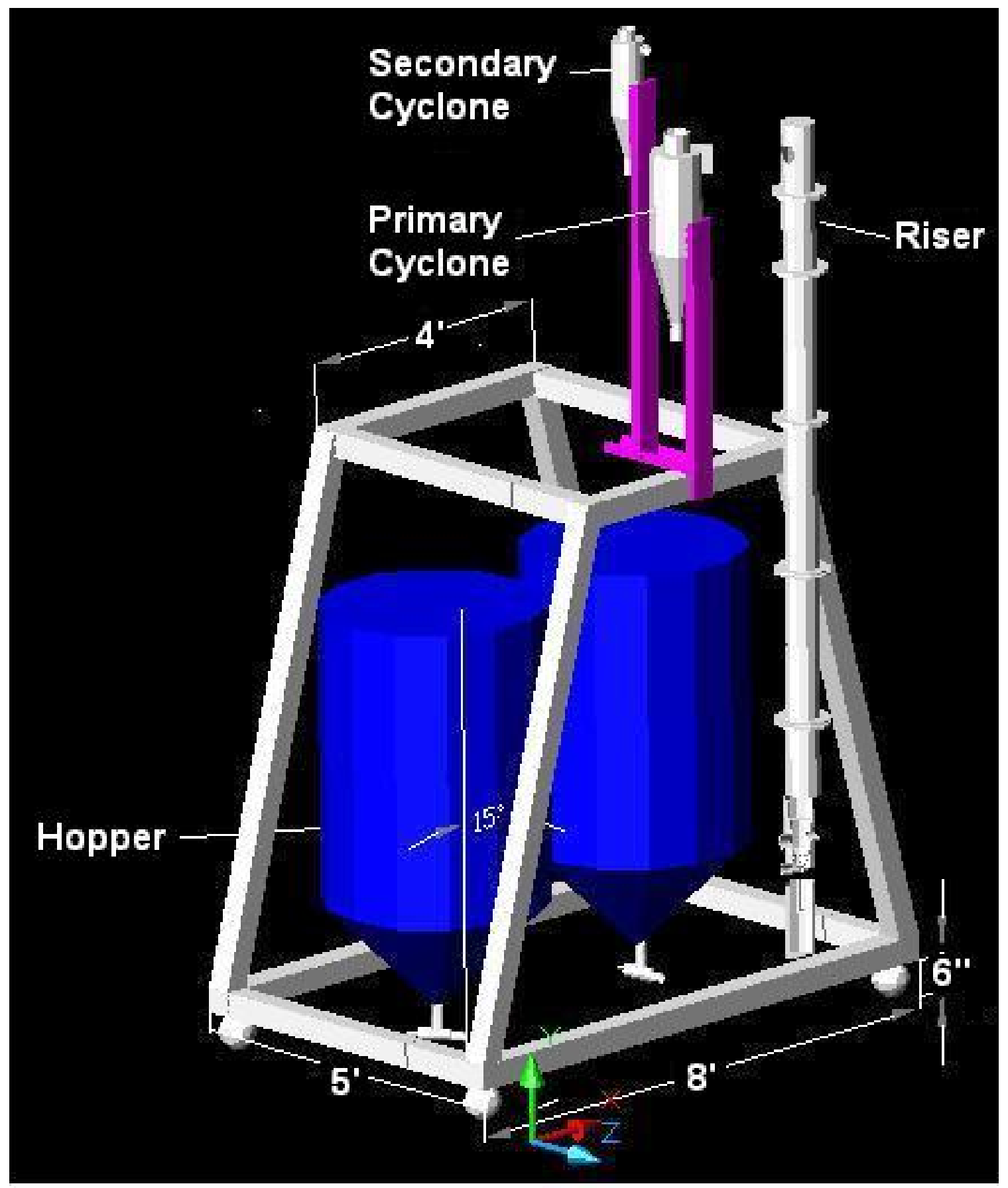

Figure 3.1.8a: System Assembly on Frame 


\subsection{Instrumentation}

The system uses two flow meters to measure air flow into the distributor and the pneumatic transport device, three pressure transducers to measure the pressure difference along the height of the riser, three pressure sensors/regulators to monitor and limit the pressure along the air supply lines, and two load cells to measure the mass flux into and out of the riser respectively. The load cells and pressure transducers were connected to a data acquisition board in a computer. The computer used a program to determine the mass flux using the change of the load cell readings with respect to time and the pressure difference was displayed and graphed on the computer. Each load cell was also connected to a strain gauge indicator that served as readout for the current weight of each hopper. The readout from the flow meters was used along with the upstream airline pressure read from the pressure sensor to determine the actual airflow rate into the system. The airflow rate was then converted to superficial riser velocity by dividing by the cross sectional area of the riser.

\subsubsection{Data Acquisition System}

A PC computer was used to observe the weight of the hoppers and the pressure difference along the riser height. The signals from the load cells were sent to an Analog Devices 5B40-03 signal conditioner in order to amplify the signal. The signal conditioners were mounted in an Analog Devices 5B-08 back plane. The signal was sent from the back plane and the pressure transducers to an MSTB 009-09 analog termination board. The signal was then sent to a Microstar Laboratories DAP 5200a/526 data acquisition board that was mounted in the PC. 
The computer program that was used to read the sensors was DAPView. DAPView was used to read the signal and converted the signal to the appropriate engineering units. The signal from the pressure transducers was converted to inches of water per inch of riser height. The signal from the load cells was compared to the time interval of the readings and was converted to pounds per minute, which are the units of mass flow rate. The mass flow rate was then converted to mass flux by dividing by the cross sectional area. The time was then converted from minutes to seconds and the final units for mass flux were $\mathrm{lb} / \mathrm{ft}^{2} \mathrm{~s}\left(\mathrm{~kg} / \mathrm{m}^{2} \mathrm{~s}\right)$.

\section{$\underline{\text { 3.2.2 Flow Meters }}$}

Two flow meters were used to monitor the flow into the distributor and the pneumatic transport system. Two Omega FLMG series in-line pneumatic flow meters were chosen. The two flow meters were rated at 100 SCFM at a pressure of $100 \mathrm{psi}$. The flow rate is read directly from the flow meter and was corrected by entering the upstream air pressure into a computer program. The air pressure was read from pressure sensors just upstream of the flow meters.

\section{$\underline{\text { 3.2.3 Pressure Transducer }}$}

The pressure transducers used were three PX-277-01D5V differential pressure transducers from Omega Engineering. The transducers were rated at a full scale of 1 inch of water and are field adjustable to full scales of 0.5 and 0.25 inches of water. The accuracy of the transducers is given as $1 \%$ of the selected full scale of the transducer. The transducers were set up to read 0.5 inches of water full scale giving them an accuracy of 
0.005 inches of water. The transducers also have a field adjustable output of 0 to 5 or 0 to 10 volts dc. The transducers were set to give an output of 0 to 5 volts dc. The riser was drilled and tapped to $1 / 8$ inch NPT at 1 foot intervals along the height of the riser starting 6 inches above the distributor. Tubing connections were screwed into the riser ports and rubber tubing was used to connect the ports to the pressure transducers.

\subsubsection{Pressure Sensors/Regulators}

Three pressure sensors/regulators were used throughout the system to monitor and control the input airline pressure throughout the air delivery system. One pressure sensor/regulator was connected just upstream of the distributor and was used to observe the pressure into the distributor and restrict the distributor pressure to a maximum of 10 psi. A second pressure sensor/regulator is connected just upstream of the distributor that splits the air supply to the flow meters. The second regulator limits the input pressure to $120 \mathrm{psi}$. The third pressure sensor/regulator is connected upstream of the hoppers. This sensor/regulator is rated at $15 \mathrm{psi}$ and is used to monitor and regulate the tank pressure according to the desired pressure required for a particular test to be performed. Two pressure sensors rated at $160 \mathrm{psi}$ were used on the system. One pressure sensor is located just upstream of each flow meter. These were used to adjust the indicated flow rate from each of the flow meters to the actual flow rates at the given pressure.

\section{$\underline{3.2 .5 \text { Load Cells }}$}

The 2 hoppers were hung by identical load cells. The load cells were Omega SBeam load cells series LC101 rated at 3000 pounds each. They were used to measure the 
original weight of the particle mixture and to monitor the mass particles in the hopper at any given moment during testing. The solid flow rate into the riser was also measured using the load cells and a computer program to determine the change in weight of the hopper with respect to time. The load cell on the product hopper was used to determine the amount of solid that was transferred to that hopper throughout the experimental procedure. 


\section{3 $\quad$ Procedures}

Experiments were made on the circulating fluidized bed system shown in Figure

3. The airflow was supplied by the Sulair high-pressure compressor in the High Bay Test Facility of the NRCCE building at West Virginia University. The distributor provided primary airflow to the riser while secondary airflow came from the pneumatic transport systems.

\subsubsection{Start-up Procedure}

The startup procedure for the CFB Riser Dry Separator is given below and references numbers are shown in Figure $\mathbf{3}$

1. Turn on the load-cell readouts.

2. Turn on the computer and open DAPView.

3. Check that all valves are closed.

4. Pour the mixture into the top of the feed hopper.

5. Attach the excess and dense particle bins (6 and 7) to the riser.

6. Open the main air pressure valve (12) completely.

7. Open the main tank air pressure valve (13) completely.

8. Open the cyclone solid exhaust valve (1e or $2 \mathrm{e})^{*}$ corresponding to the product hopper.

9. Open the distributor solid feed valve (1f or $2 \mathrm{f}$ )* corresponding to the feed hopper.

10. Open the tank pressurizing valve ( $1 \mathrm{~d}$ or $2 \mathrm{~d})^{*}$ corresponding to the feed hopper.

11. Adjust the main tank pressurizing gate valve (18) to the proper pressure shown by the pressure gauge (19). 
12. Adjust the distributor valve (5) to the desired flow rate shown by the corresponding flow meter.

13. Adjust the low pressure solid feed valve ( $1 \mathrm{~b}$ or $2 \mathrm{~b})^{*}$ for the feed hopper to the desired flow rate.

14. Adjust the high pressure solid feed valve (1a or $2 a)^{*}$ for the feed hopper to the desired setting.

15. Check the flow meters and the pressure gauge for equilibrium at the desired test conditions.

16. Start the DAPView program to read the load cells and produce mass flux readings.

17. Open the feed hopper valve (1c or $2 \mathrm{c})^{*}$ completely.

\subsubsection{Observations}

During operation, the quantities frequently observed to insure steady state was attained and maintained were:
a) All pressure gauges
b) Air flow rate into the riser
c) Solids mass flux using the computer
d) Riser pressure distribution using the computer

\subsubsection{Shut Down Procedure}

The shut-down procedure for the system is given below according to Figure 3:

1. Close the main tank pressurization gate valve (18).

2. Ease the distributor valve (5) closed.

3. Ease the high pressure solid feed valve (1a or $2 a)^{*}$ closed. 
4. $\quad$ Ease the low pressure solid feed valve $(1 b \text { or } 2 b)^{*}$ closed.

5. Close the main air pressure valve (12)

6. Close the main tank air pressure valve (13)

7. Record the mass flux into the product hopper and out of the feed hopper.

8. Use the magnet to separate the steel shot from the contents in the excess bin and particle bin and record the weight of the steel.

9. Record the weight of the sand in the excess bin and particle bin.

The asterisk $(*)$ in the start-up and shutdown procedures show that both hoppers 1 and 2 may be used as either feed hoppers or product hoppers. Typically hopper 1 was used for the initial mixture as the feed hopper and hopper 2 was used as the product hopper. If the solid was to be re-circulated through the system, the use of the hoppers were switched each time the mixture is re-circulated.

\subsubsection{Calibration}

The instruments were calibrated to reduce the error of the measurements taken. Instruments that were calibrated include the load cells and the pressure transducers. The load cells were calibrated using known calibration weights that were added to the weight of the empty hoppers to confirm the voltage to weight ratio of the load cells. The pressure transducers were calibrated to a known zero and for linearity using a high sensitivity, electronic calibration device. The pressure transducers were also re-zeroed periodically. 
The A/D converter board was calibrated using known zero voltage input and known 5 volt input.

\subsection{Test Matrix}

\subsubsection{Initial Particle Sizing}

The first step was to determine the size distribution of the steel and the sand. The sand must be a comparable size to the steel in order to show separation due to density rather than size. The sand used for the experiment was bought in $50 \mathrm{lb}$ bags that had been dried and sieved from the packaging plant. The steel used was bought commercially and were smooth and spherical. The sand and steel were both sieved separately at the Energy Research Building at West Virginia University using screens with mesh numbers of 30, $35,50,60,100$, and 140 .

TABLE 3.4 shows the mesh number, the size of opening for each screen, the weight that was collected in each screen from the 100 gram sample, and the percent of the sample collected in each screen for the steel shot and sand. 


\begin{tabular}{|c|c|c|c|}
\hline \multicolumn{4}{|c|}{$\begin{array}{l}\text { Quickrete Play Sand } \\
\text { Weight of Sample }(\mathrm{g})=\mathbf{1 0 0}\end{array}$} \\
\hline Mesh \# & Mesh Opening (microns) & Weight from sample (g) & Weight \% \\
\hline 30 & 500 & 0.3 & 0.3 \\
\hline 35 & 420 & 14.8 & 14.8 \\
\hline 60 & 250 & 59.2 & 59.2 \\
\hline 100 & 147 & 22.5 & 22.5 \\
\hline 140 & 106 & 1.73 & 1.73 \\
\hline$>140$ & $>106$ & 0.2 & 0.2 \\
\hline \multicolumn{4}{|c|}{$\begin{array}{l}\text { Steel Shot } \\
\text { Weight of Sample }(\mathrm{g})=100\end{array}$} \\
\hline Mesh \# & Mesh Opening (microns) & Weight from sample (g) & Weight \% \\
\hline 30 & 500 & 0.2 & 0.2 \\
\hline 35 & 420 & 58.3 & 58.25 \\
\hline 50 & 300 & 33.8 & 33.8 \\
\hline 60 & 250 & 0.7 & 0.7 \\
\hline$>60$ & 147 & 0.5 & 0.48 \\
\hline
\end{tabular}

Table 3.4: Size Distribution of Steel and Sand Test Particles

The size distribution of both the sand and the steel is represented in Figure 3.4. The figure shows that the steel has a slightly larger size distribution than the sand, which is not ideal, but not thought to be enough to dramatically affect the ability to show separation according to density difference. The figure shows that there is on average a 100 to 150 micron difference in size between the steel and the sand. The effect that a 150 microns increase will have on the steel terminal velocity is approximately $8 \mathrm{ft} / \mathrm{s}(2.44$ $\mathrm{m} / \mathrm{s}$ ) according to Figure 2.4.1a. The effects of the density difference at an average particle size of the sand of 350 microns are approximately $12 \mathrm{ft} / \mathrm{s}(3.66 \mathrm{~m} / \mathrm{s})$ according to Figure 2.4.1a. While the size difference does have a noticeable effect on the particle terminal velocity, the density difference between steel and sand has the dominate effect within our test size distribution. 


\subsubsection{Initial CFB Flow Tests}

Tests were performed in order to determine the flow characteristics in the riser at various combinations of superficial air velocities and mass fluxes of sand into the riser. The distributor of the circulating fluidized bed system was equipped with a ring that closed the gap between the riser wall and the distributor. The height was set at 8 feet with a side outlet. The flow characteristics were observed in order to determine which regimes would most likely fit the characteristics needed for separation.

The flow regime diagram is a diagram that is used to shows the flow regime in the riser for combinations of the mass fluxes of the solids and the superficial air velocity into the system. The three distinct flow regimes of a CFB riser are dilute, dense, and core/annulus or fast fluidization regime. Dilute flow occurs when the solid content in the riser is very dilute and essentially moves primarily upward through the riser and through the outlet of the riser without excessive circulation within the riser. Dense flow occurs when the solid concentration in the riser due to re-circulation becomes high enough to disrupt the upward flow of the air through the riser and causes a bubbling action of the air through some or all of the riser. Core/annulus flow occurs in the transition between dilute and dense flow and is characterized by heavy circulation of the particles within the riser in which the particles flow rapidly upward in the core of the riser and flow downward along the wall or annulus of the riser. The particles may circulate back and forth from the core to the annulus flow numerous times before traveling through the outlet of the riser. 


\subsubsection{Initial Separation Tests}

The initial separation tests were conducted with the $1 / 8$ inch gap ring for the distributor. The test mixture was comprised of $50 \mathrm{lbs}(22.7 \mathrm{~kg})$ of sand and $2.2 \mathrm{lbs}(1000$ grams) of steel for each run. The tests were made by varying the mass flux of the mixture from approximately $0.24 \mathrm{lb} / \mathrm{ft}^{2} \mathrm{~s}$ to $0.98 \mathrm{lb} / \mathrm{ft}^{2} \mathrm{~s}\left(2.58 \mathrm{~kg} / \mathrm{m}^{2} \mathrm{~s}\right.$ to $\left.10.6 \mathrm{~kg} / \mathrm{m}^{2} \mathrm{~s}\right)$. The superficial air velocity was varied from $10.4 \mathrm{ft} / \mathrm{s}$ to $12.2 \mathrm{ft} / \mathrm{s}$ in $0.6 \mathrm{ft} / \mathrm{s}$ increments $(3.17$ to $3.72 \mathrm{~m} / \mathrm{s}$ in $0.18 \mathrm{~m} / \mathrm{s}$ increments). Each test was recycled through the riser 2 or 3 times depending on the efficiency of the runs.

\subsubsection{Effect of Collection Gap Width}

The gap between the distributor and the riser wall in which the heavy particles were expected to fall in for collection was varied in order to determine what effect, if any, was made to the separation process. The gap is $1 / 4$ inch $(6.4 \mathrm{~mm})$ between the distributor and the riser. A ring was place on the distributor that decreased the gap by one half to $1 / 8$ inch $(3.2 \mathrm{~mm})$. The tests were conducted at both test gaps for two superficial air velocities as well as three different internal ring configurations for each superficial air velocity condition. The mass flux into the system was kept constant for all tests at approximately $0.56 \mathrm{lb} / \mathrm{ft}^{2} \mathrm{~s}\left(6.03 \mathrm{~kg} / \mathrm{m}^{2} \mathrm{~s}\right)$.

\subsubsection{Effect of Riser Height}

The height of the riser was changed in order to examine the effects that the riser height has on the separation characteristics of the riser. Tests were run to compare the heights of 8 and 14 feet ( 2.44 and 4.27 meters). The side outlet was used for the tests as 
well as the $1 / 8$ inch $(3.2 \mathrm{~mm})$ collection gap ring. The tests were conducted at both test heights for three superficial air velocities.

\subsubsection{Effect of Internal Ring}

It was observed during earlier testing that the solid clusters consisting of both heavy and light particles were traveling down rapidly along the riser wall. As the mass flux of solids into the riser increases, the particle clusters traveled further down the riser before being broken up and being caught in the up flow in the core. Whenever the clusters were breaking up above the distributor, much of the heavy particles would continue downward along the wall as the lighter particles were primarily re-entrained by the up-flow of air in the core. At a certain mass flux, the particle clusters begin to flow completely down the riser to the distributor. As the cluster reached the distributor, some of the solid mixture was carried back up the riser in the core while much was dropped through the collection gap and into the heavy particle collection bin. This leads to high collection rates of light particles in the heavy particle collection bin when mass fluxes were increased to this point.

A method of breaking up these downward annulus clusters of particles before they reach the distributor was needed in order to increase the mass flux that could be processed by the system in order to make the system practical. To do this, the riser was equipped with internal rings with smaller diameters than the riser that act as a barrier along the wall to downward flow. They were installed approximately 3 feet above the distributor. As the solid clusters move downward along the wall from the top of the riser they hit the rings. The clusters were broken up and diverted back into the core of the 
riser. The heavy particles were expected to continue to flow downward, past the ring, and back to the annulus of the riser below the internal ring. The heavy particles travel down past the distributor through the collection gap and into the heavy particle collection bin. The light particles were expected to begin traveling back up the core of the riser once they were reintroduced to the core by the internal ring. Rings with internal diameters of 4 and 4.5 inches (102 and $114 \mathrm{~mm}$ ) were tested and compared to tests without any internal ring.

\subsubsection{Effect of Outlet}

The outlet was changed in an attempt to limit the circulation of solids within the riser to increase capacity without increasing sand collection. The new outlet was only be tested on the 14 foot $(4.27 \mathrm{~m})$ riser since it is assumed that an 8 foot $(2.44 \mathrm{~m})$ riser would likely allow excessive amounts of steel to flow directly through the riser and not have enough room to be separated. The side outlet riser is compared to the 90 degree swept outlet in this section.

\subsubsection{Effects of Initial Heavy Particle Mass Fraction}

The steel to sand ratio of the test mixture was altered in order to determine the effect on the performance of the system. The first mixture tested consisted of $4.2 \%$ steel and $95.8 \%$ sand. The results were then compared to tests conducted with a mixture of $34.0 \%$ steel and $66 \%$ sand. 


\subsubsection{Size Distribution after Tests}

The size distribution of select tests was observed in order to determine what size of sand was collected and what size was not as well as the steel collected. The sizes were

observed as they were before testing began by sieving samples of steel and sand. A sample of sand and steel that were collected as well as the sand that was not collected was sieved. 


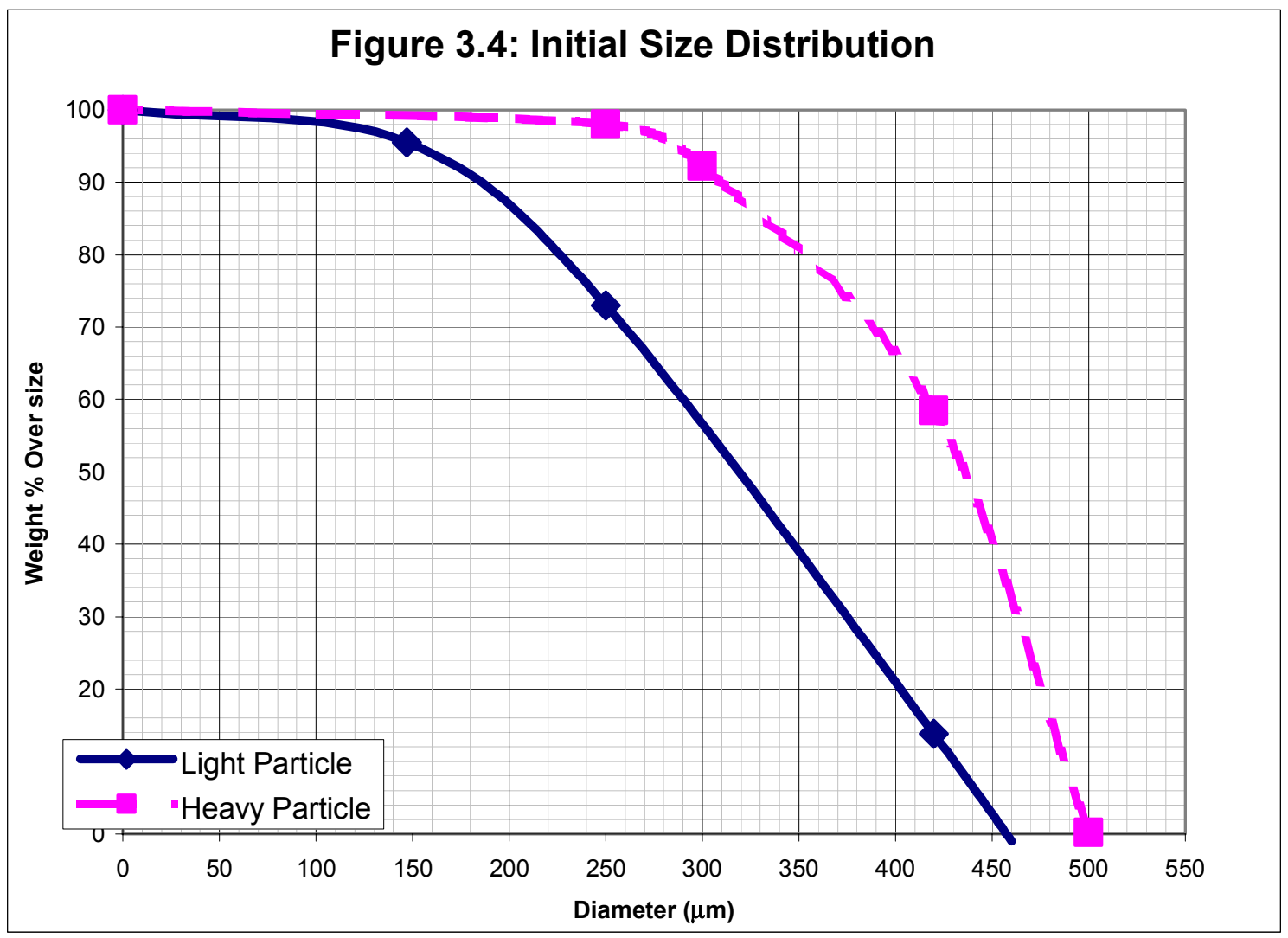




\section{CHAPTER 4}

\section{RESULTS AND ANALYSIS}

\subsection{Introduction to the Data}

The results from the tests that were conducted on the experimental circulating fluidized bed riser system are shown below. Due to the large amount of data that was taken and the numerous graphs that are necessary to present all of the information attained, only a representative set of data will be presented in this chapter. A number of the figures showing the data for other specific tests are presented in the appendix of this paper.

\subsection{Initial CFB Flow Tests}

Tests were performed for various combinations of mass and superficial air velocities to determine conditions for acceptable solids separation. The data was also used to develop the flow regime diagram shown in Figure 4.2a for the riser with the initial test geometry. It was observed early in the tests that dense flow and fully developed core/annulus flow would not be practical separation regimes due to high amounts of un-separated solid flowing into the collection gap. The most promising flow regime corresponded to a lightly loaded, low mass flux into the riser, core-annulus flow. Therefore, the majority of the initial tests were used to develop the flow regime diagram.

The regime that was determined to be the most probable for successful separation was the transitional phase from the dilute phase to the core/annulus phase. This phase is characterized by downward pulses of solid clusters in the annulus of the riser that extend downward into the lower one-half of the riser without actually reaching the distributor. 
The downward motion of the clusters broke up in the lower one-half of the riser and the majority of the solids were re-entrained by the flow through the core. The break up of particles near the distributor allowed heavy particles to continue down the wall and through the gap and the light particles in the cluster to re-entrain into the upward core flow.

The flow within the riser can also be broken into core/annulus, dilute, and dense regions throughout the height of the riser. In dense riser flow, the riser is actually characterized by a dense region in the bottom and a core/annulus region above that. In the transitional phase between core/annulus and dilute flow, the riser can be divided into two sections. The upper section is core/annulus flow with an apparent dilute region below that. Figure 4.2b shows the percentage of the riser height that was occupied by the different flow regimes for various conditions. A complete collection of these figures can be seen in $\underline{\text { Appendix A. }}$. All of the figures show trends consistent to that of Figure 4.2b .

Figure 4.2c shows the height of the transition from the dilute flow regime to core/annulus flow regime versus the mass flux into the system for various superficial air velocities. The height was defined as the height above the distributor in which the downward flowing clusters typically broke up. The figure shows that for a constant mass flux, the height of the transition increases as the air velocity increases. For a constant air velocity, the transition height increases as the mass flux decreases. It can be noted that for a transition height of zero, the clusters are reaching the collection gap before breakup occurs. This should correspond to a dramatic increase in sand collection, effectively decreasing the efficiency of separation for the system. 


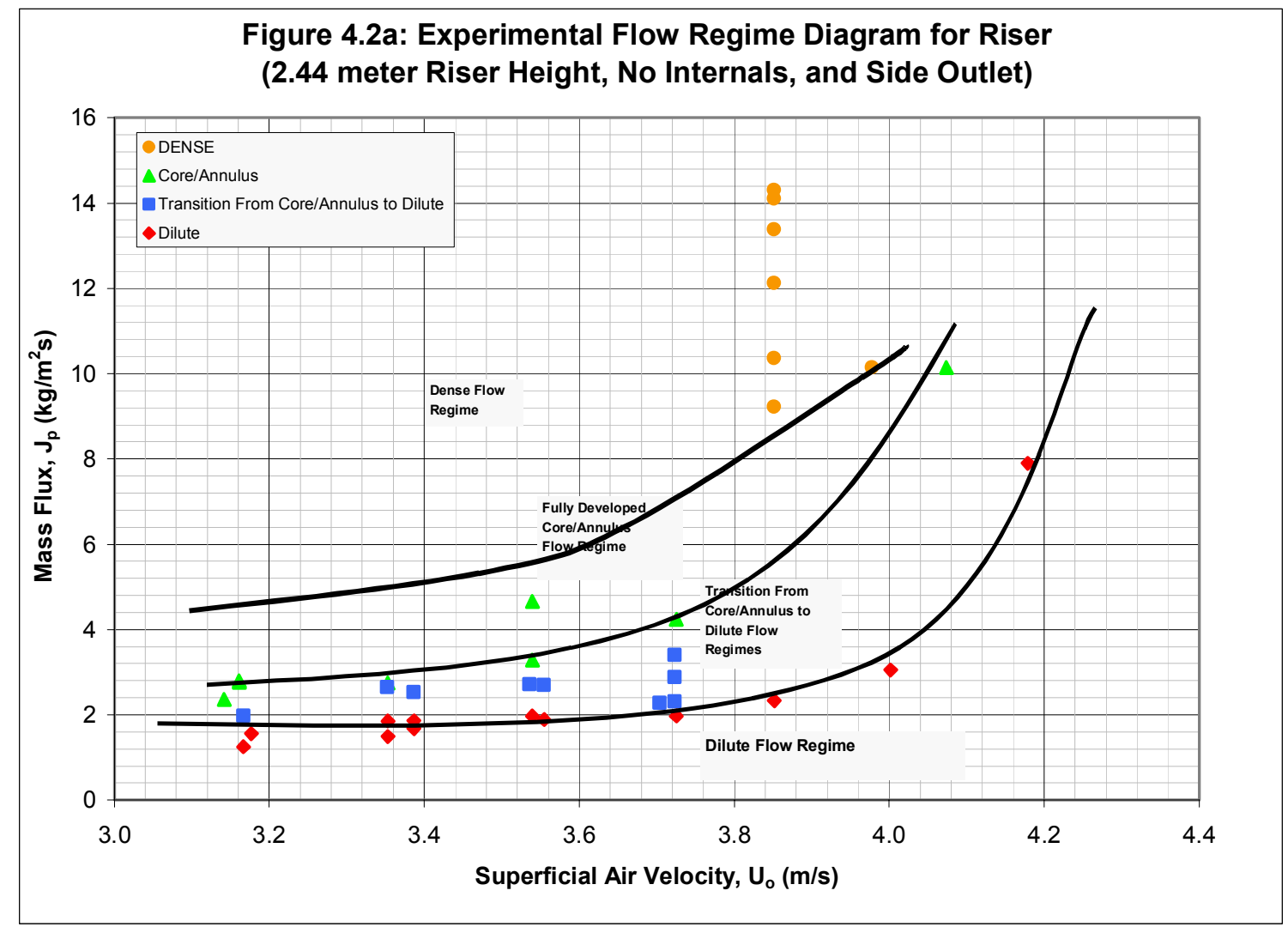

Figure 4.2b: Percent of Riser Occupied by Different Flow Regimes (2.44 meter Riser Height, No Internals, and Side Outlet)

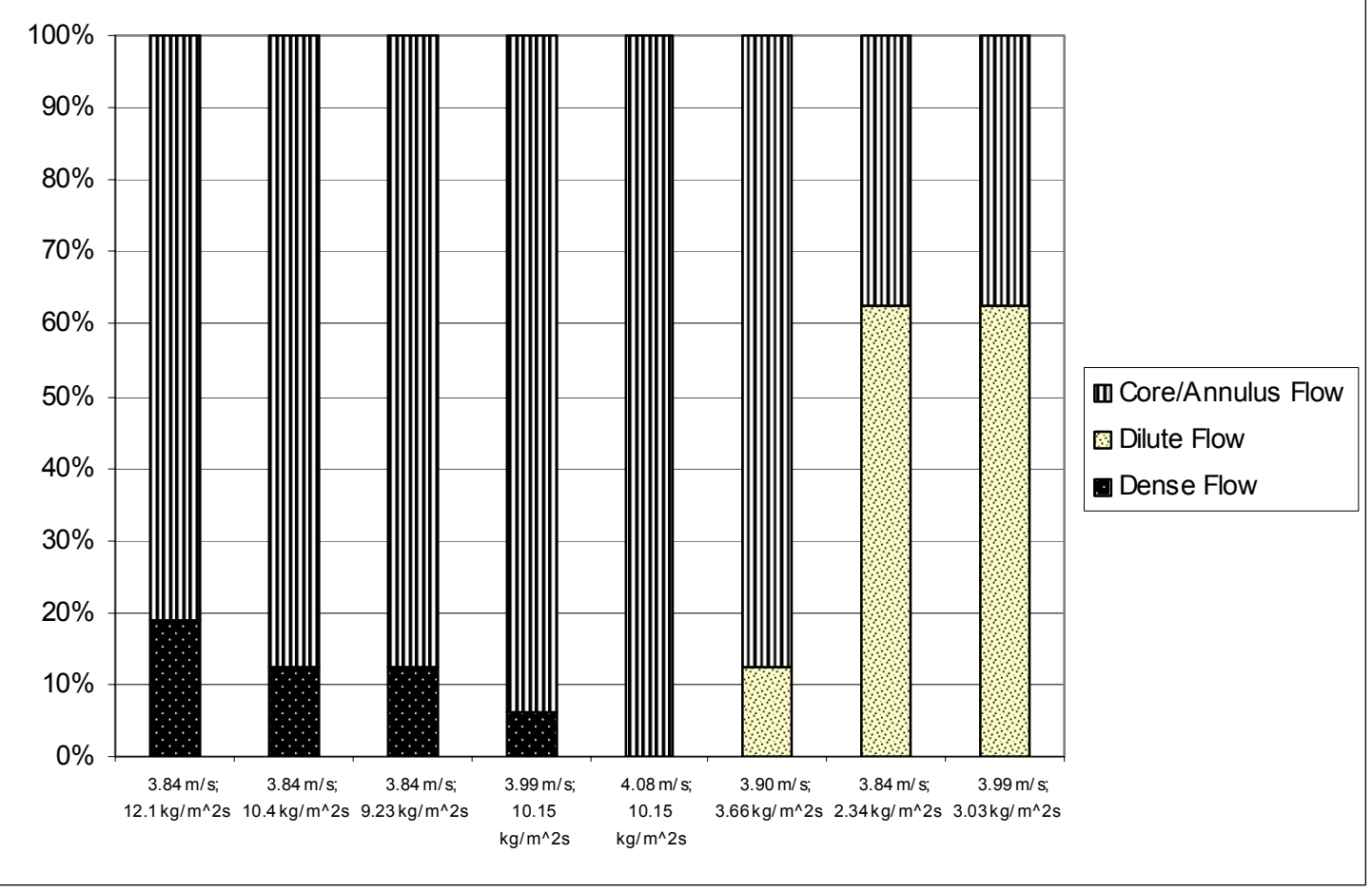




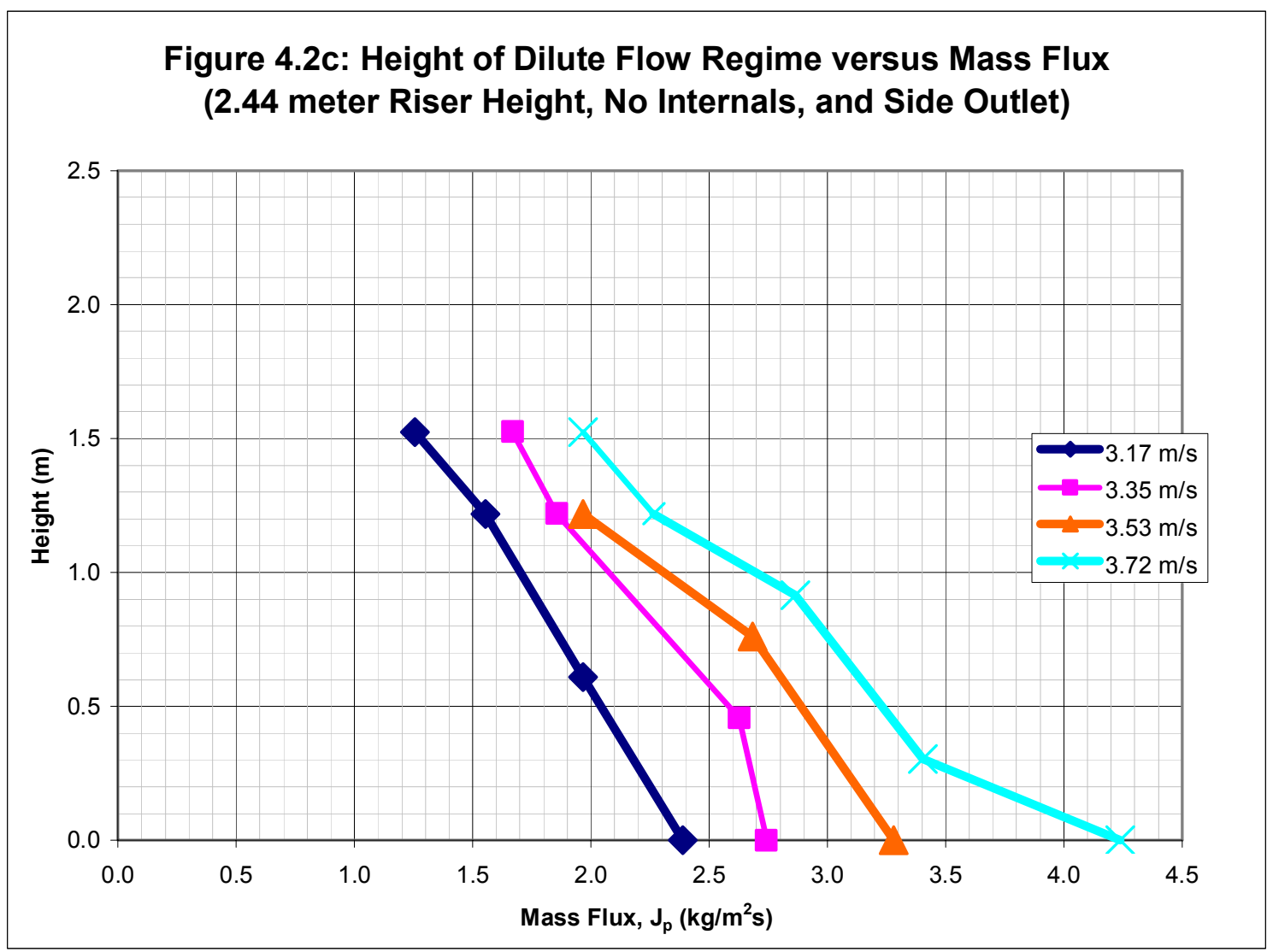




\section{$\underline{4.3 \text { Initial Separation Tests }}$}

The initial separation tests were conducted with the side outlet, a gap size of $1 / 8$ inch $(3.2 \mathrm{~mm})$, and a riser height of $8 \mathrm{ft}(2.44 \mathrm{~m})$. The test mixture had a heavy particle mass fraction of 0.042 . The effects of recycling the solid mixture through the riser numerous times was observed in order to determine the feasibility of external recycling as a means to increase the high density particle collection efficiency. To determine the effectiveness of separation, the particles that were collected in the heavy particle collection bin were analyzed after each cycle.

Figure 4.3 a, b, and c show the collection efficiency of the heavy particles, light particles and the heavy particle mass fraction respectively for the initial separation tests at a superficial air velocity of $11.6 \mathrm{ft} / \mathrm{s}(3.54 \mathrm{~m} / \mathrm{s})$. The figures show tests conducted at various mass fluxes with multiple passes of the mixture through the riser. The particles that were collected from the top outlet of the riser and through the series of cyclones was recycled through the riser system a number of times. The results for each pass for a test condition are represented in the figure. The figure shows that the highest heavy particle collection was seen for the highest mass flux of $0.93 \mathrm{lb} / \mathrm{ft}^{2} \mathrm{~s}\left(10.0 \mathrm{~kg} / \mathrm{m}^{2} \mathrm{~s}\right)$. The high mass flux also resulted in a very high light particle collection of $24 \%$ after only one run. This shows that while heavy particle collection was high, the density separation phenomenon was not dominant. When the mass flux was decreased to $0.66 \mathrm{lb} / \mathrm{ft}^{2} \mathrm{~s}\left(7.10 \mathrm{~kg} / \mathrm{m}^{2} \mathrm{~s}\right)$, the heavy particle collection decreased by approximately $15 \%$ but the light particle collection decreased by over $50 \%$ resulting in a more efficient separation. As the mass flux decreased below $0.66 \mathrm{lb} / \mathrm{ft}^{2} \mathrm{~s}\left(7.10 \mathrm{~kg} / \mathrm{m}^{2} \mathrm{~s}\right)$, the heavy particle collection steadily increased and the light particle collection steadily decreased. The effect of multiple 
passes through the system on collection efficiency was consistent for all mass fluxes. The amount of sand collected for each pass was consistent while the amount of steel collected decreased significantly for each successive pass that the mixture made through the riser. This decrease in heavy particle collection efficiency after each pass is due to the dramatic decrease in heavy particle concentration in the mixture due to the collection of previous passes. Appendix B shows figures similar to Figure $4.3 \mathrm{a}, \mathbf{b}$, and $\mathbf{c}$ for tests conducted with three different superficial air velocities.

Figure $4.3 \mathrm{~d}$, $\mathrm{e}$, and $\mathbf{f}$ show a comparison of the heavy particle collection efficiency, light particle collection efficiency, and heavy particle mass fraction respectively for three different superficial air velocities tested at the same mass flux. The heavy particle collection and light particle collection both increase as the superficial air velocity decreases. The heavy particle mass fraction decreases as the superficial air velocity decreases.

The heavy particle collection efficiency versus mass flux can be seen for each of the superficial air velocities tested in Figure 4.3g. The figure shows that the heavy particle collection efficiency decreases as the mass flux increases until approximately $0.61 \mathrm{lb} / \mathrm{ft}^{2} \mathrm{~s}\left(5.57 \mathrm{~kg} / \mathrm{m}^{2} \mathrm{~s}\right)$. At this point, the downward annular flow rate in the riser is so high that the solid clusters entered the gap. This results in higher heavy particle collection but also much higher light particle collection as can be seen in Figure 4.3h. This figure shows the light particle collection versus mass flux for the superficial air velocities tested. A significant increase in the effect of a mass flux causes an increase of the light particle collection, which can be seen at a mass flux of around 0.49 to $0.61 \mathrm{lb} / \mathrm{ft}^{2} \mathrm{~s}(5.27$ to 6.57 
$\mathrm{kg} / \mathrm{m}^{2} \mathrm{~s}$ ). The heavy particle mass fraction can be seen as a function of mass flux for the various superficial air velocities tested in Figure 4.3i.

The pressure change along the height of the riser was monitored using three differential pressure transducers. The riser height was divided into three even lengths and the differential pressures across each of the three sections were measured. The differential pressure for each section was then divided by the length of the individual section so that an average pressure difference per unit length could be determined for each of the three sections.

The average height of the pressure measurements were plotted against the average differential pressure per inch for three superficial air velocities at the same mass flux in Figure 4.3j. The figure shows that at the highest section of the riser the pressure difference is greater for a higher superficial air velocity. At the bottom of the riser the pressure difference is lower for a higher superficial air velocity. The slope of the line increases as the velocity decreases.

The pressure difference per inch along the riser height is shown in Figure 4.3k for a superficial air velocity of $11.0(3.35 \mathrm{~m} / \mathrm{s})$ respectively. The figure shows that for an increasing mass flux at the same superficial air velocity, the pressure difference increases along the entire length of the riser but the slope of the line stays constant with a constant superficial air velocity regardless of the mass flux. A large pressure difference generally implies that there is a large amount of particles in the riser across that pressure reading. $\underline{\text { Appendix B }}$ shows additional differential pressure figures for various superficial air velocities and mass fluxes. 


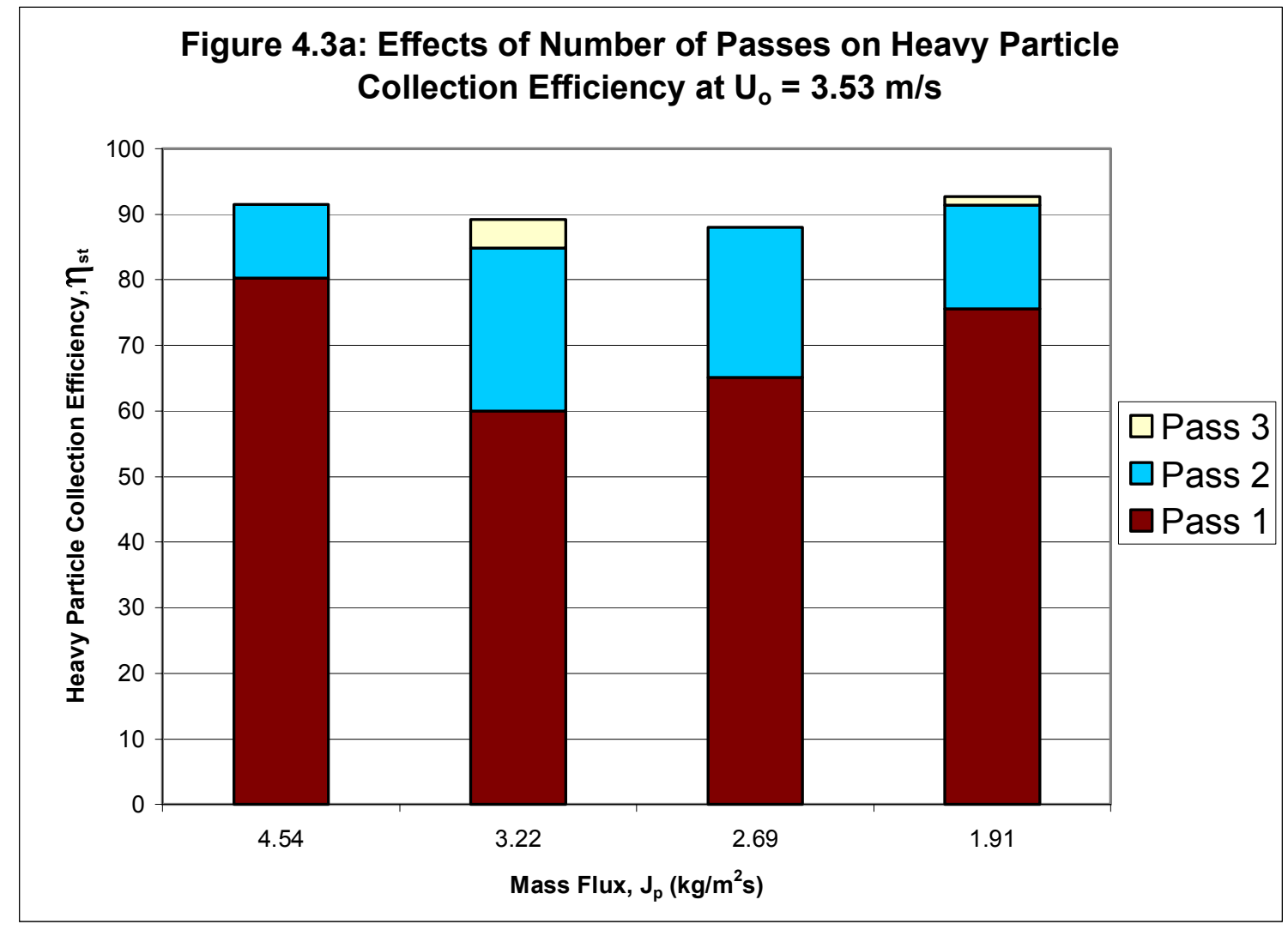

Figure 4.3b: Effects of Number of Passes on Light Particle Collection Efficiency at $U_{0}=3.53 \mathrm{~m} / \mathrm{s}$

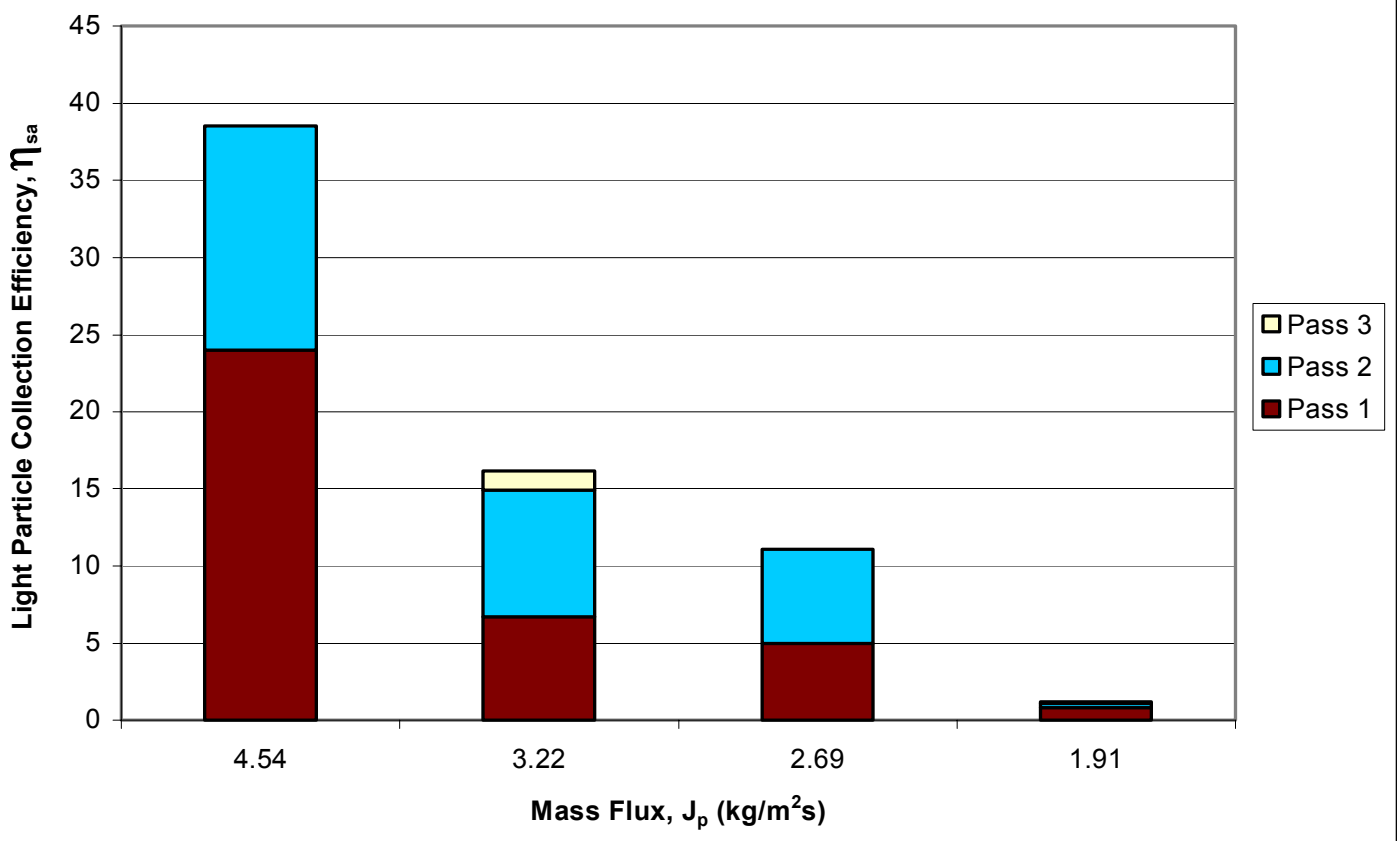


Figure 4.3c: Effects of Number of Passes on Heavy Particle Mass

Fraction at $U_{0}=3.53 \mathrm{~m} / \mathrm{s}$

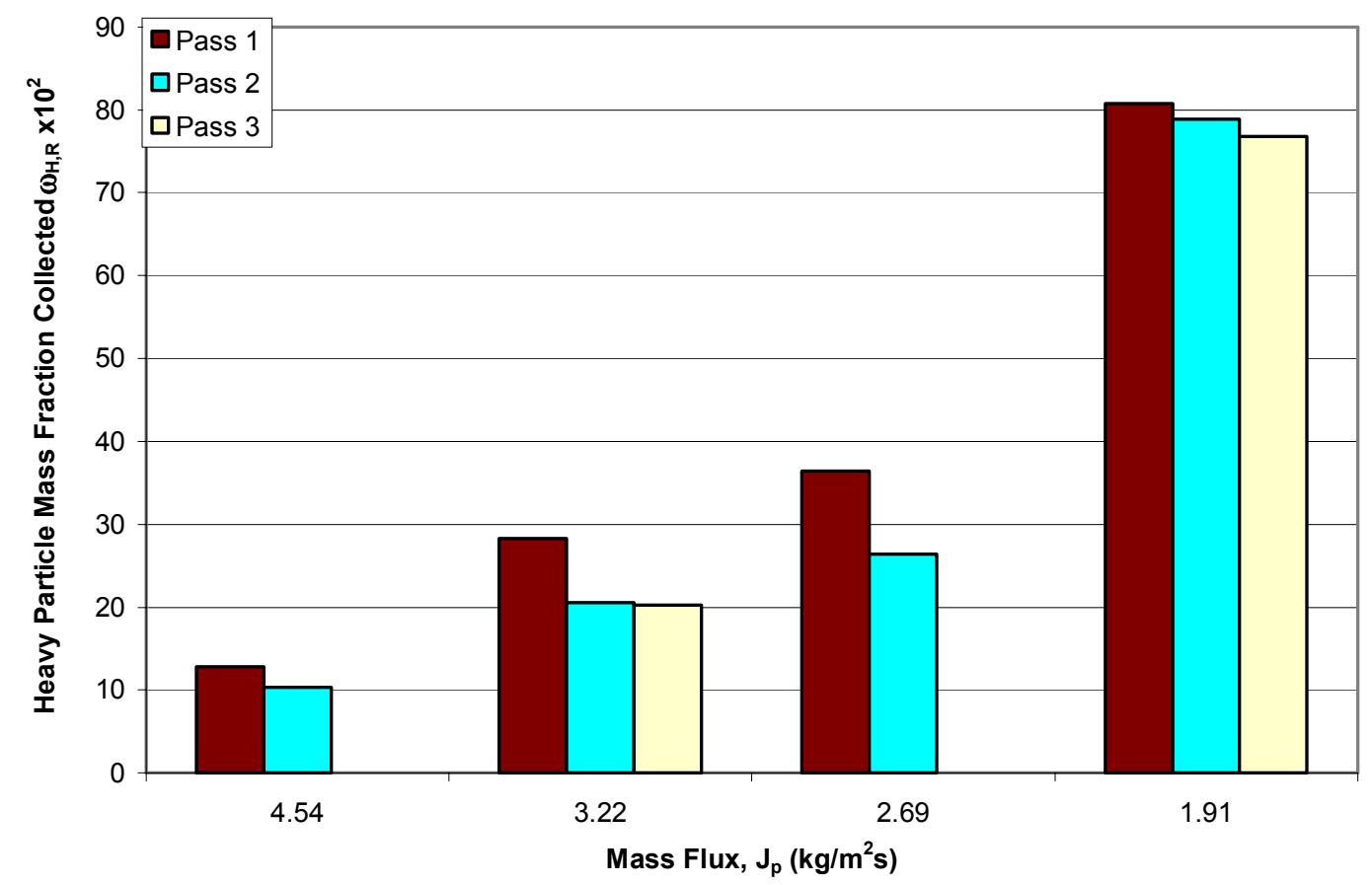

Figure 4.3d: Effects of Superficial Velocity and Number of Passes on Heavy Particle Collection Efficiency at $J_{p}=1.90 \mathrm{~kg} / \mathrm{m}^{2} \mathrm{~s}$

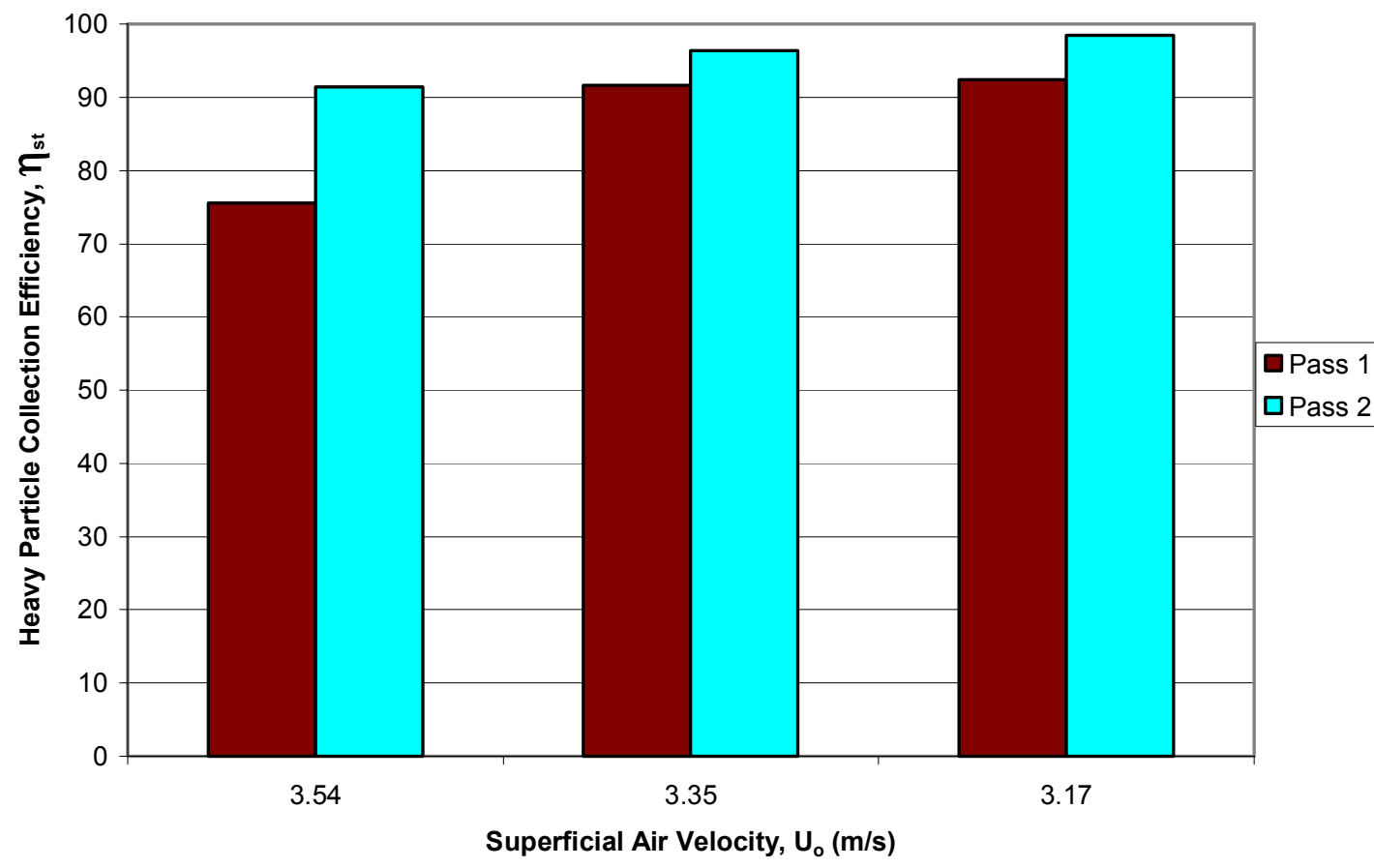


Figure 4.3e: Effects of Superficial Velocity and Number of Passes on Light Particle Collection Efficiency at $J_{p}=1.90 \mathrm{~kg} / \mathrm{m}^{2} \mathrm{~s}$
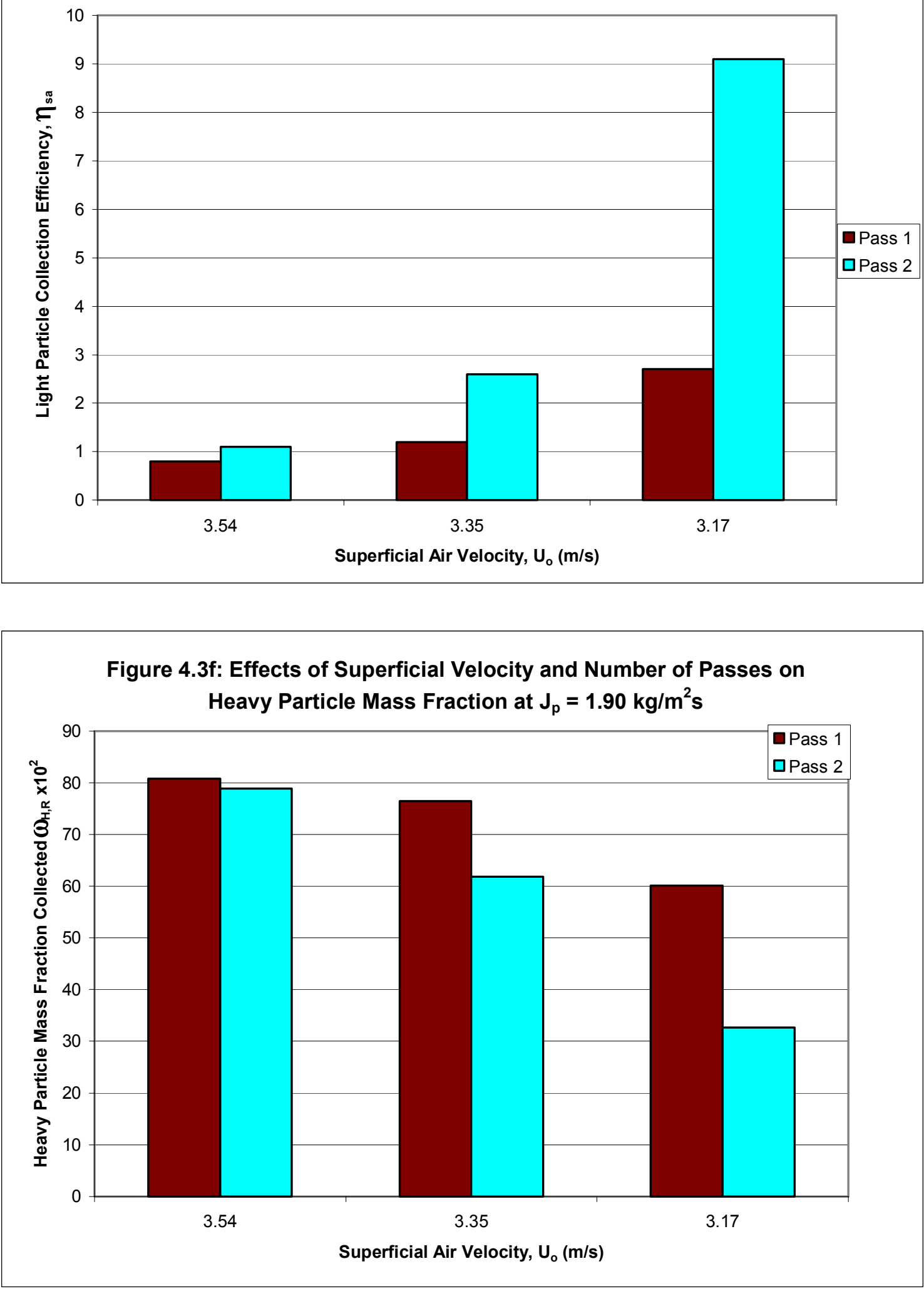

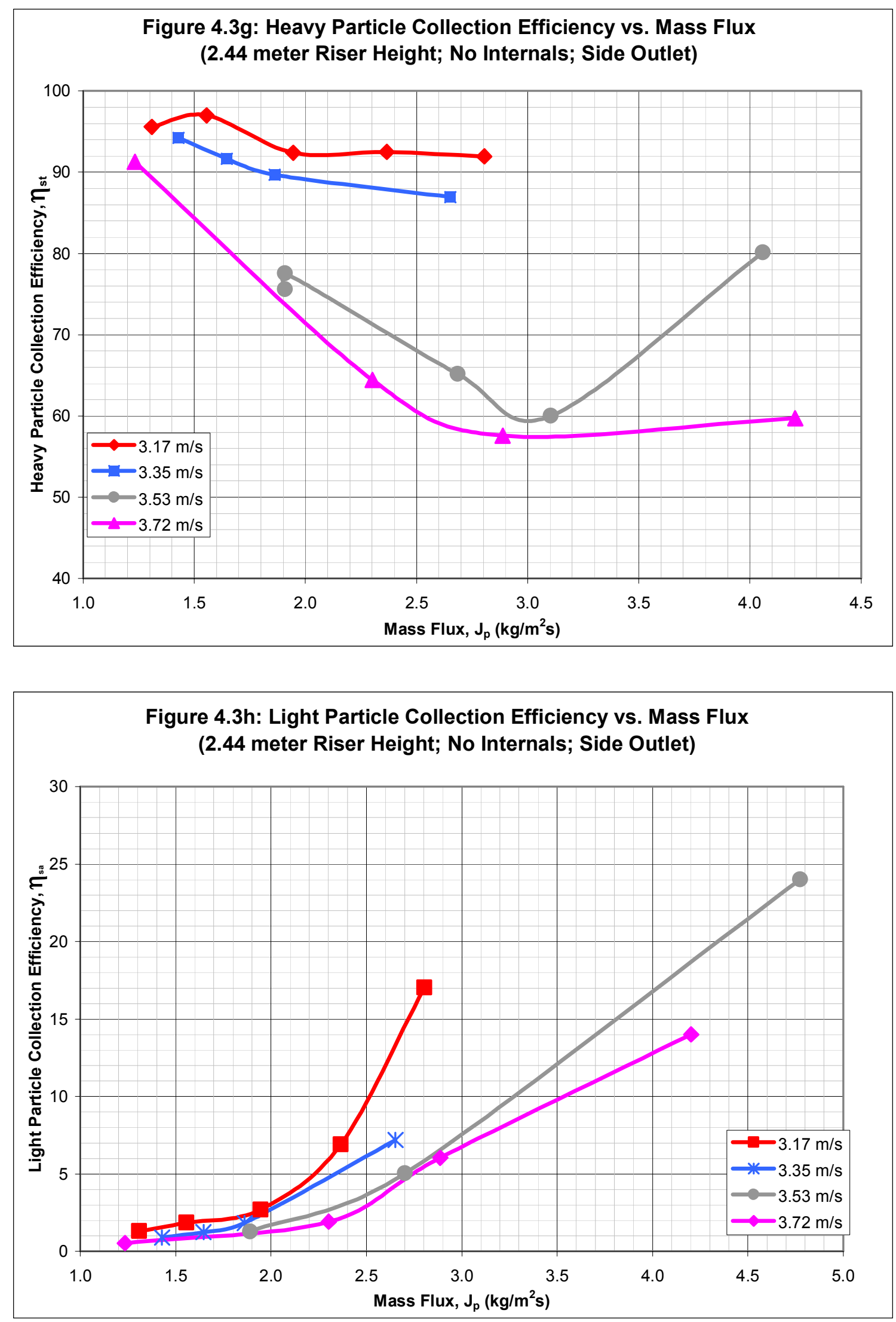

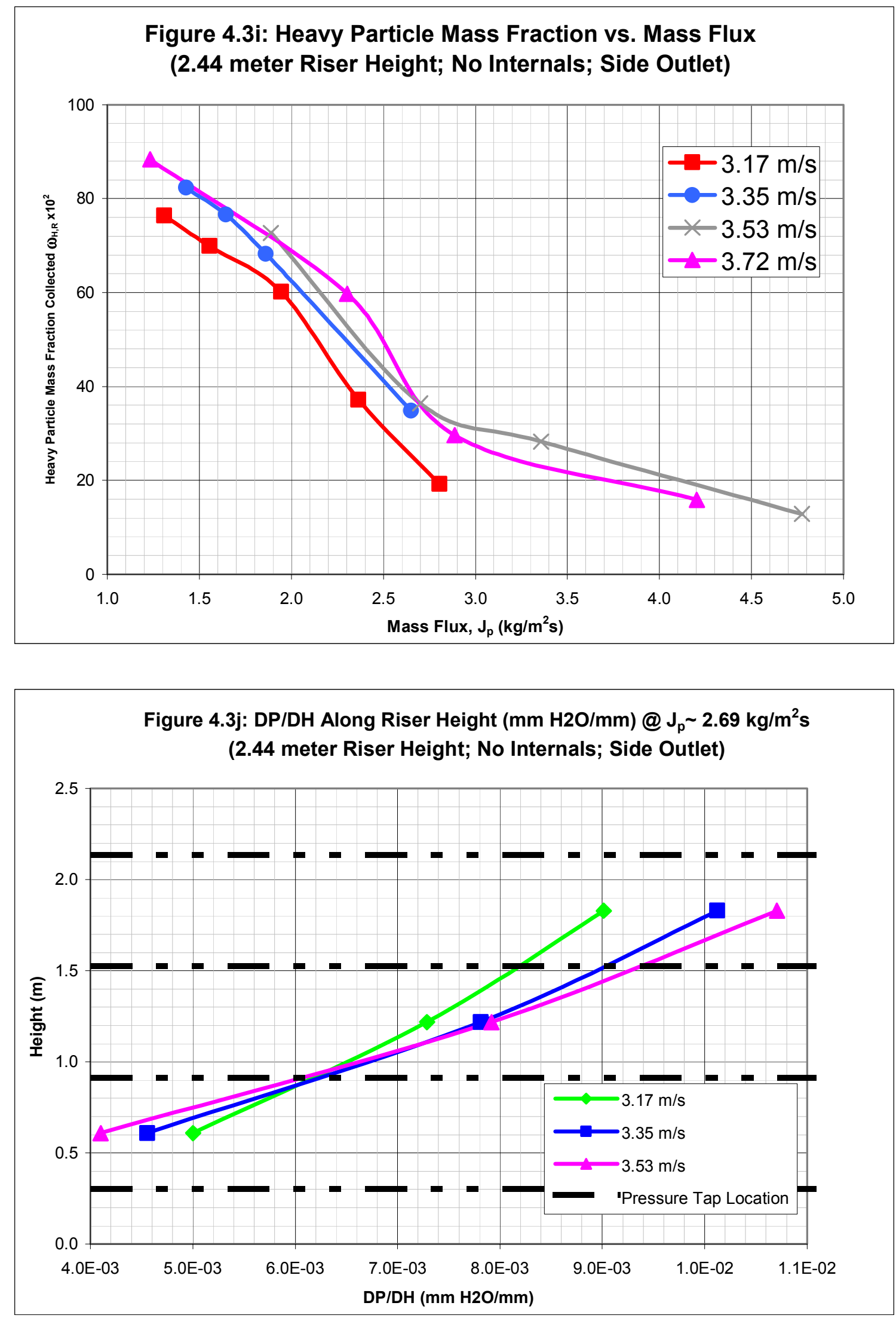


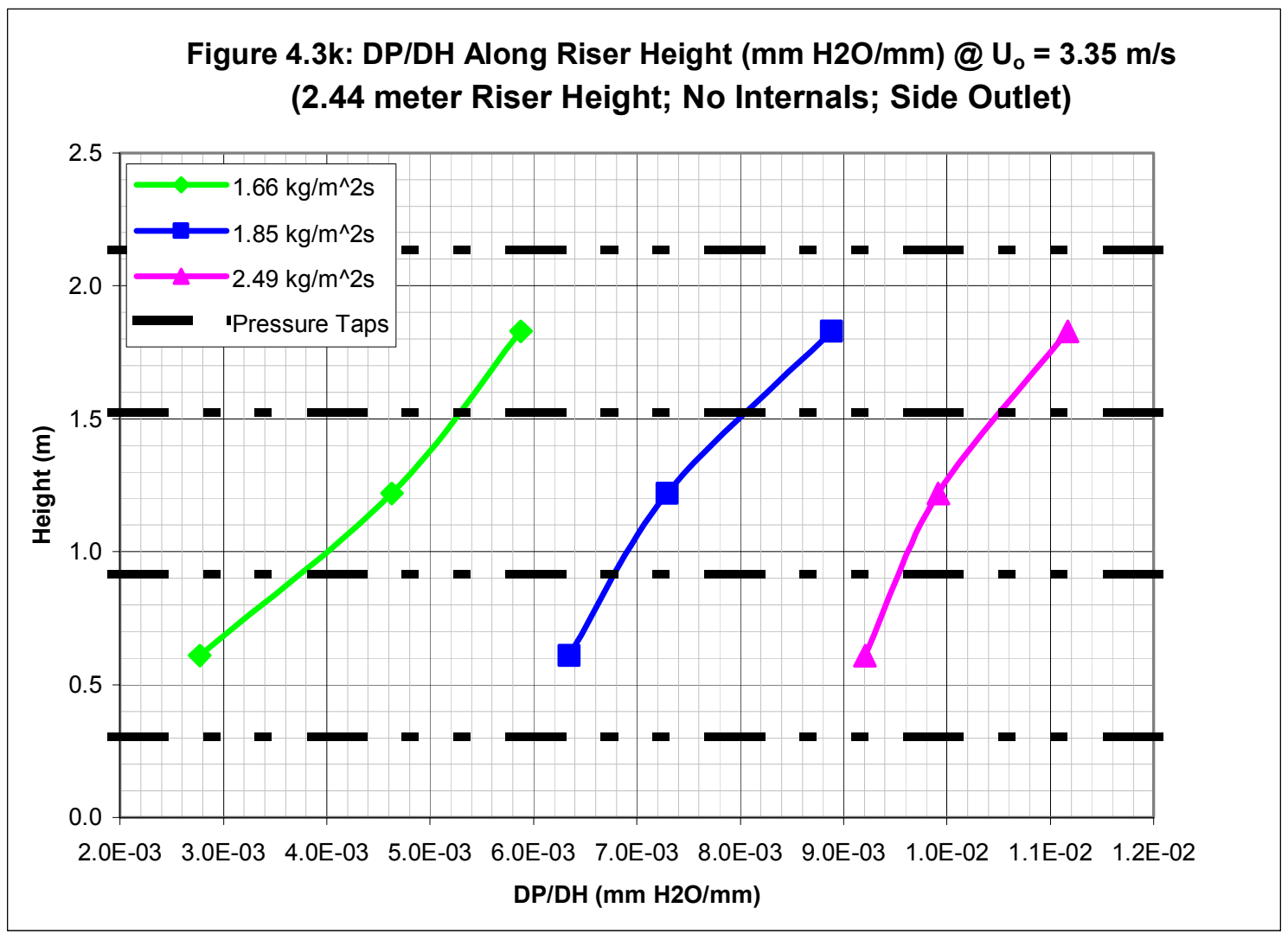




\section{$\underline{4.4 \text { Effect of Collection Gap Width }}$}

Figure 4.4a shows the effects of the gap width on the heavy particle collection, light particle collection, and heavy particle mass fraction with a superficial air velocity of $11.6 \mathrm{ft} / \mathrm{s}(3.54 \mathrm{~m} / \mathrm{s})$. The figure shows an increase in collection of both sand and steel when the gap was increased. The heavy particle mass fraction was consistent as the gap increased. Appendix $\mathbf{C}$ shows numerous other tests comparing the effects of gap width with results consistent to Figure 4.4a.

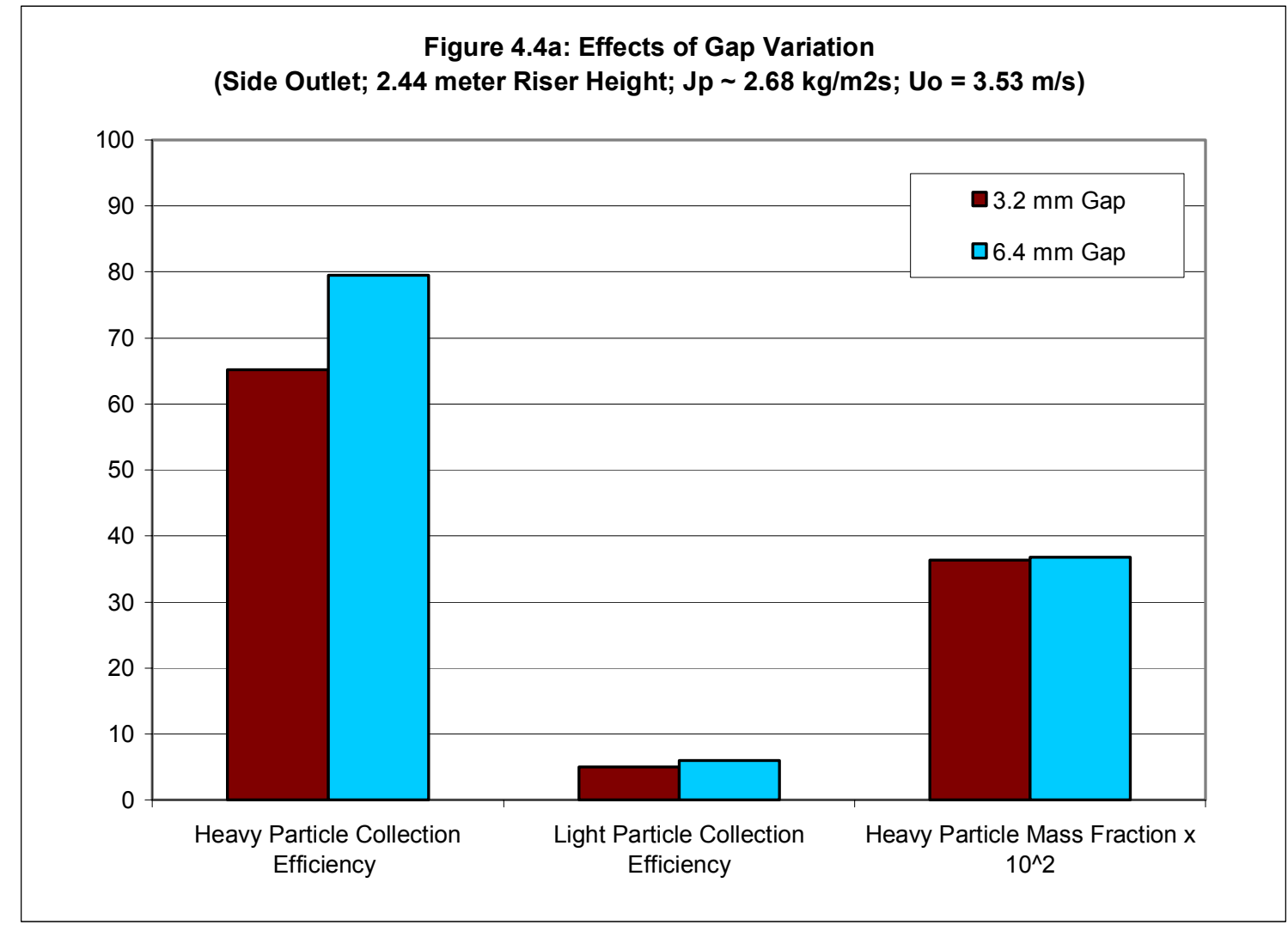




\section{$\underline{4.5}$ Effect of Riser Height Variation}

The mass flux into the system was kept constant for all tests at approximately $0.55 \mathrm{lb} / \mathrm{ft}^{2} \mathrm{~s}\left(5.92 \mathrm{~kg} / \mathrm{m}^{2} \mathrm{~s}\right)$. Figure 4.5 a and $\mathbf{b}$ show the tests conducted at the two different heights for three different superficial air velocities, for the same mass flux, and no internals. The side outlet was used and only one pass was conducted on the mixture. Figure 4.5a shows the heavy particle collection efficiency and shows a consistent increase in heavy particle collection for the 14 foot $(4.27 \mathrm{~m})$ high riser. Figure $\mathbf{4 . 5 b}$ shows the heavy particle mass fraction collected. A decrease in heavy particle mass fraction collected at the 14 foot $(4.27 \mathrm{~m})$ height is shown at $10.4 \mathrm{ft} / \mathrm{s}(3.17 \mathrm{~m} / \mathrm{s})$ while the heavy particle mass fraction increased for tests conducted at 11.0 and $11.6 \mathrm{ft} / \mathrm{s}(3.35$ and $3.54 \mathrm{~m} / \mathrm{s})$.

Figure 4.5c shows the effect of the height on the heavy particle collection efficiency, light particle collection efficiency, and heavy particle mass fraction respectively for the various test conditions conducted at $11.6 \mathrm{ft} / \mathrm{s}(3.54 \mathrm{~m} / \mathrm{s})$ The heavy particle mass fraction collected consistently increased for the increased riser height at this velocity. Appendix D shows height comparisons for numerous other test conditions conducted and show similar results. 
Figure 4.5a: Effect of Riser Height on Heavy Particle Collection Efficiency

(Side Outlet, $\mathrm{J}_{\mathrm{p}} \sim 2.68 \mathrm{~kg} / \mathrm{m}^{2} \mathrm{~s}$ )

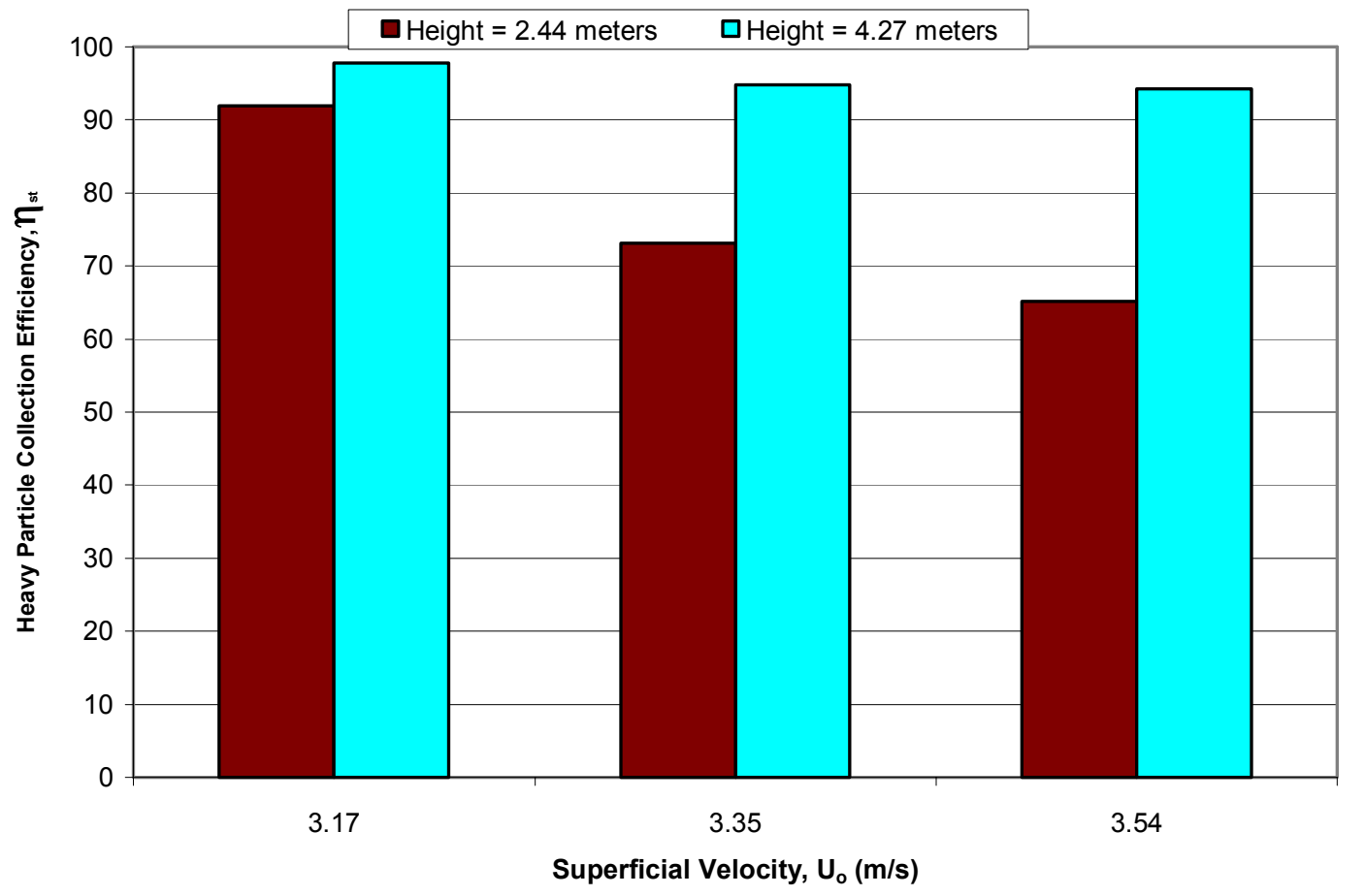

Figure 4.5b: Effect of Riser Height on Heavy Particle Mass Fraction

(Side Outlet, $\mathrm{J}_{\mathrm{p}} \sim 2.68 \mathrm{~kg} / \mathrm{m}^{2} \mathrm{~s}$ )

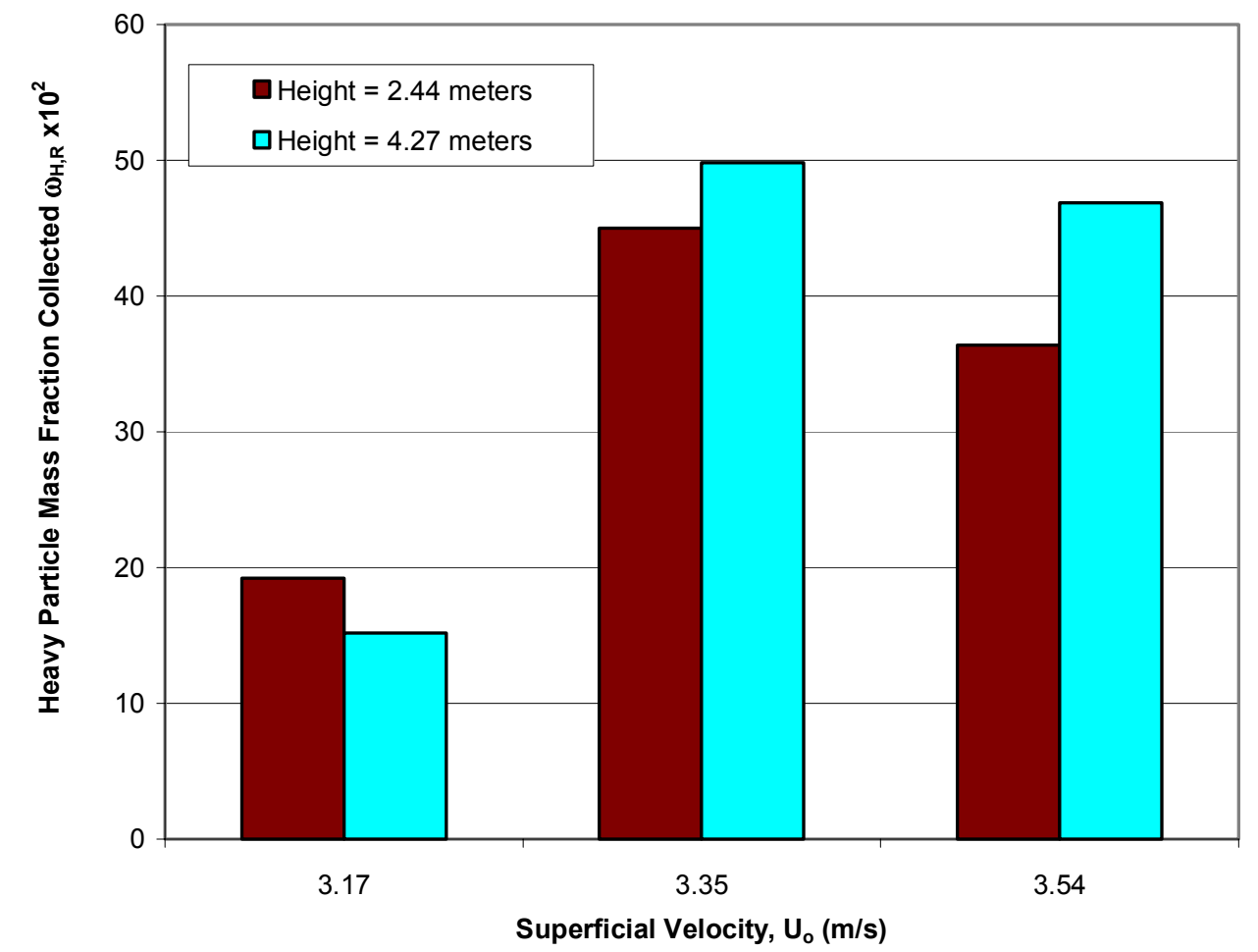




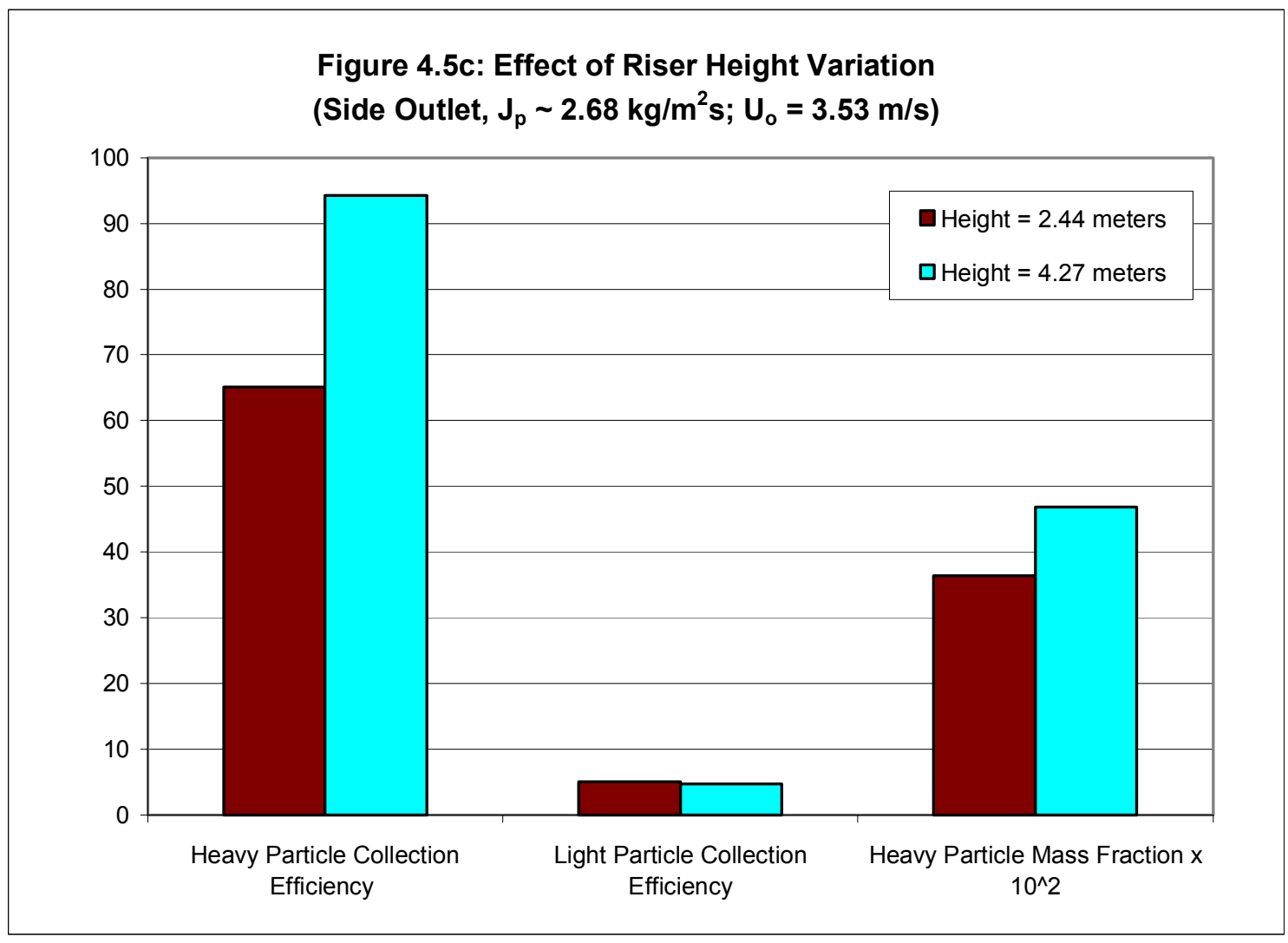




\section{$\underline{4.6 \text { Effect of Internal Rings }}$}

Figure 4.6a shows the effects of the ring diameter to riser diameter ratio on the collection efficiency of steel and sand for three different superficial air velocities at the same mass flux. The tests were performed with a 1/8 inch $(3.2 \mathrm{~mm})$ collection gap and an 8 foot $(2.44 \mathrm{~m})$ riser height with a side outlet. The figure shows that the 4.5 inch (114 $\mathrm{mm}$ ) internal diameter ring, or a ring to riser diameter ratio of 0.9 , had little effect on both the steel and light particle collection efficiencies at all three superficial air velocity conditions. The 4 inch $(102 \mathrm{~mm})$ internal diameter ring, corresponding to a 0.8 ring to riser diameter ratio, caused a dramatic decrease in both steel and light particle collection for all three superficial air velocity conditions.

The most dramatic effects can be seen for the tests conducted with a superficial air velocity of $10.4 \mathrm{ft} / \mathrm{s}(3.17 \mathrm{~m} / \mathrm{s})$. While the tests without a ring showed a very high heavy particle collection efficiency of over $90 \%$, the system also collected over $15 \%$ of the sand in the mixture. By using the 4 inch $(102 \mathrm{~mm})$ internal ring, the light particle collection was dropped to only $5 \%$ while heavy particle collection was only somewhat effected and remained over $85 \%$.

Figure 4.6b shows the effects that the rings had on the heavy particle mass fraction collected for the tests shown in Figure 4.6a. The 0.9 diameter ratio ring showed little effect on the heavy particle mass fraction when compared to no ring conditions. On the other hand the heavy particle mass fraction collected was significantly higher at all superficial air velocity conditions for the tests conducted with the 0.8 diameter ratio ring when compared to the smaller ring and no ring conditions. This shows that while the heavy particle and light particle collection efficiencies both decrease for the small ring, 
the light particle collection is more dramatically reduced than the heavy particle collection.

Figure 4.6c shows the pressure difference along the 8 foot $(2.44 \mathrm{~m})$ riser for each of the internal rings and no ring tests at a superficial air velocity of $11.6 \mathrm{ft} / \mathrm{s}(3.54 \mathrm{~m} / \mathrm{s})$. The internal rings height is shown on the graph as well as the height of each of the pressure taps. The internal ring was between the pressure taps for the middle differential pressure transducer. The figure shows that the differential pressure decreases below a smaller diameter internal ring. The opposite happens just above the ring as a smaller diameter ring yields significantly higher differential pressures. At the top section of the riser, the differential pressure is higher for a smaller diameter internal ring. Appendix E shows figures that compare the effects of the internal rings for numerous other conditions tested with similar results. 

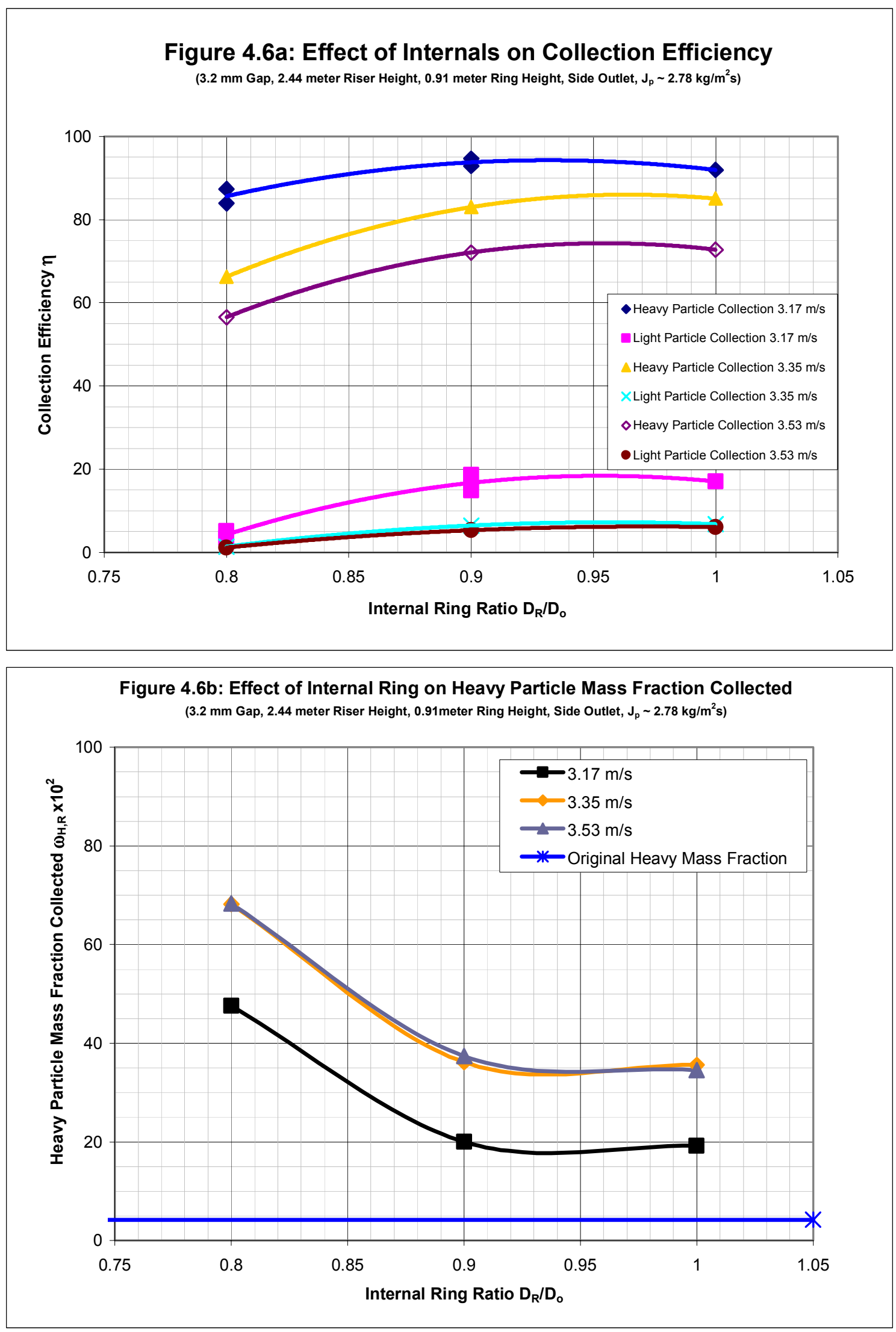


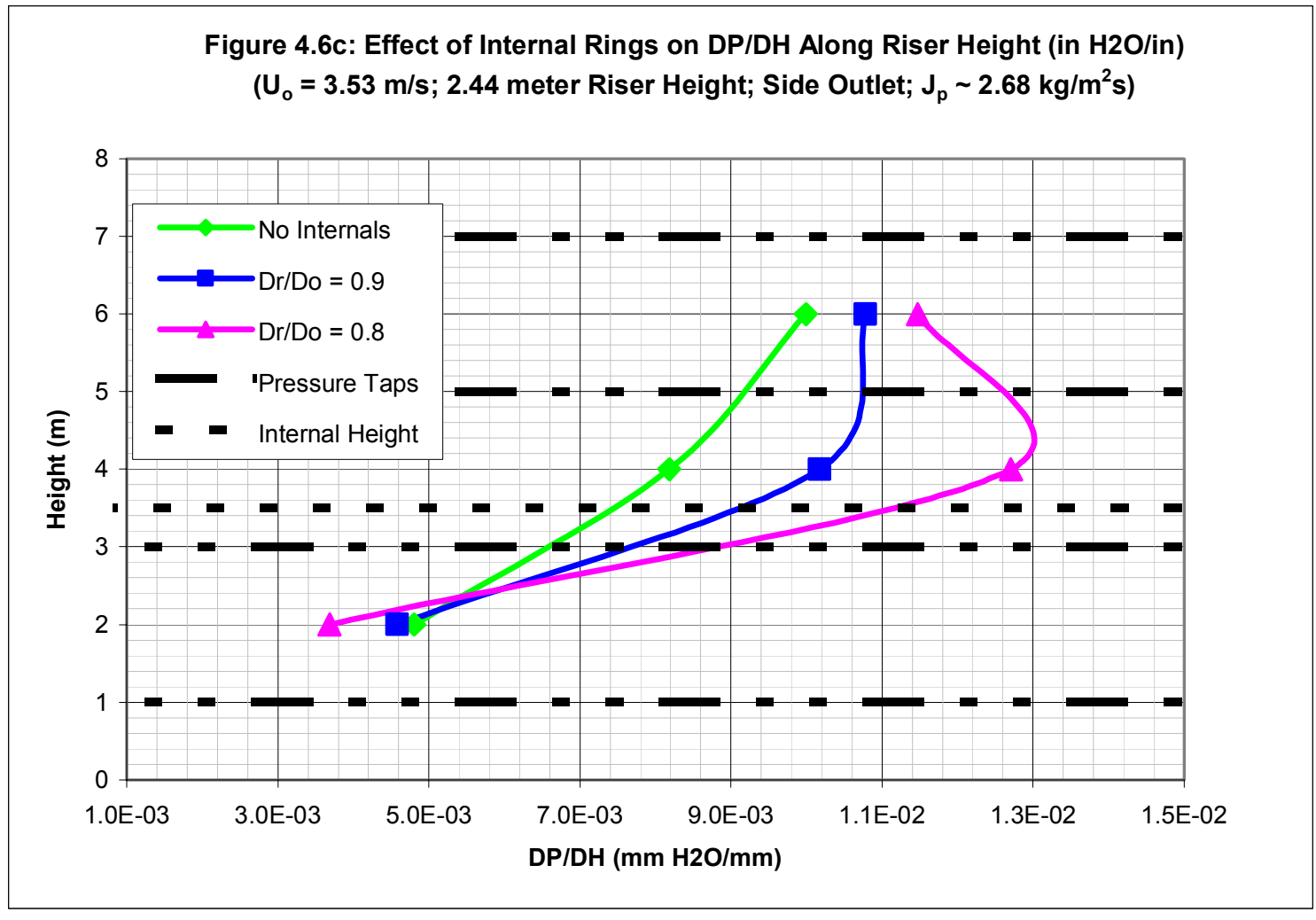




\subsection{Effect of Outlet}

Tests were first conducted to determine if the collection gap width would have a considerable effect on the heavy particle mass fraction collected with the new outlet geometry since the new outlet does not promote nearly the same annulus down flow.

Figure 4.7a shows the comparison of the gap width at a superficial air velocity of 11.6 $\mathrm{ft} / \mathrm{s}(3.54 \mathrm{~m} / \mathrm{s})$ and a mass flux of $0.57 \mathrm{lb} / \mathrm{ft}^{2} \mathrm{~s}\left(2.78 \mathrm{~kg} / \mathrm{m}^{2} \mathrm{~s}\right)$. The figure shows a noticeable increase in heavy particle collection with the wider gap but not nearly as high of an increase in light particle collection as with the old outlet design. This resulted in a very small decrease in heavy particle mass fraction with a slight increase in overall heavy particle collection for the wider collection gap. These results lead the future tests with the new outlet to be conducted with a $1 / 4$ inch $(6.4 \mathrm{~mm})$ collection gap to maximize heavy particle collection efficiency.

In Figure 4.7b, the 90 degree swept outlet was tested against the side outlet at $11.6 \mathrm{ft} / \mathrm{s}(3.54 \mathrm{~m} / \mathrm{s})$. The 90 degree swept outlet was tested at an equal mass flux to the side outlet tests. The new outlet was also tested with a much higher mass flux than the side outlet test. These tests show that the heavy particle collection decreased slightly for the new outlet at the same mass flux. The light particle collection was dramatically decreased for the new outlet resulting in nearly twice the heavy particle mass fraction for the new outlet at the same mass flux. It also showed a comparable heavy particle mass fraction for the new outlet at a much higher mass flux than the side outlet. The tests show that the mass flux can be increased by nearly $80 \%$ over the old outlet with comparable results. 
Figure 4.7c shows the comparison of three tests conducted with the new outlet. It shows that if high heavy particle collection is of importance, the superficial air velocity of $11.0 \mathrm{ft} / \mathrm{s}(3.35 \mathrm{~m} / \mathrm{s})$ can collect $97 \%$ of the steel with a much improved mass flux over the old outlet and still retain a very good heavy particle mass fraction. If low collection of sand is important and only moderate heavy particle collection is needed, the superficial air velocity can be increased to $11.6 \mathrm{ft} / \mathrm{s}(3.54 \mathrm{~m} / \mathrm{s})$ and light particle collection can be reduced. Further tests were conducted to determine a wide range of performance curves for this configuration so that a variation in product results can be obtained to optimize performance depending on desired results.

Figure 4.7d shows the difference in the pressure difference along the 14 foot riser for both outlets at $11.6 \mathrm{ft} / \mathrm{s}(3.54 \mathrm{~m} / \mathrm{s})$. The figure shows an increase in the pressure difference as you move upward through the riser with the side outlet. With the 90 degree swept outlet, the pressure difference decreases as you move up the riser. This is due to a much less restrictive outlet configuration. Appendix F shows additional tests comparing the new 90 degree swept outlet with the old side outlet for various conditions with similar results. 


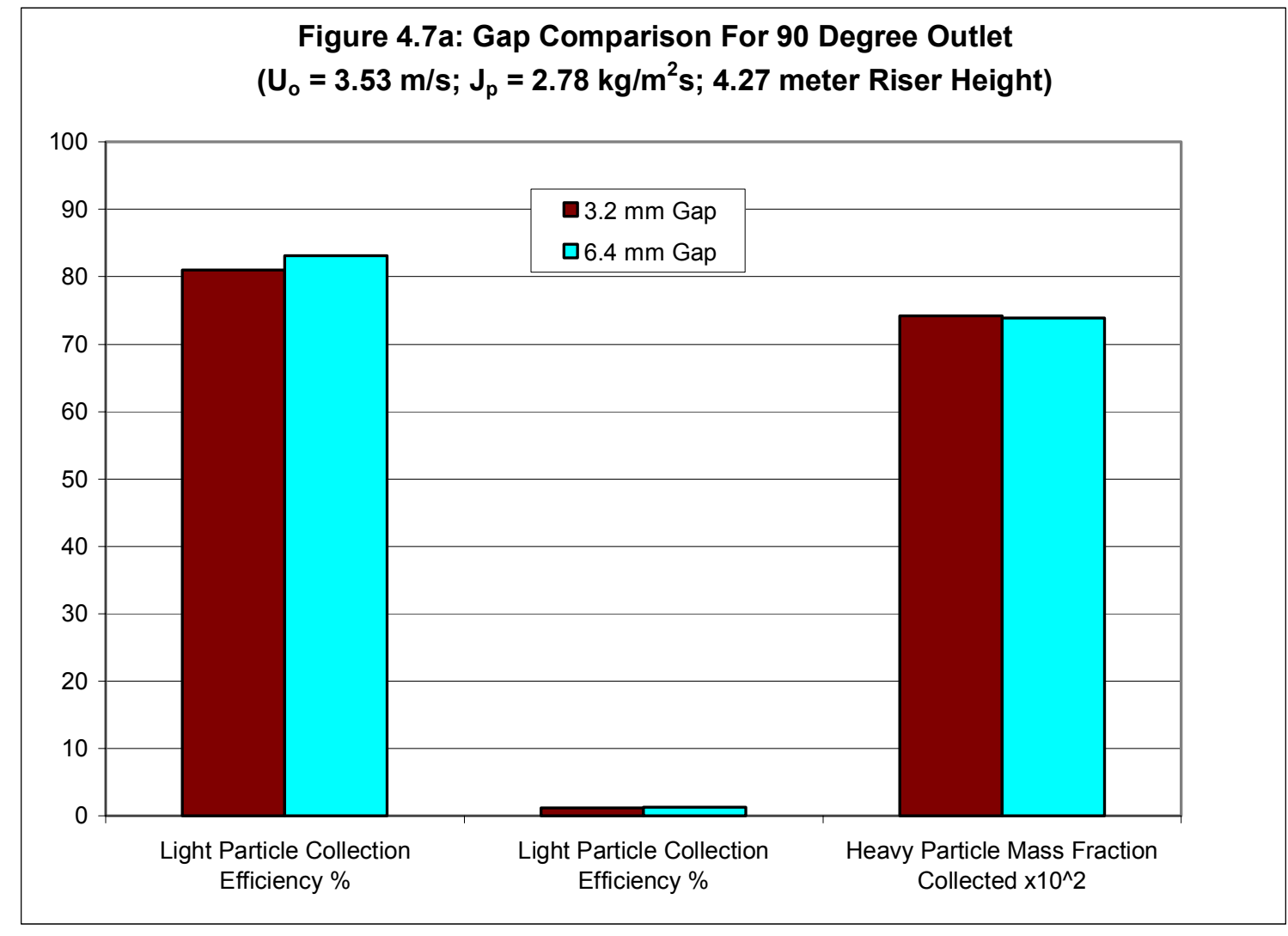

Figure 4.7b: Outlet Comparison

$\left(U_{o}=3.53 \mathrm{~m} / \mathrm{s} ; 4.27\right.$ meter Riser Height; $6.4 \mathrm{~mm}$ Gap)

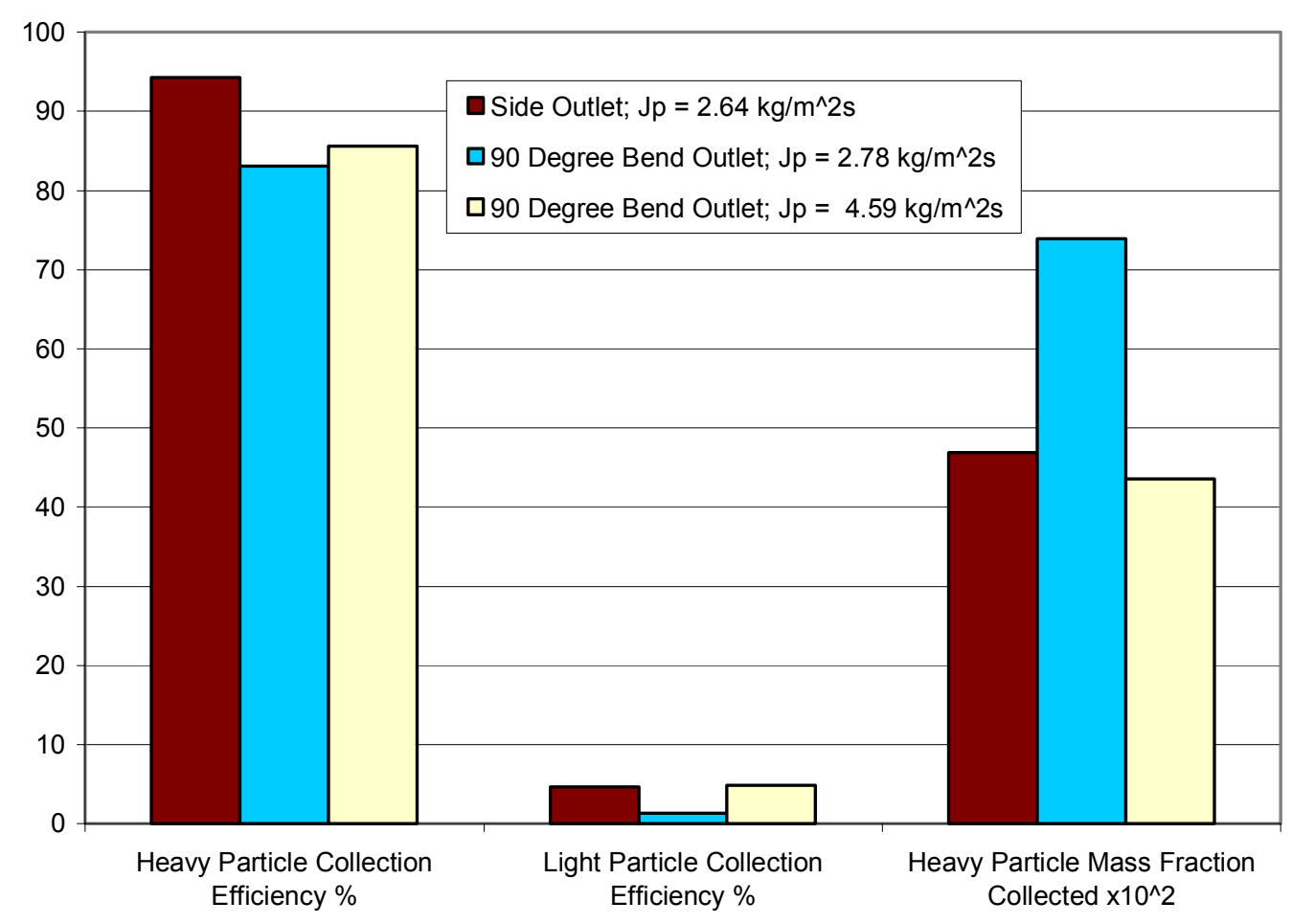



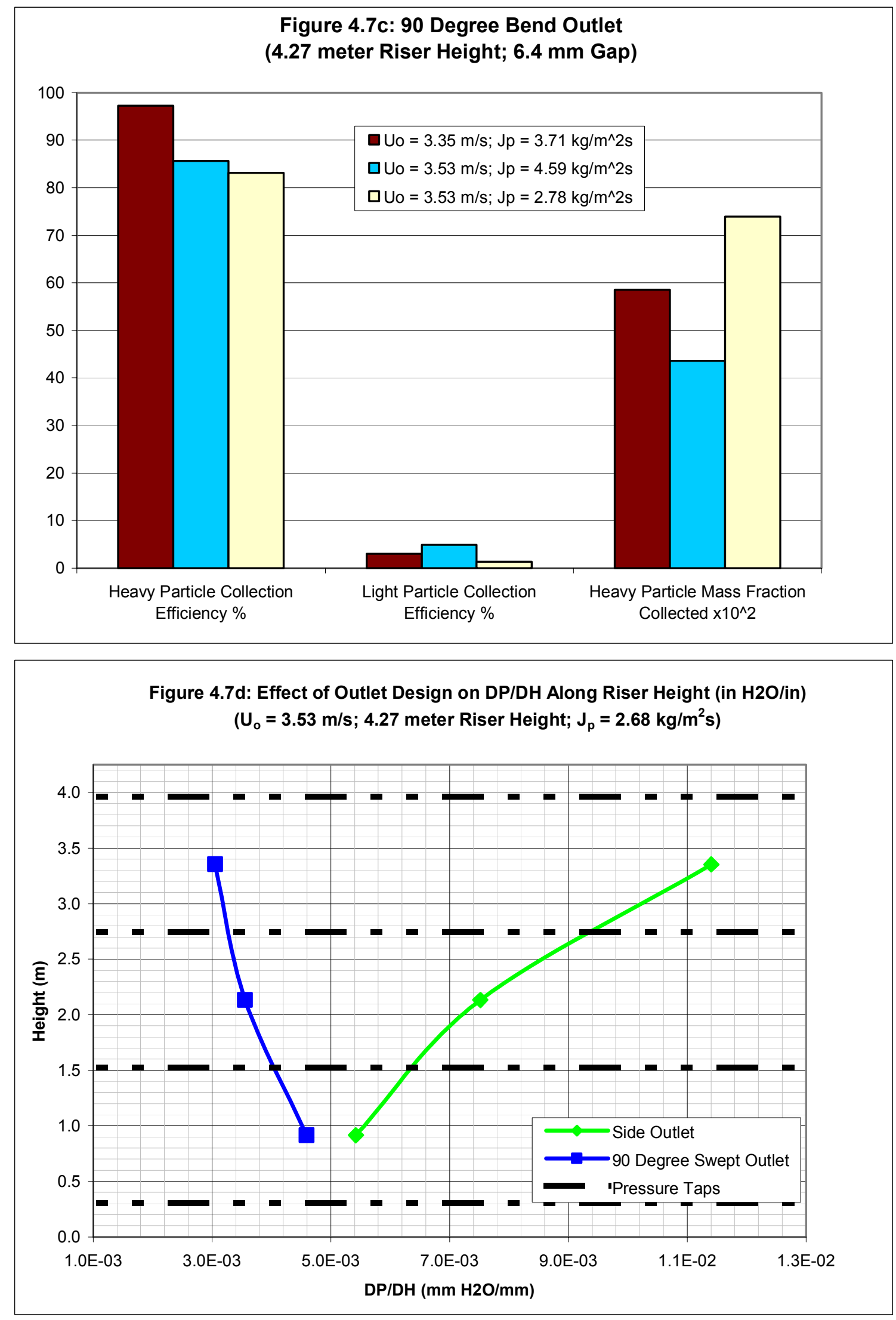


\section{$\underline{4.8 \text { Effects of Initial Heavy Particle Mass Fraction }}$}

Tests were conducted to determine the effect that the heavy particle mass fraction of the initial test mixture has on the performance of the system. Figure 4.8a shows the two tests conducted with the same riser configuration, superficial air velocity, and mass flux into the system. The first test was conducted with the test mixture used for the earlier tests with a heavy particle mass fraction of 0.042 , or $4.2 \%$ steel by weight. The second test was conducted with a heavy particle mass fraction of 0.340 or $34 \%$ steel by weight. This test is important in order to determine how the system will be affected by varying mineral compositions. The figure shows that the heavy particle collection efficiency decreased and the light particle collection increased with an increased initial heavy particle mass fraction. Figure 4.8b shows the initial heavy particle mass fraction of the test mixture compared to the collected heavy particle mass fraction for both mixtures. Although the separation isn't as efficient for the $34 \%$ steel mixture, the heavy particle mass fraction was still increased significantly. 
Figure 4.8a: Effects of Initial Heavy Particle Mass Fraction

$\left(U_{0}=3.53 \mathrm{~m} / \mathrm{s} ; \sim 2.78 \mathrm{~kg} / \mathrm{m}^{\wedge} 2 \mathrm{~s} ; 4.72\right.$ meter Riser Height;90 Degree Swept Outlet,3.2 mm Gap)

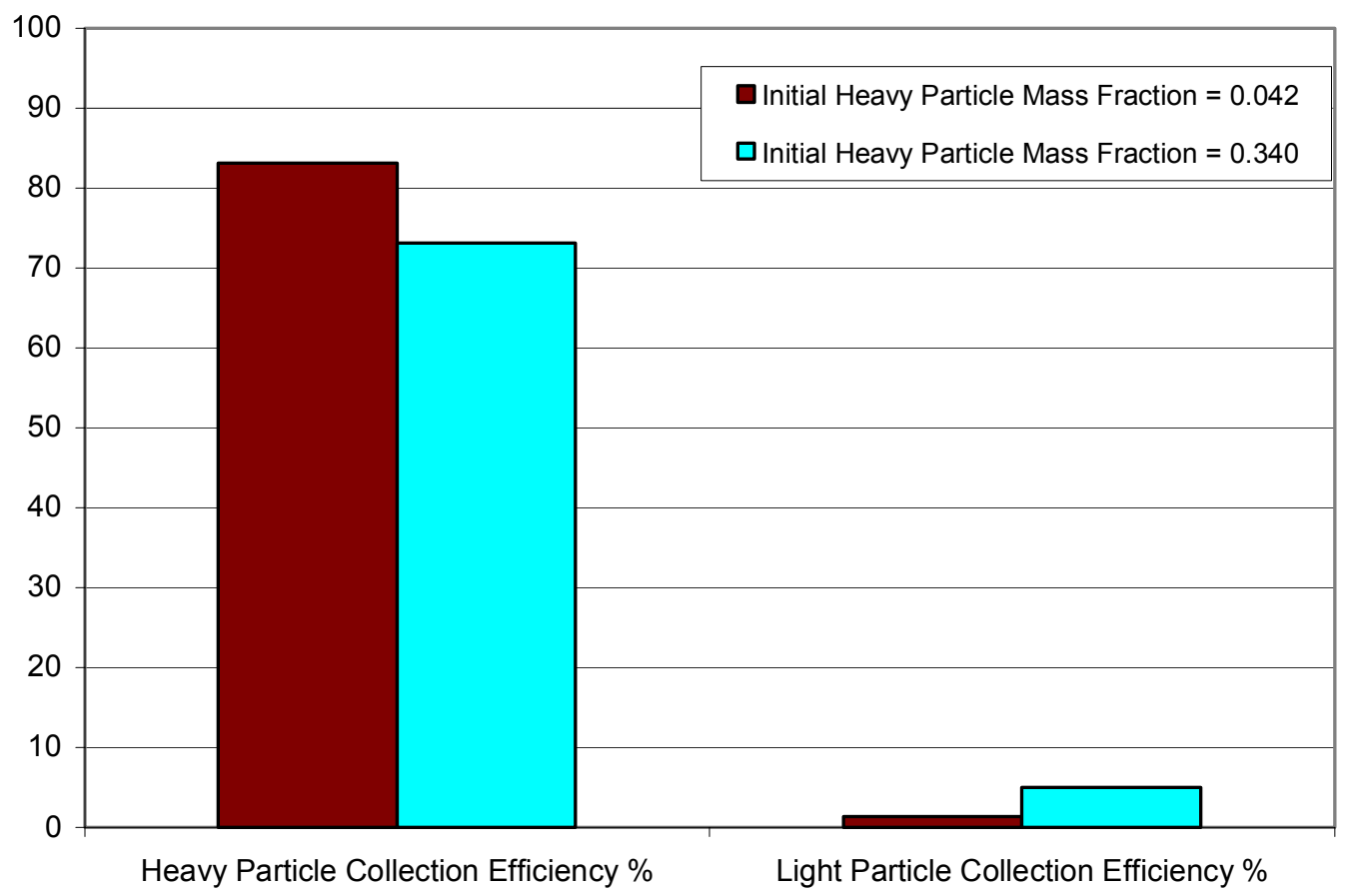

Figure 4.8b: Effects of Initial Heavy Particle Mass Fraction

(Uo=3.53 m/s; 2.78 kg/m^2s;4.72 meter Riser Height;90 Degree Swept Outlet,3.2 mm Gap)

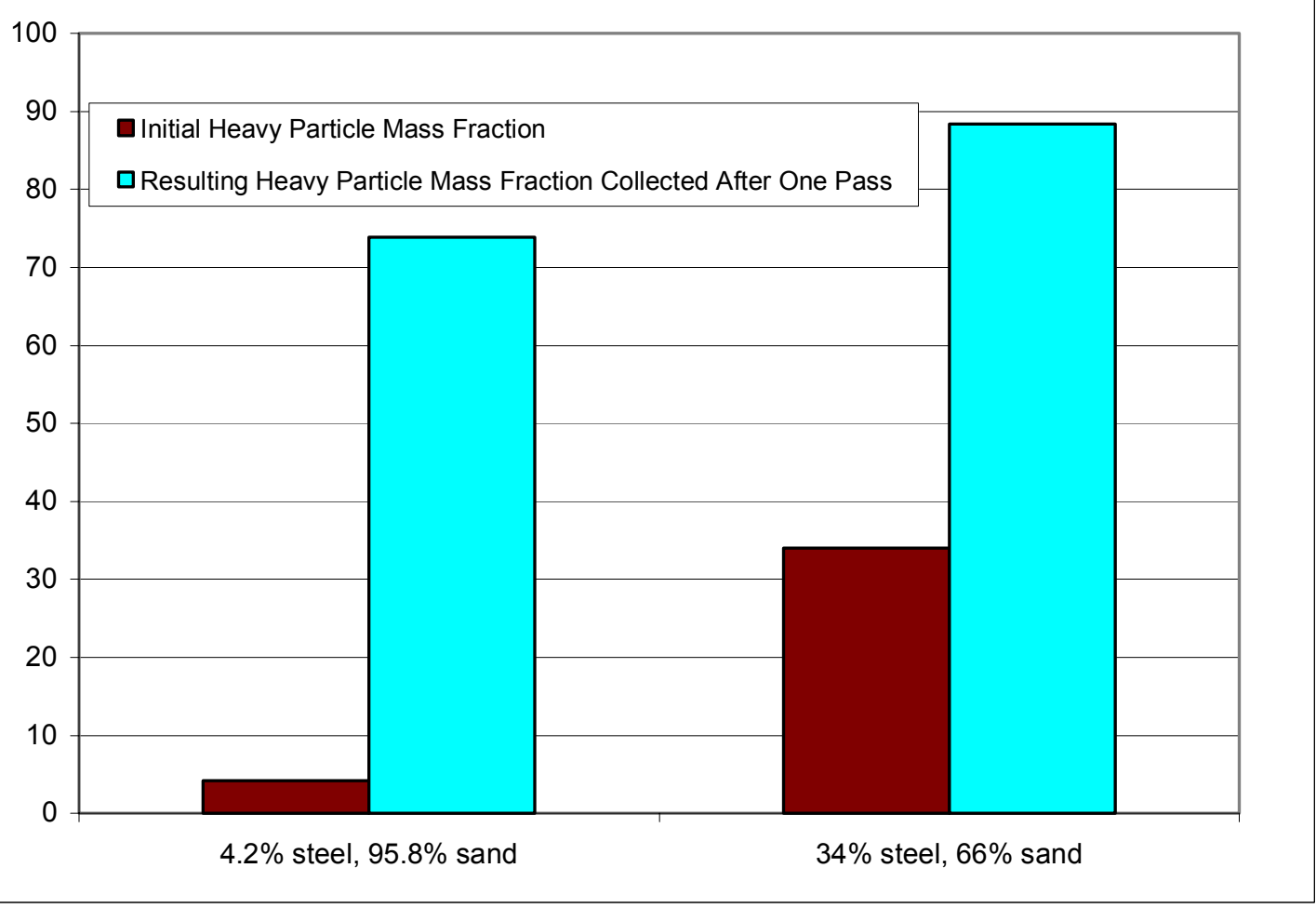




\subsection{Size Distribution of Individual Tests}

The size distribution of the sand and steel collected and the sand rejected in the test using an air velocity of $10.4 \mathrm{ft} / \mathrm{s}(3.17 \mathrm{~m} / \mathrm{s})$ and a mass flux of $0.29 \mathrm{lb} / \mathrm{ft}^{2} \mathrm{~s}(3.12$ $\mathrm{kg} / \mathrm{m}^{2} \mathrm{~s}$ ) was examined and is shown in FIGURE 4.9. This test was used due to the high efficiency of heavy particle collection and low light particle collection. It can be seen that the collected sand size distribution is made up of a slightly larger overall size than the sand that was not collected. The graph shows that there was still a large amount of sand that was of a larger size that was not collected during the test. There was also a fair amount of smaller sand particles that were collected, showing that the particles were not collected due to their large size alone.

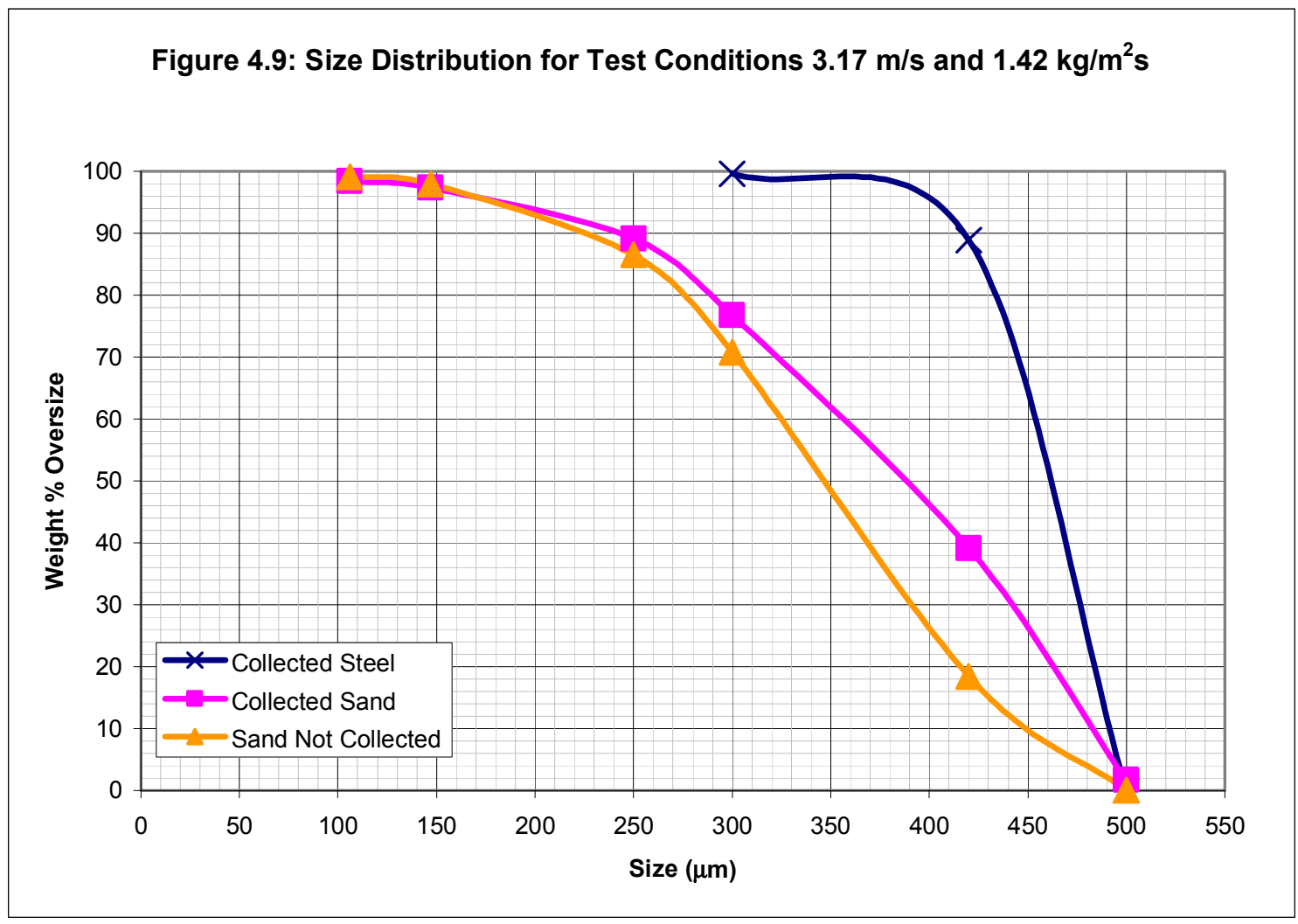




\section{CHAPTER 5}

\section{$\underline{5.1 \text { Conclusions }}$}

\section{CONCLUSIONS and RECOMENDATIONS}

The exploratory study on the separation of particles according to density using a circulating fluidized bed riser system has been conducted. The system has established that a circulating fluidized bed riser is a possible dry separation process based on density. The effects that numerous variables had on the performance of the system were observed in order to maximize the system efficiency. Additional variables were assigned to the system according to the observed flow patterns of the particles during the testing process.

The original riser geometry with a riser height of 8 feet $(2.44 \mathrm{~m})$ and a side outlet was capable of collecting over $75 \%$ of the heavy particles after one pass and over $91 \%$ after two passes at a low mass flux of $0.39 \mathrm{lb} / \mathrm{ft}^{2} \mathrm{~s}\left(1.91 \mathrm{~kg} / \mathrm{m}^{2} \mathrm{~s}\right)$ and a superficial air velocity of $11.6 \mathrm{ft} / \mathrm{s}(3.54 \mathrm{~m} / \mathrm{s})$. Less than $1 \%$ of the light particles were collected after both passes at these conditions resulting in a heavy particle mass fraction of around 0.77 after both passes.

The collection gap width had little or no effect on the separation phenomenon. By increasing the gap, both the heavy particle and light particle collection efficiencies increased comparably. The gap can be sized according to the desired product or the importance of a high heavy particle collection efficiency compared to a low light particle collection efficiency. By increasing the height of the riser from 8 to 14 feet (2.44 to 4.27 $\mathrm{m})$, the heavy particle collection efficiency increased by as much as $45 \%$ as well as an increase in heavy particle mass fraction of as much as $28 \%$. The addition of internal rings resulted in a slight decrease in both heavy particle and light particle collection efficiency but the rings increased heavy particle mass fraction by $100 \%$ in some cases. By changing 
from a side outlet to a 90 degree swept outlet, the heavy particle collection efficiency was decreased by about 10 to $15 \%$. The light particle collection efficiency was decreased by around $75 \%$, resulting in an increase in the heavy particle mass fraction of around $57 \%$. By increasing the heavy particle mass fraction of the test mixture from 0.042 to 0.340 , the heavy particle collection efficiency was decreased by around $12 \%$ with an increase in the light particle collection efficiency of nearly $300 \%$. Although a significant increase in light particle collection was made with a mixture containing much more steel, the system was still very effective at separating the particles.

It was concluded that within the scope of the tests performed in this study that a riser that was 14 feet $(4.27 \mathrm{~m})$ tall with a 90 degree swept outlet combined the best separation characteristics with the highest observed mass flux through the system. This system geometry allowed for a collection efficiency of heavy particles of over $80 \%$ and a mass fraction of collected particles of over 0.70 at a mass flux of $0.57 \mathrm{lb} / \mathrm{ft}^{2} \mathrm{~s}(2.78$ $\left.\mathrm{kg} / \mathrm{m}^{2} \mathrm{~s}\right)$.

While it is hard to determine the economical feasibility of the system in industry at this point, the system has the potential for a very efficient separation of particles by density difference. Future work should determine the capacity and operating costs of a full-scale industrial system. 


\subsection{Recommendations}

The CFB riser system designed, built and tested for this work was successful in completing the objectives but certain improvements can be made for future work conducted on this subject.

The air supply must be consistent throughout the testing procedure and fluctuations in line pressure must be minimized. Special care should be taken when choosing the air source and any additional upstream air requirements for the air source must be monitored to eliminate or reduce the effects.

The mass flow rate into the riser is a very important variable due to the operation of the riser at the transitional point between two flow regimes. The mass flow should be mechanically supplied to the riser in order to eliminate fluctuations that occurred during the pneumatic transport that was used during these tests. A screw feed would perhaps be the most consistent mass feed device and should be considered.

Variations in the riser diameter should be observed. Further tests conducted with internal rings of various diameters and locations should occur. Various riser heights should be observed to determine the ideal riser height. While the tests conducted in this study observed the general effects of each of these variables, further tests should help understand the full potential of the riser system.

Ideally, a computer control system should be used to consistently monitor and adjust the airflow and mass flow into the system. More differential pressure transducers should be used along the riser. 


\section{REFERENCES}

Bai et al, (1992), "The Axial Distribution of the Cross-Sectionally Averaged Voidage in Fast Fluidized Beds", Powder Technology, Vol. 71, p51-58.

Bolton, L.W. and Davidson, J.F. (1988) "Recirculation of Particles in Fast Fluidized Risers.", Circulating Fluidized Bed Technology II Ed. Basu, P. and Large, J. Pergamon Press.

Chen, Q. and Yang, Y. (2003), "Development of Dry Beneficiation of Coal in China", Coal Preparation, Vol. 23, p 3-12.

Danielson, J. A., (1967) Air Pollution Engineering Manual, U.S. Department of Health, Education, and Welfare, Cincinnati Ohio.

Dry, R. J., 1987, Radial Particle Sized Segregation in a Fast Fluidized Bed. $\underline{\text { Powder }}$ Technology, Vol. 52, p 7-16.

Donnelly, James., (1999) "Potential Revival of Dry Cleaning of Coal.", The Australian Coal Review October 1999, 26 - 30.

Fan, L.S. and Zhu, C. (1998) Principles of Gas-Solid Flow Ed. Varma, A. Cambridge University Press.

Fonseca, A.G, "The Challenge of Coal Preparation", High Efficiency Coal Preparation: An International Symposium. 1995, 3-21. Crushing-Malloy, Inc., Ann Arbor Michigan

Herb, B. et al, (1992), "Solid Mass Fluxes in Circulating Fluidized Beds", $\underline{\text { Powder }}$ Technology, Vol. 70, p 197-205.

Hirama, T. et al, (1992) "Regime Classification of Macroscopic Gas-Solid Flow in a Circulating Fluidized Bed Riser”, Powder Technology, Vol. 70, p 215-222.

Hucko, R. E. and Schimmoller B.K., (1995), "Review of the XII International Coal Preparation Congress", Coal Preparation, Vol. 15, p 207-214.

Luttrell, G.H. et al, (1998), "Removal of Hazardous Air Pollutant Precursors by Advanced Coal Preparation", Coal Preparation, Vol. 19, p 243-255.

Pugsley, T. S. et al, (1993), "A Predictive Model for the Gas-Solid Flow Structure in Circulating Fluidized Bed Risers", Circulating Fluidized Bed Technology IV, 1993, p 40.

Rhodes, M. et al, (1992), "Particle Motion at the Wall of a Circulating Fluidized Bed", Powder Technology, Vol. 70, p 207-214. 
Yoon, R.H., (1997), "Improving Pyrite Rejection by Galvanic Control", Coal Preparation, Vol. 18, p 53-68.

Yamamoto, f. et al, (1991), "Particle Lift and Drag in High Reynolds Number Linear Shear Flow", Gas-Solid Flows Vol. 121, p 191-195.

Yang, H., (1995) "Experimental Study on the Hydrodynamics in the Riser of a Circulating Fluidized Bed.” Dissertation, West Virginia University.

Zhang, W., (1991) Fluid Dynamic Boundary Layers in Circulating Fluidized Bed Boilers, Dissertation, Publisher: Chalmers Biblioteks Reproservice, Goteborg, Sweden, 1991 p $36,46,82$.

Zimmels, Y. (1985), “Theory of Density Separation of Particulate Systems", $\underline{\text { Powder }}$ Technology, Vol. 43, p 127-139. 


\section{Appendices}




\section{Appendix A}

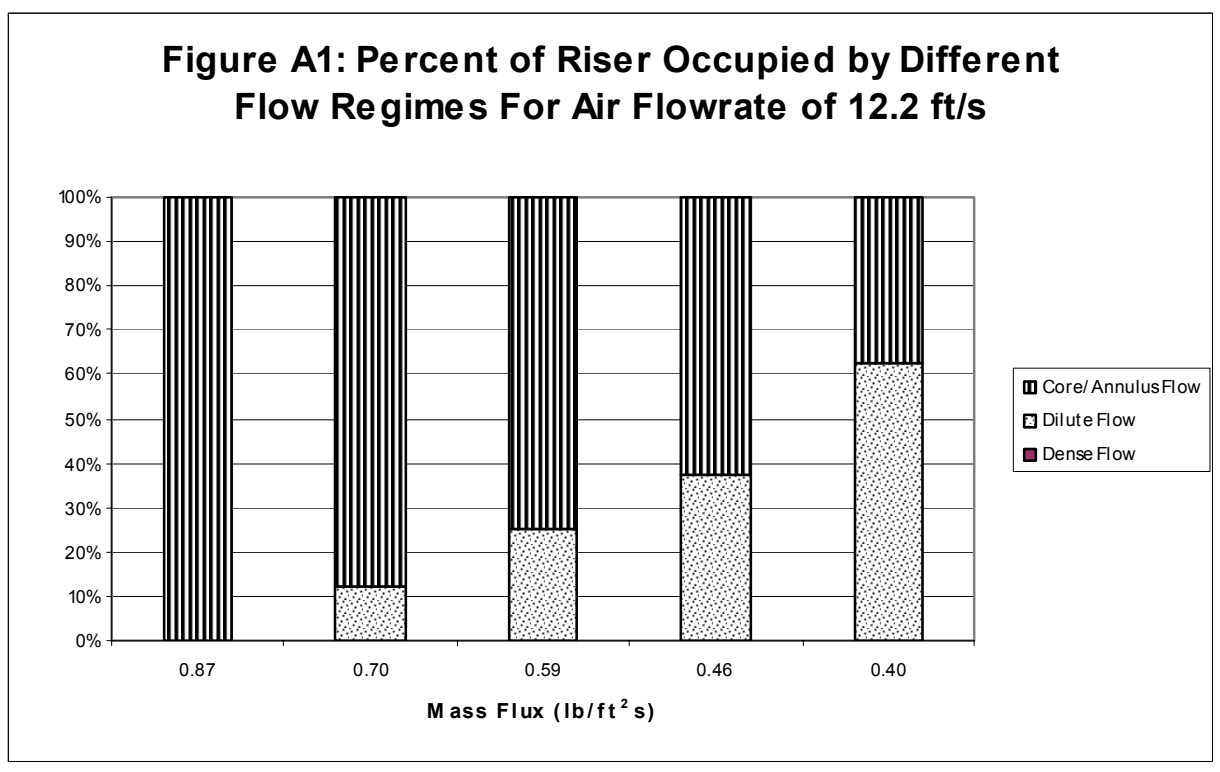

Figure A2: Percent of Riser Occupied by Different Flow Re gimes For Air Flowrate of $11.6 \mathrm{ft} / \mathrm{s}$

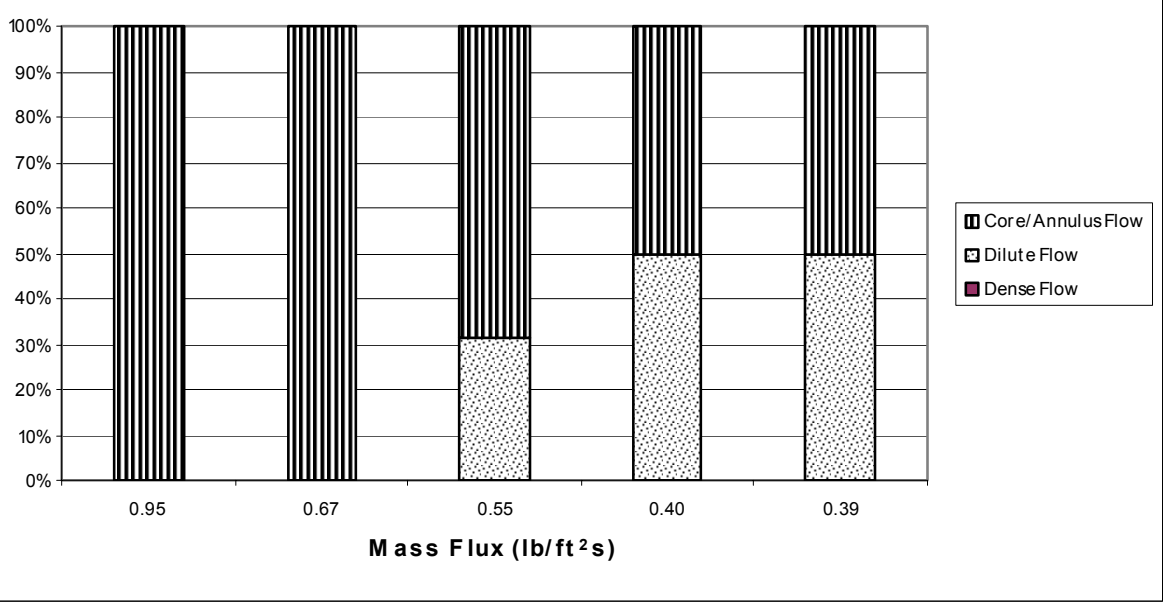

Figure A3: Percent of Riser Occupied by Different Flow Regimes For Air Flowrate of $11.0 \mathrm{ft} / \mathrm{s}$

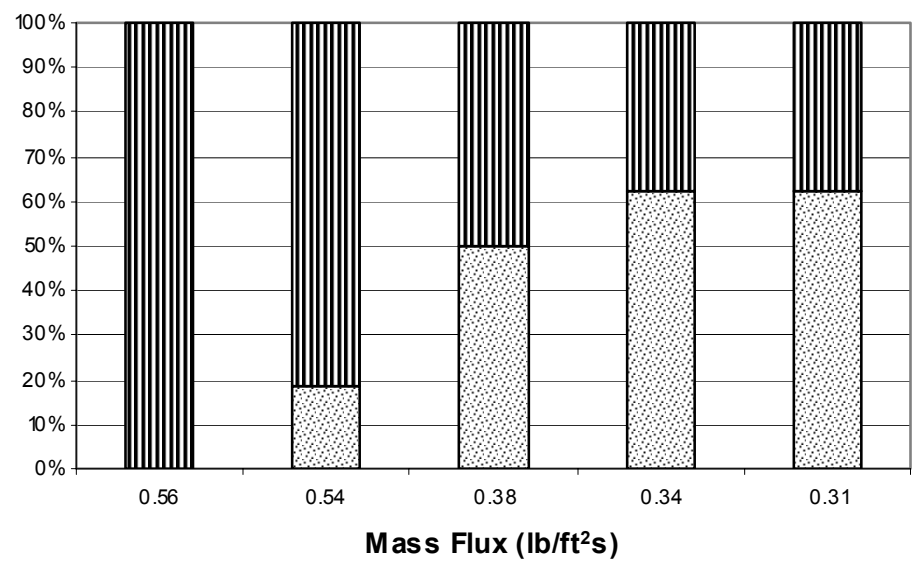

Q Core/Annulus Flow $\rightarrow$ Dilute Flow

口Dense Flow 


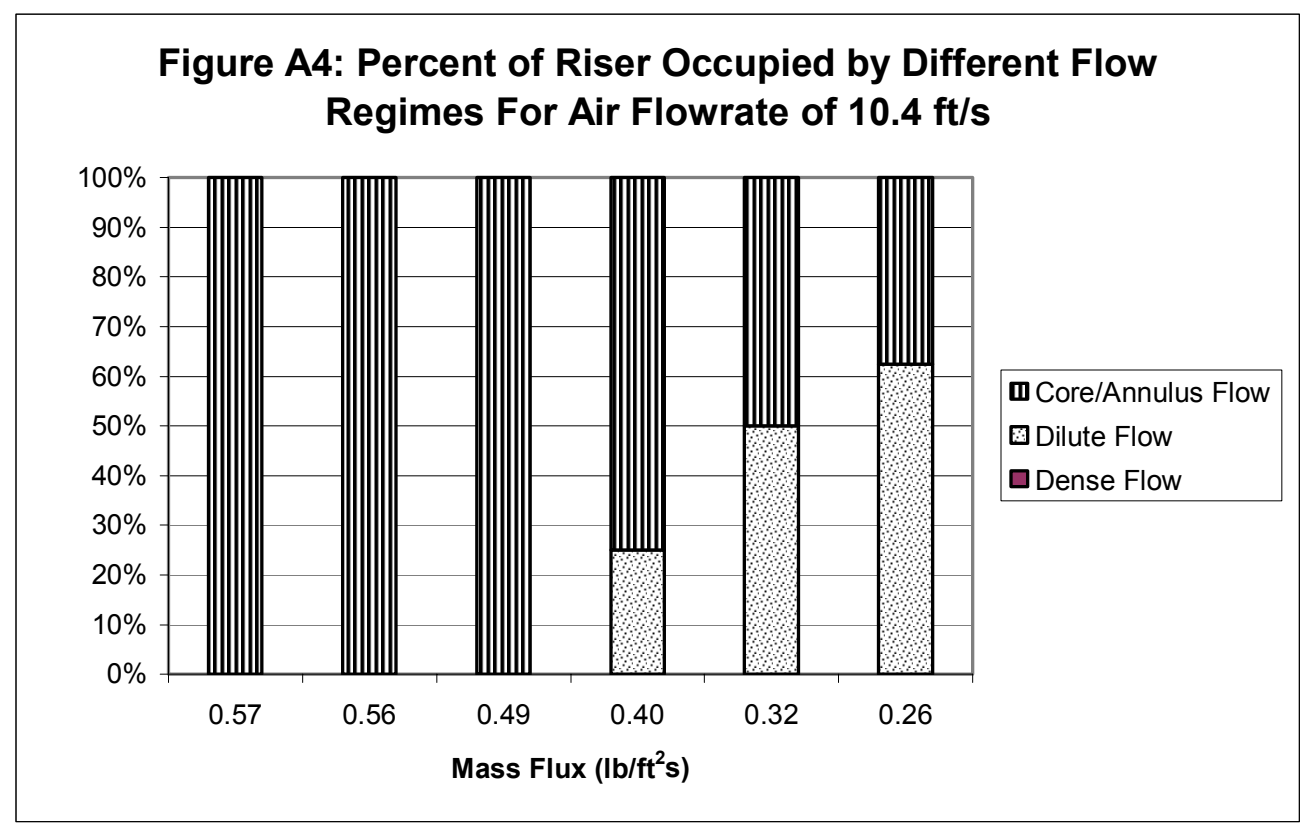




\section{Appendix B}
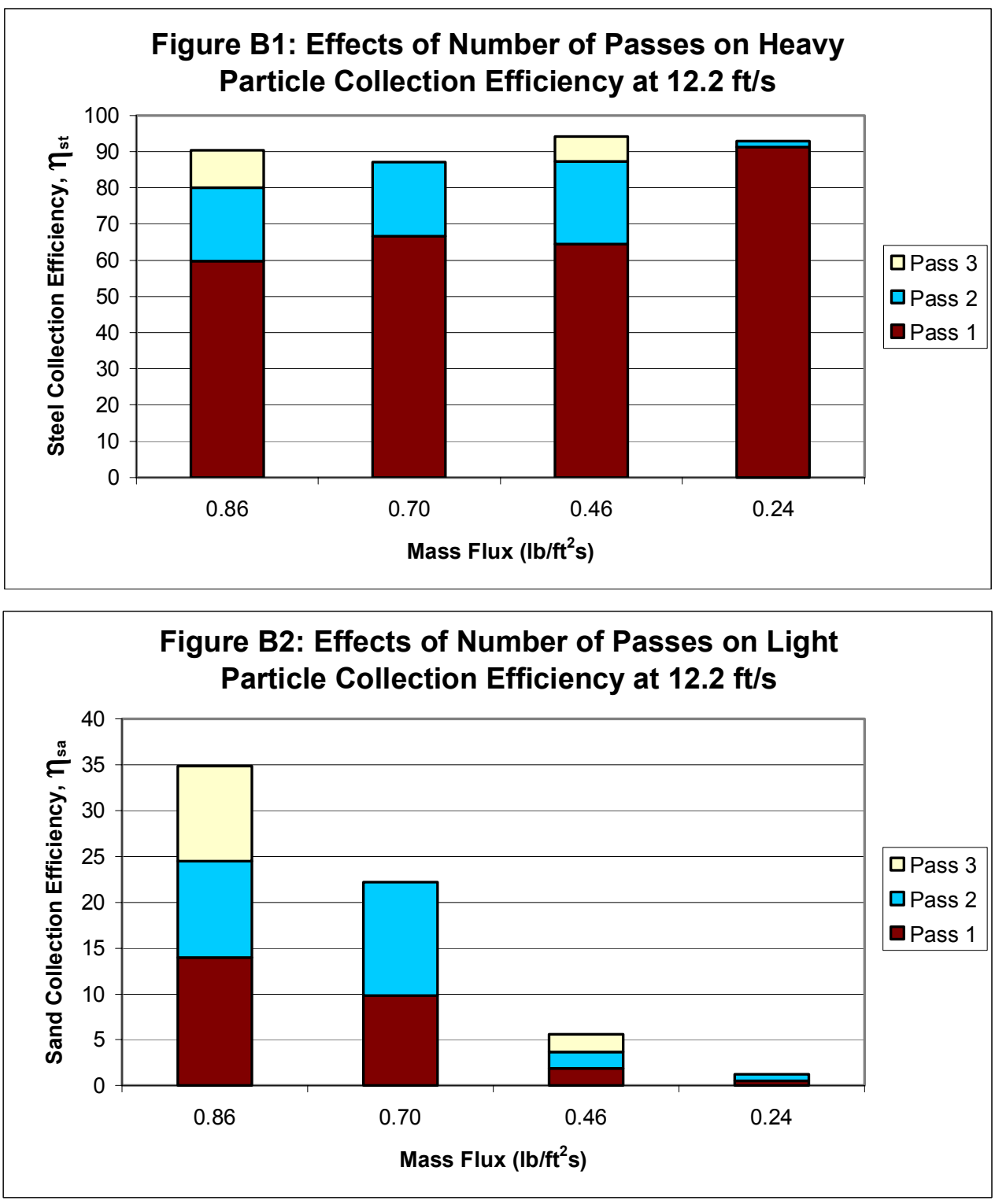

Figure B3: Effects of Number of Passes on Heavy Particle Mass

Fraction at $12.2 \mathrm{ft} / \mathrm{s}$

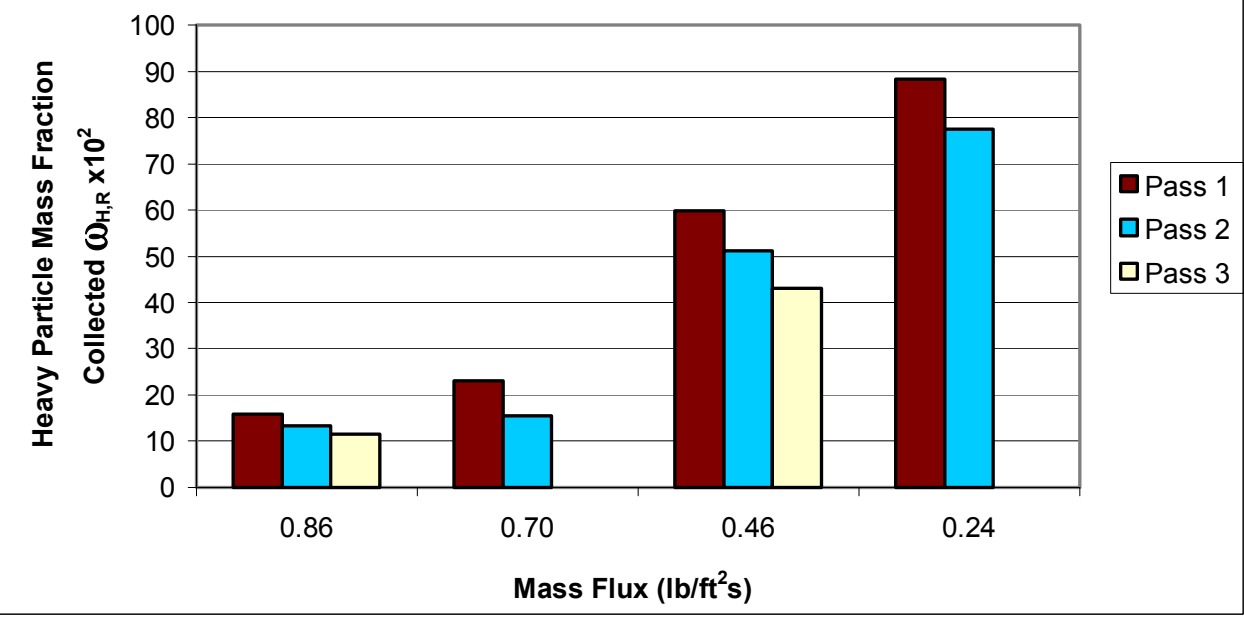



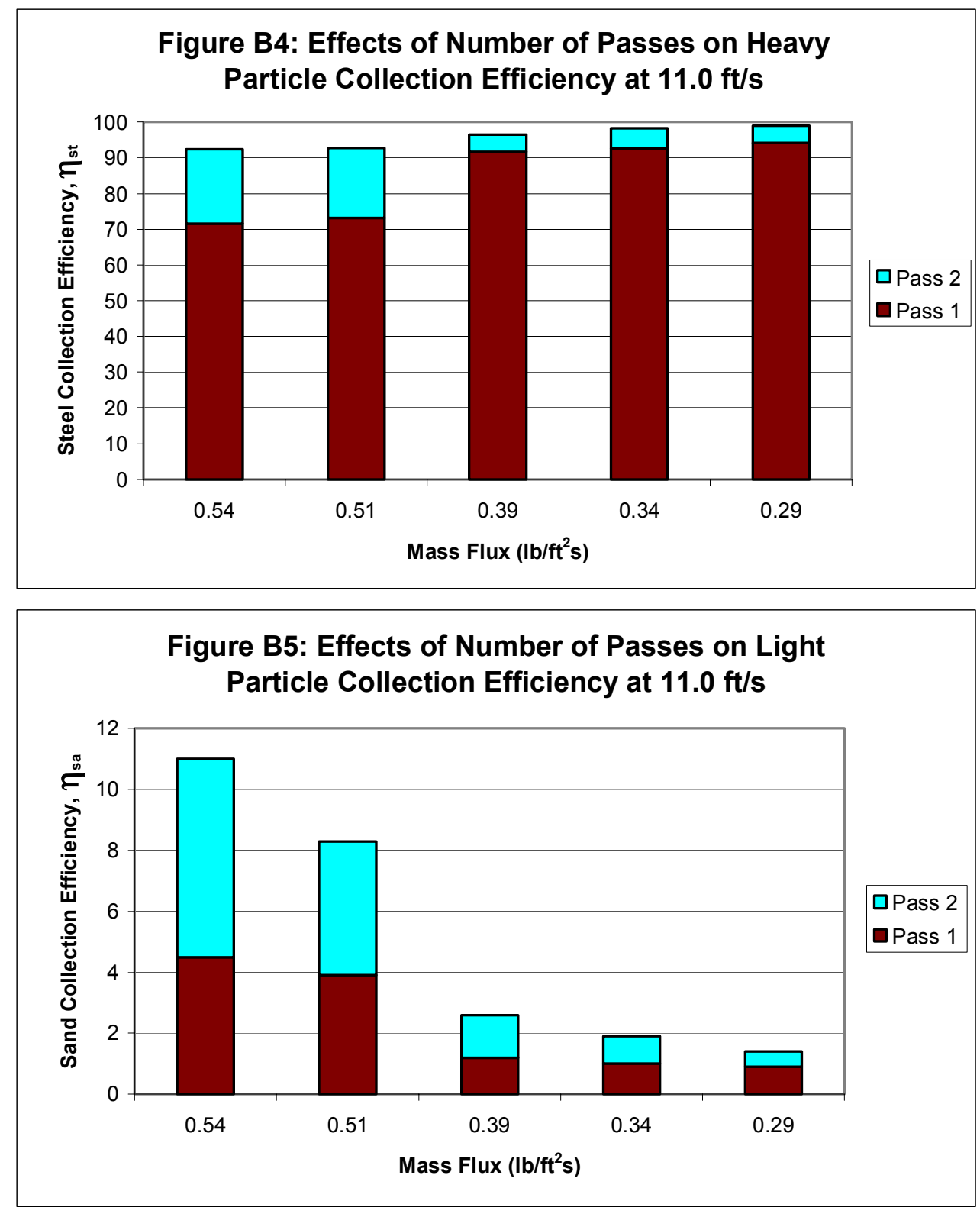

Figure B6: Effects of Number of Passes on Heavy Particle Mass Fraction at $11.0 \mathrm{ft} / \mathrm{s}$

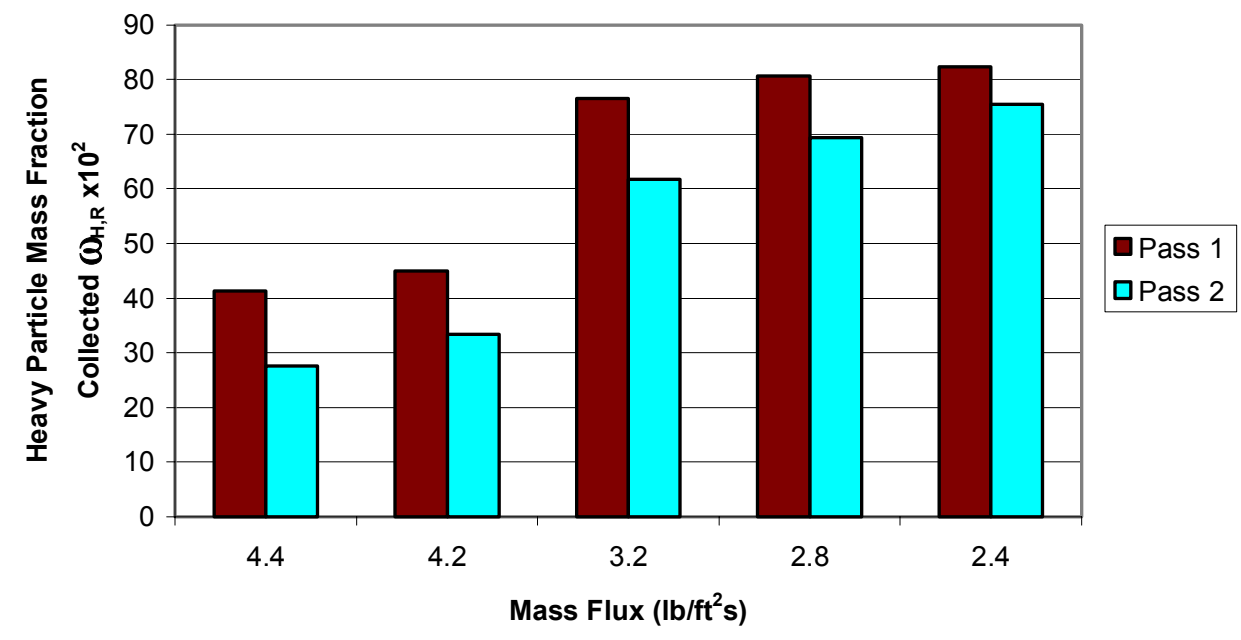


Figure B7: Heavy Particle Collection Efficiency at 10.4

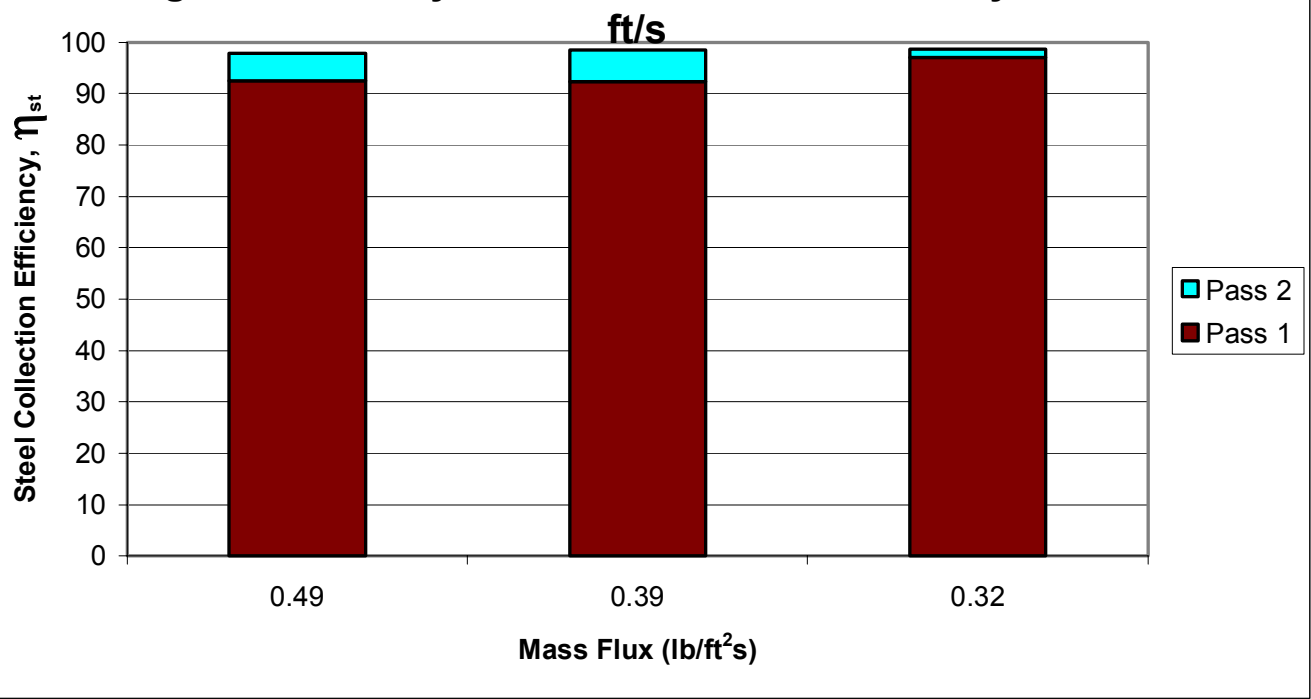

Figure B8: Effects of Number of Passes on Light Particle Collection Efficiency at $10.4 \mathrm{ft} / \mathrm{s}$

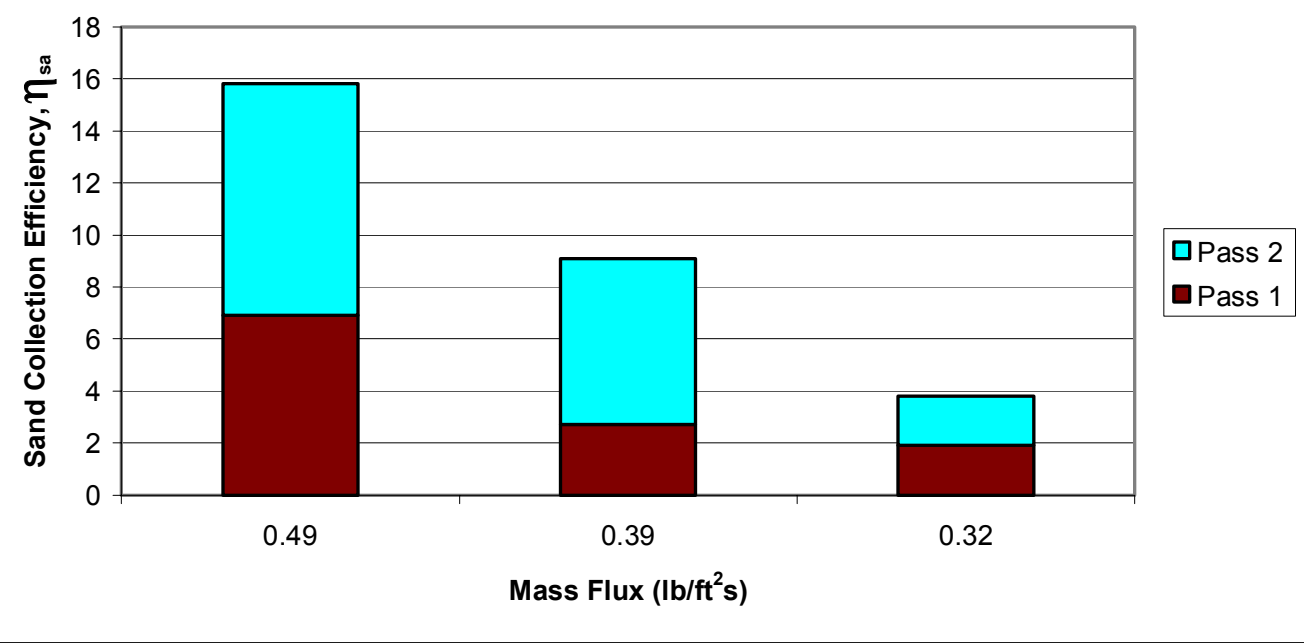

Figure B9: Effects of Number of Passes on Heavy Particle Mass Fraction at $10.4 \mathrm{ft} / \mathrm{s}$

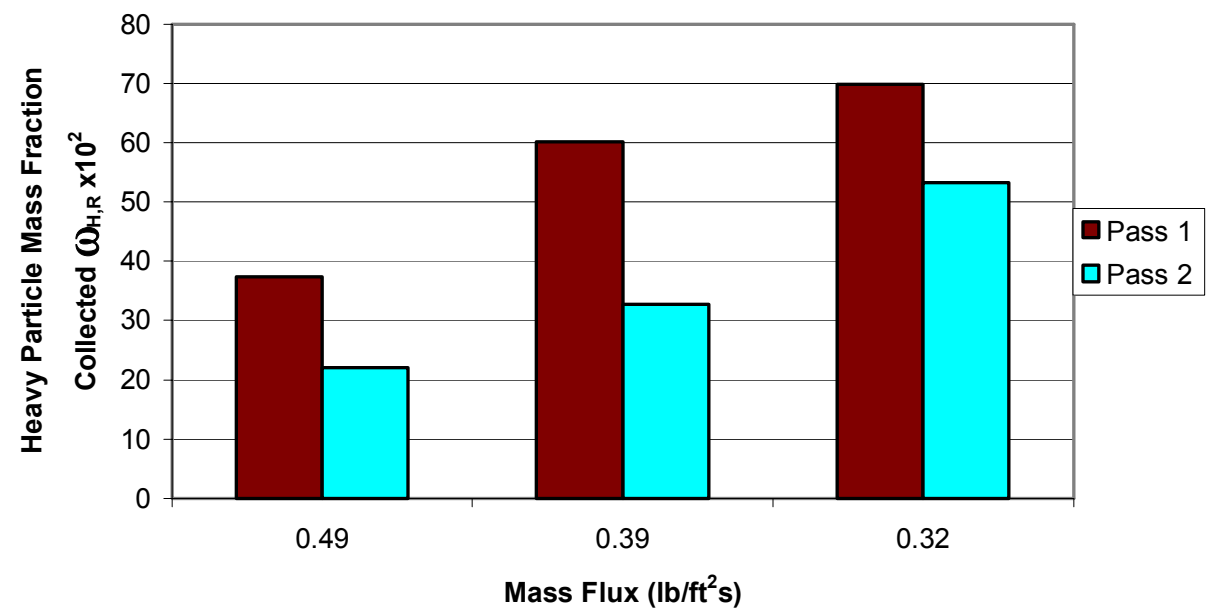



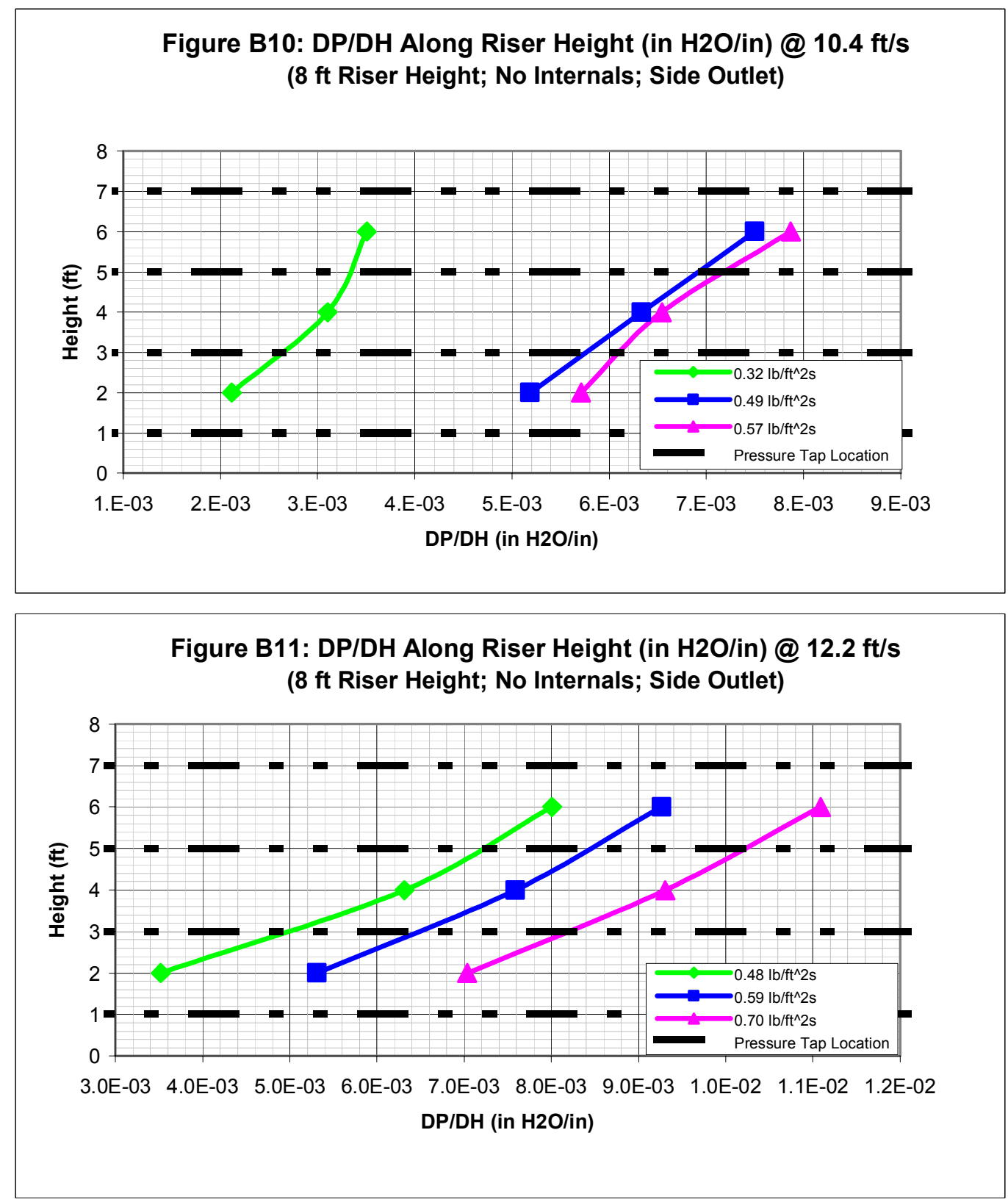


\section{Appendix C}
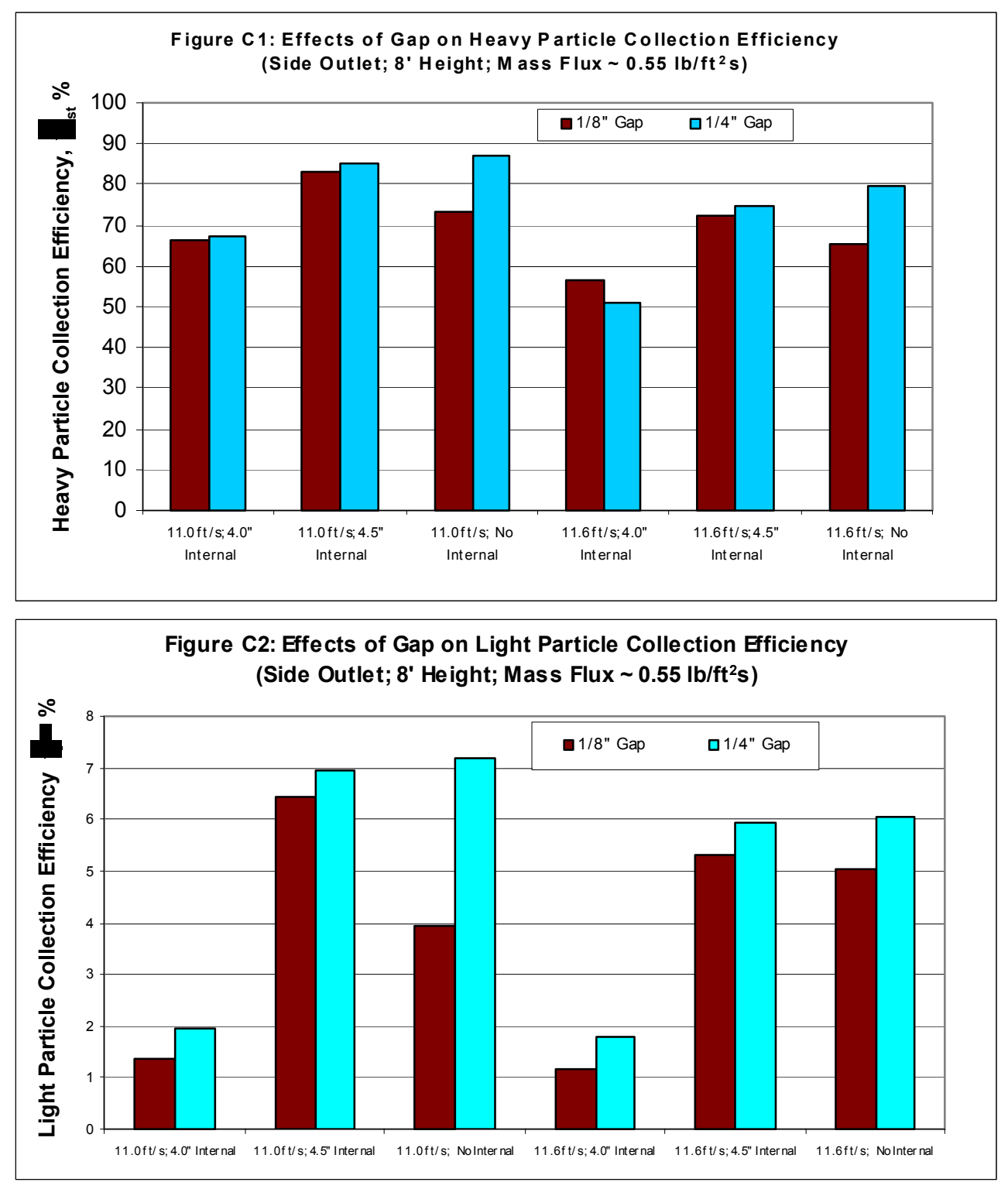

Figure C3: Effects of Gap on Heavy Particle Mass Fraction

(Side Outlet; 8' Height; Mass Fux $\sim 0.55 \mathrm{lb} / \mathrm{ft}^{2} \mathrm{~s}$ )

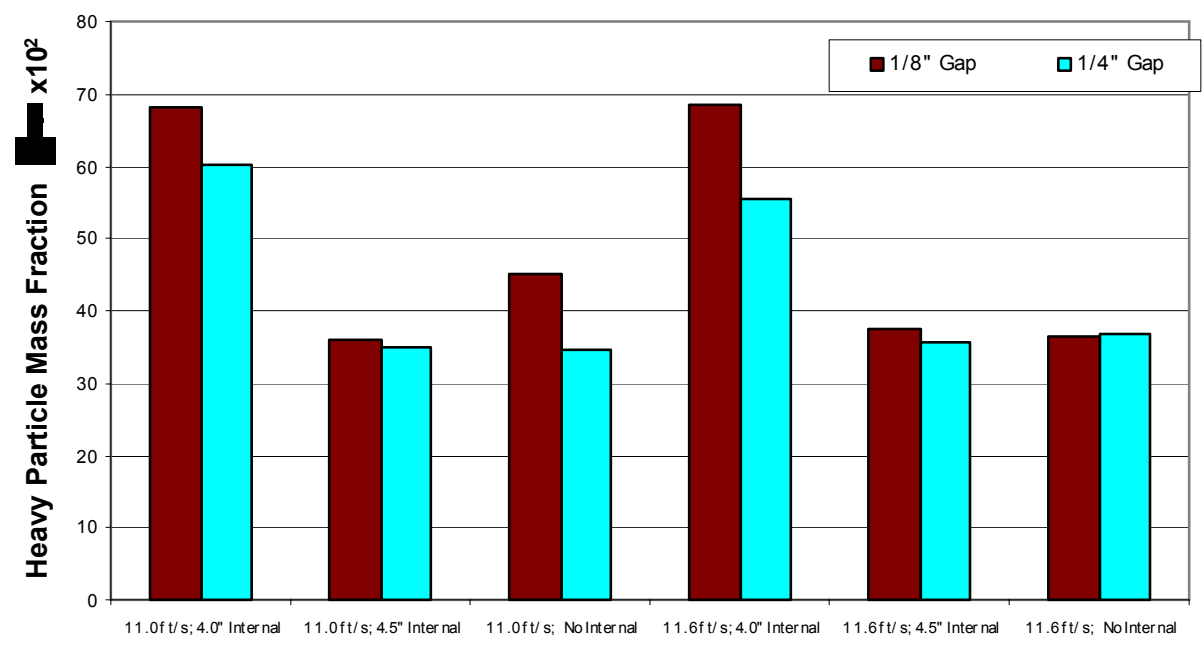




\section{Appendix D}
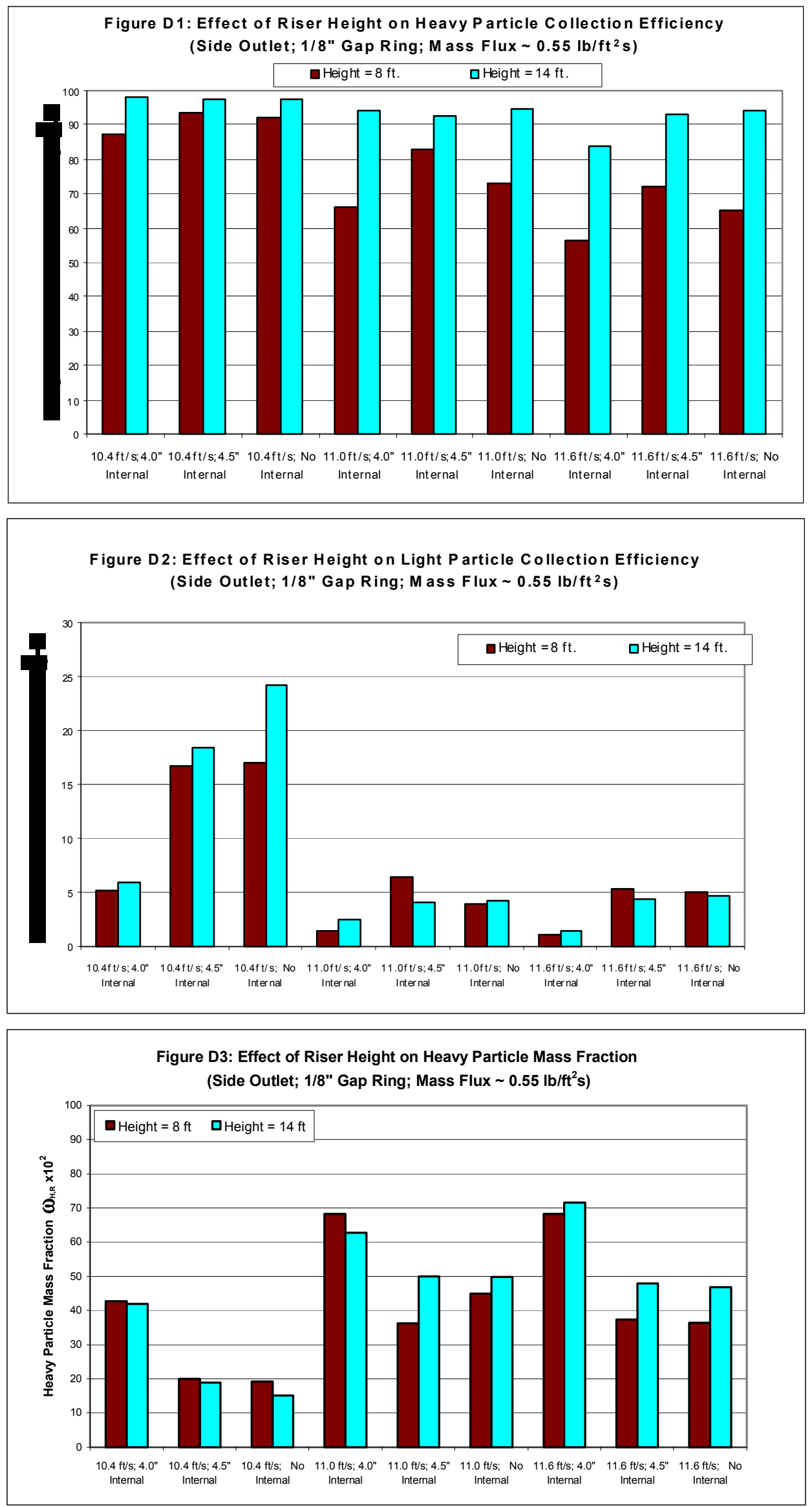


\section{Appendix E}
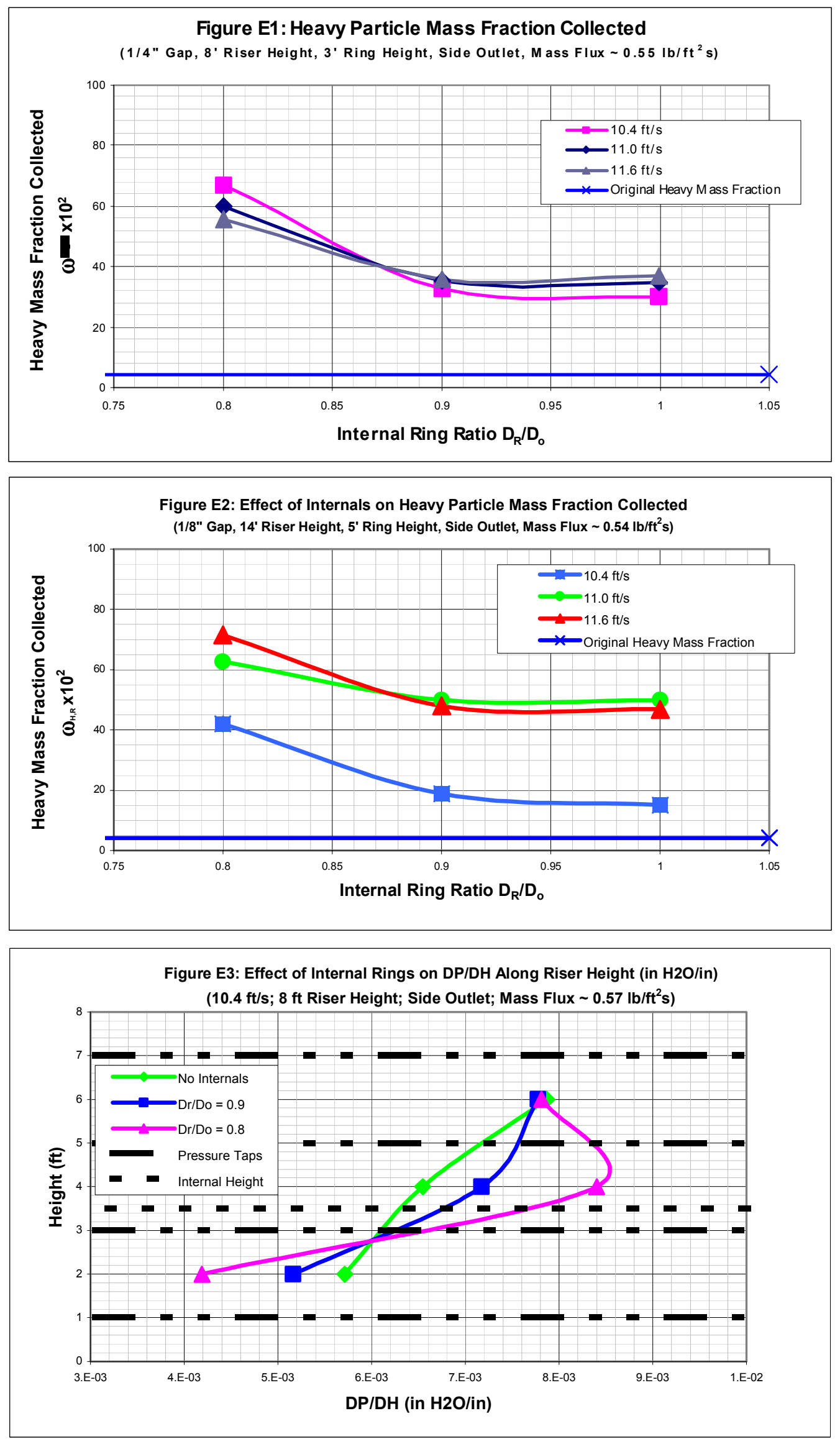

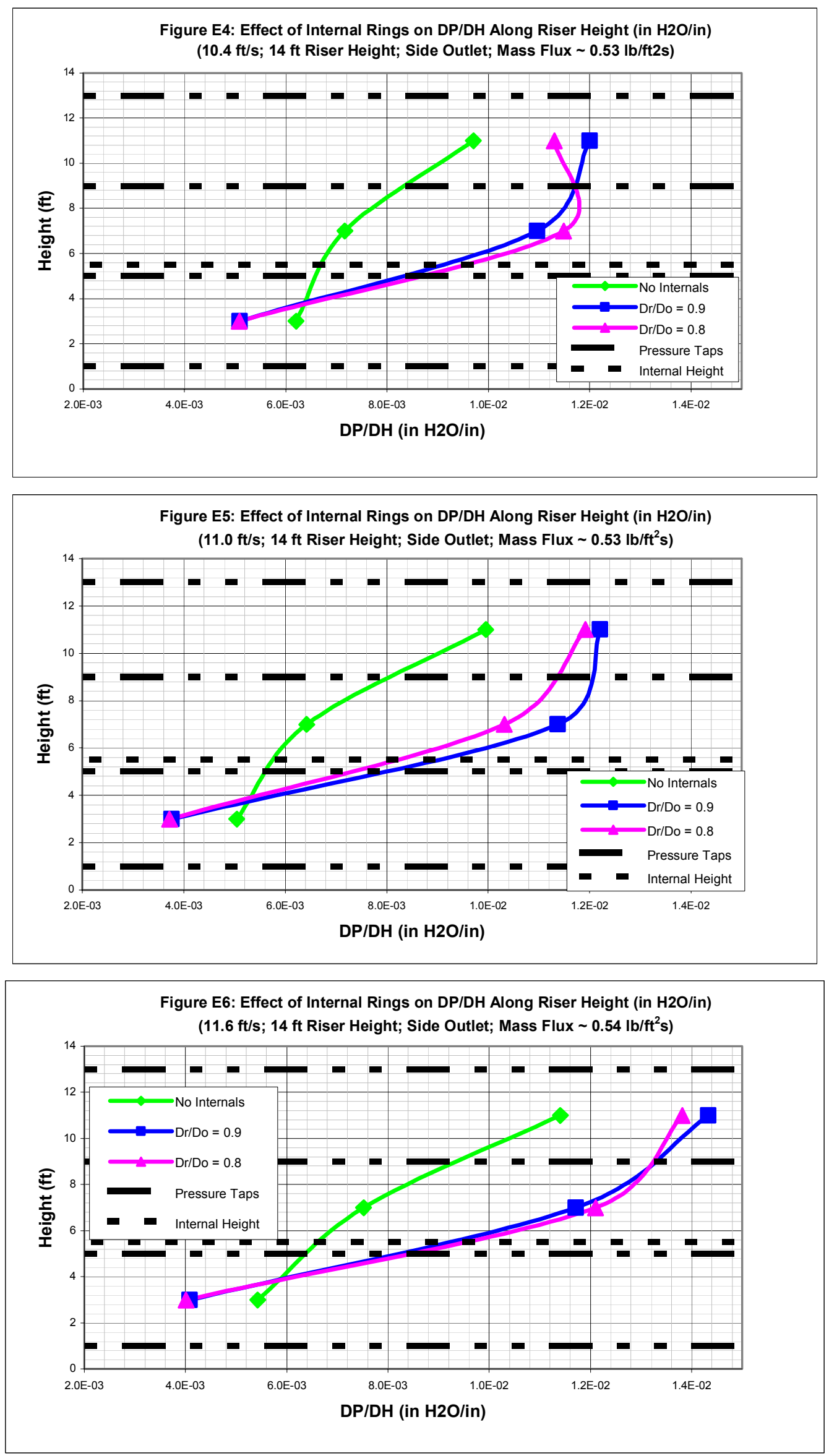


\section{Appendix F}

Figure F1: Gap Comparison For 90 Degree Outlet

(11.0 ft/s; $0.56 \mathrm{lb} / \mathrm{ft}^{2} \mathrm{~s}, 14 \mathrm{ft}$ Riser Height)

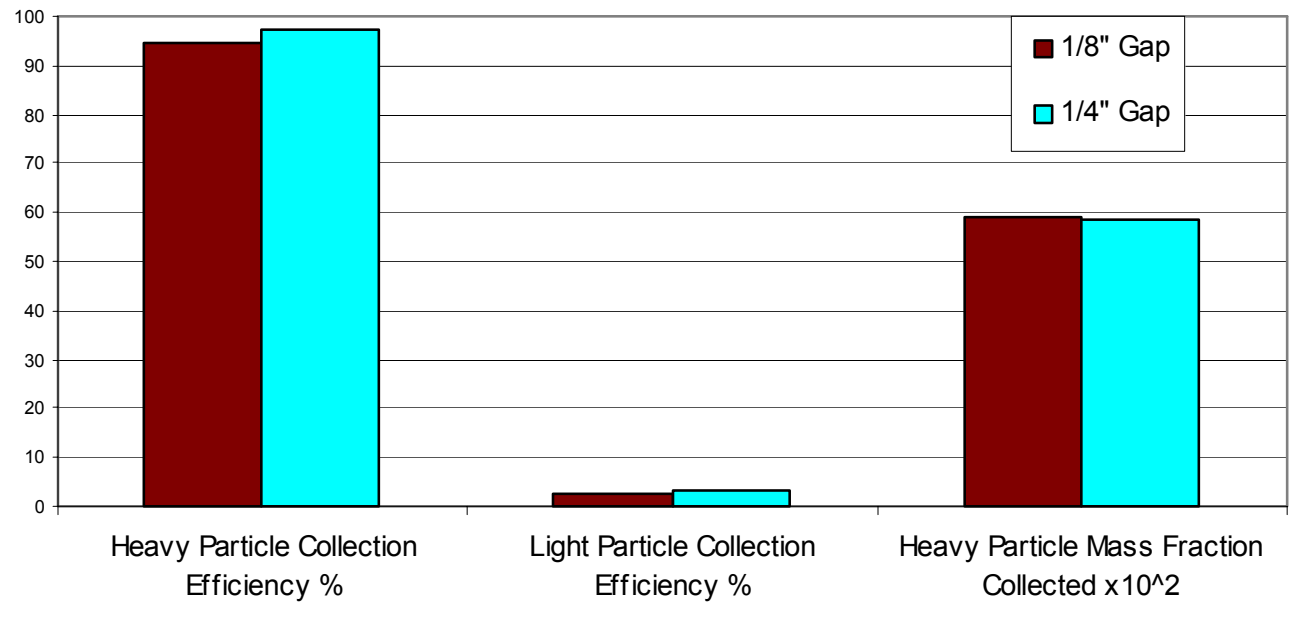

Figure F2: Outlet Comparison

(11.0 ft/s; 14' Riser Height; 1/4" Gap)

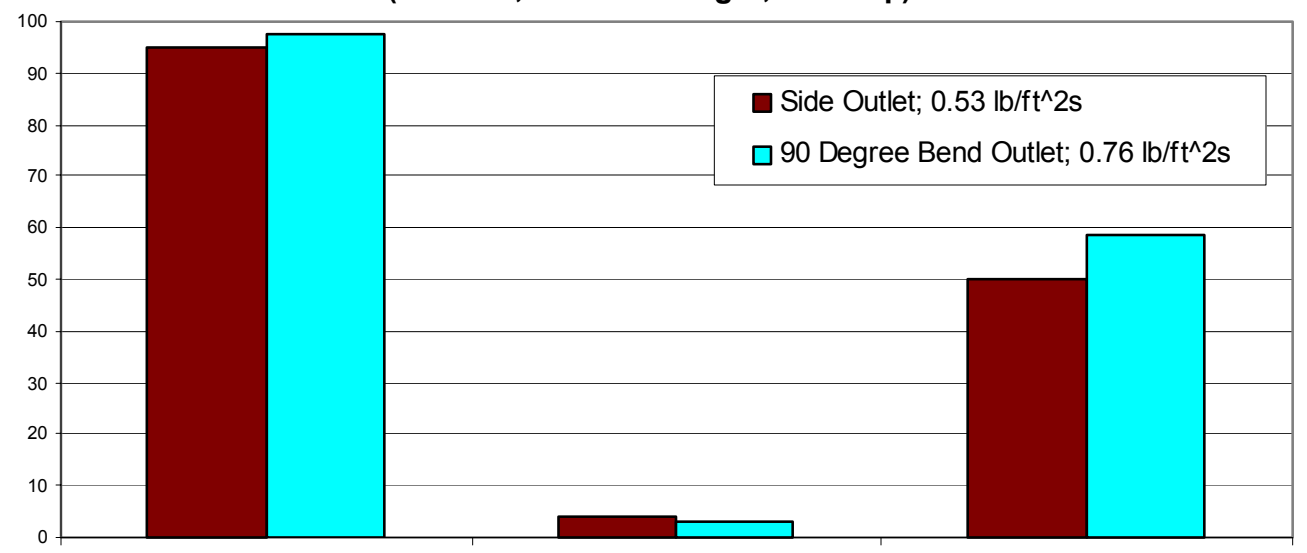

Heavy Particle Collection Efficiency \%
Light Particle Collection Efficiency \%
Heavy Particle Mass Fraction Collected $\times 10^{\wedge} 2$ 


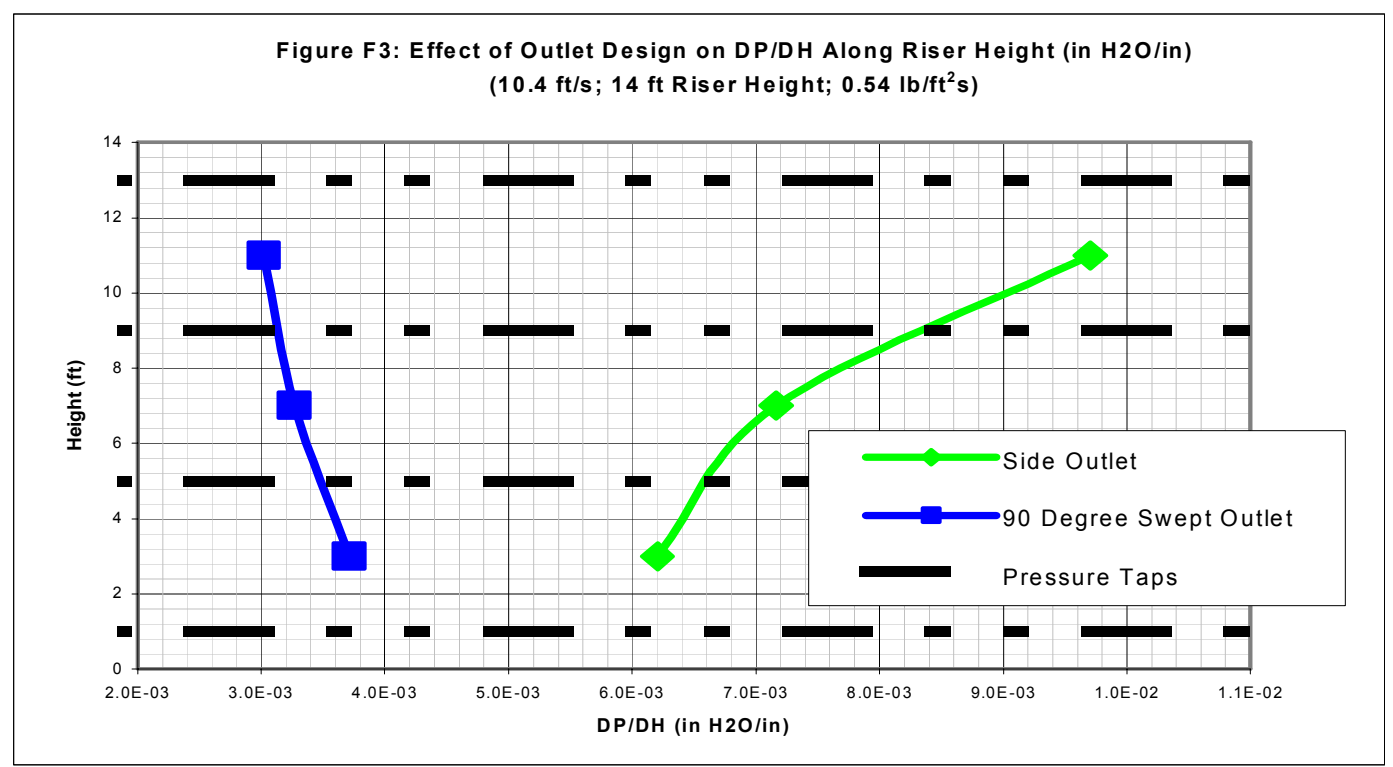

Figure F4: Effect of Outlet Design on DP/DH Along Riser Height (in H2O/in) (11.0 ft/s; $14 \mathrm{ft}$ Riser Height; $0.53 \mathrm{lb} / \mathrm{ft}^{2} \mathrm{~s}$ )

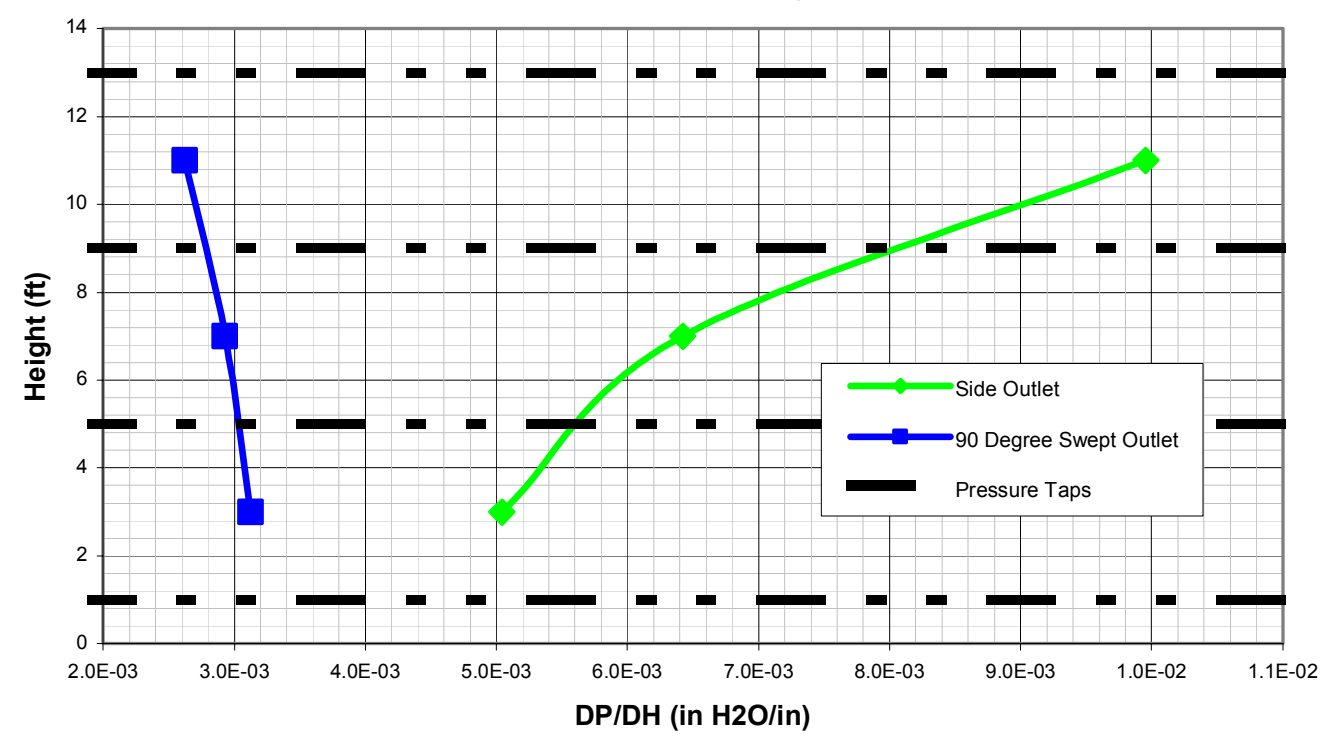

